REVIEW

\title{
Human pancreatic exocrine response to nutrients in health and disease
}

\author{
J Keller, P Layer
}

Gut 2005;54(Suppl VI):vi1-vi28. doi: 10.1136/gut.2005.065946

\subsection{INTRODUCTION}

Optimal digestion and absorption of nutrients requires a complex interaction among motor and secretory functions of the gastrointestinal tract. Digestion of macronutrients is a prerequisite for absorption and occurs mostly via enzymatic hydrolysis. In this context, pancreatic enzymes, in particular lipase, amylase, trypsin, and chymotrypsin, play the most important role but several brush border enzymes as well as other pancreatic and extrapancreatic enzymes also participate in macronutrient digestion. The crucial importance of pancreatic exocrine function is reflected by the detrimental malabsorption in patients with untreated pancreatic exocrine insufficiency, which is a typical complication of, for example, chronic pancreatitis. ${ }^{1-4}$

Comprehensive knowledge about the physiological pancreatic exocrine response to normal diets and to individual food components and about alterations in pancreatic exocrine insufficiency is necessary to administer a pancreatic enzyme preparation which imitates physiological conditions closely. Although many efforts have been made to substitute for pancreatic exocrine insufficiency by specially designed pancreatic enzyme preparations, these still have several disadvantages compared with physiological enzyme secretion. In particular lipid absorption is not completely normalised in most patients. ${ }^{5}$

As a basis for a better understanding of pancreatic exocrine function in health and disease this review will first summarise literature data on pancreatic exocrine response to a normal diet and to administration of individual food components in healthy humans. The next chapter will focus on pancreatic responses to a normal diet and to administration of individual food components in patients with pancreatic diseases, in particular chronic pancreatitits, but also in patients with other pancreatic and non-pancreatic diseases which are associated with intraluminal lack of pancreatic enzymes, for instance coeliac disease and diabetes mellitus. Other evidence of pancreatic involvement and dysfunction in these diseases will also be discussed, particularly if sufficient data on endogenously stimulated pancreatic secretion are lacking.

See end of article for authors' affiliations

Correspondence to:

Dr J Keller, Israelitic Hospital, University of Hamburg, Orchideenstieg 14, D-22297 Hamburg Germany; keller@ik-h.de

Accepted 29 March 2005

\subsection{SECRETORY RESPONSE OF THE EXOCRINE PANCREAS TO NUTRIENTS IN HEALTHY HUMANS \\ 2. 1 Introduction}

The healthy human pancreas adopts exocrine secretion to nutrient ingestion and there are numerous studies investigating pancreatic exocrine response to various endogenous stimuli. This chapter will summarise literature data on pancreatic exocrine response to a normal diet, its physical and biochemical properties, and to administration of individual food components in healthy humans with respect to total pancreatic secretion, secretion of individual enzymes, ratios of enzymes, intraluminal $\mathrm{pH}$ and bicarbonate and bile acid secretion.

\subsection{Pancreatic response to a normal diet} In the fasting state, human pancreatic exocrine secretion is cyclical and closely correlated with upper gastrointestinal motility (fig 1). ${ }^{16}$ Ingestion of a regular meal disrupts this interdigestive pattern within a few minutes and induces postprandial enzyme secretion instead, which has also been shown to follow a consistent pattern: enzyme delivery into the duodenum increases rapidly and reaches maximal values within the first postprandial hour, ${ }^{7-10}$ or even within 20-30 minutes postprandially. ${ }^{11-13}$ Following peak output, enzyme secretion decreases to a fairly stable secretory rate before decreasing again after about 3-4 hours postprandially to finally reach the interdigestive range at the end of the digestive period (fig 2)..$^{7-13}$ The degree and the duration of the digestive enzyme response are determined by the caloric content, ${ }^{13} 14$ nutrient composition, and physical properties of the meal.

In addition, the route or site of administration of nutrients strongly influences pancreatic enzyme responses: oral and duodenal application of a complex formula initiate similar increases in secretion of amylase, lipase, and trypsin. ${ }^{15}$ In contrast, jejunal infusion of nutrients has lower stimulatory potency than duodenal (about $25 \%)^{9}{ }^{16}$ while ileal nutrient perfusion inhibits enzyme secretion (compare 2.2.9). ${ }^{.7-20}$ Moreover, intraduodenal administration of an elemental formula equicaloric with the complex formula halved the stimulation of enzyme secretion. ${ }^{15}$

2.2.1 Influence of the caloric content Duodenal nutrient exposure is the dominant stimulatory mechanism for the postprandial enzyme response. In order to permanently

Abbreviations: CCK, cholecystokinin; CFTR, cystic fibrosis transmembrane regulator; DPPHR, duodenum preserving pancreatic head resection; ERCP, endoscopic retrograde cholangiopancreatography; GLP-1, glucagenlike peptide-1; IDDM, insulin dependent diabetes mellitus; $M M C$, migrating motor complex; NIDDM, non-insulin dependent diabetes mellitus; PPPD, pylorus preserving pancreatoduodenectomy. 


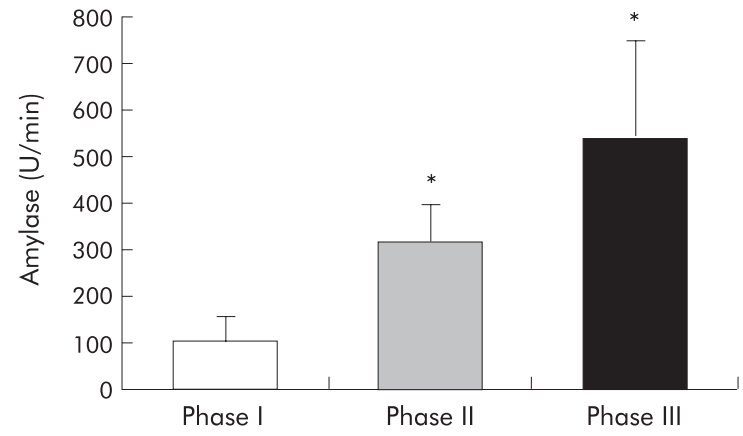

Figure 1 Interdigestive amylase output in healthy volunteers during daytime. Enzyme output is cyclical: it is associated with intestinal motility and is higher during phases II and III compared with phase I ( ${ }^{*} p<0.05 \mathrm{v}$ phase I). ${ }^{322}$

stimulate pancreatic enzyme secretion and to convert the interdigestive secretory pattern to the fed pattern in response to a mixed meal, intraduodenal nutrient loads of about $1 \mathrm{kcal} / \mathrm{min}$ are required. Thus, the cyclical interdigestive pattern was clearly preserved with duodenal nutrient loads of $0.36 \mathrm{kcal} / \mathrm{min}$, independently of whether proteins, carbohydrates, or lipids were perfused..$^{21}$ However, a recent study has shown that even higher duodenal nutrient delivery rates (1.5-2.67 kcal/min) did not completely abolish cycles of enzyme secretion but modulated cycles by increasing the nadir instead. ${ }^{22}$ Duodenal perfusion rates in the latter study were chosen to imitate physiological gastric emptying rates of $2-3 \mathrm{kcal} / \mathrm{min}$ following ingestion of a normal meal in healthy humans. ${ }^{23}$ With meals ranging from about 200-500 kcal, a positive correlation between postprandial amylase secretion and meal energy density was observed as a result of initially higher and also longer lasting output of amylase after high energy meals. ${ }^{13}$ By contrast, when healthy subjects ingested three meals per day containing either 20,30 , or $40 \mathrm{kcal} / \mathrm{kg}$, maximal enzyme response was already achieved by the $20 \mathrm{kcal} / \mathrm{kg} \mathrm{diet}{ }^{14}$ (which means $1500 \mathrm{kcal}$ per day or $500 \mathrm{kcal}$ per meal in a subject with $75 \mathrm{~kg}$ bodyweight). Therefore, meals containing about $500 \mathrm{kcal}$ seem to be sufficient to induce maximal enzyme response. However, there is a positive correlation between the duration of digestive secretion and nutrient content also with high caloric meals, ${ }^{14}$ because digestive pancreatic response is maintained as long as nutrients are emptied at stimulatory rates from the stomach into the duodenum.

\subsubsection{Influence of nutrient composition}

Chronic ingestion of a high fat diet is associated with higher enzyme outputs than a carbohydrate rich diet (fig 3). ${ }^{24}$ Following ingestion of a diet low in carbohydrate content (10\%) and high in fat content (40\%) for four weeks, interdigestive pancreatic enzyme output was about four times higher compared with a high carbohydrate (80\%), low fat $(10 \%)$ diet. Moreover, digestive response to the high fat diet was about twice as high as to the high carbohydrate diet. Diets with more physiological nutrient composition (50\% carbohydrate, $10-40 \%$ fat, $10-40 \%$ protein) had intermediary effects. These alterations were not explained by different caloric content of the meals because caloric content of all diets was adjusted to body weight (at least 30 calories per $\mathrm{kg}$ ) and usual daily activity $(+20 \%)$. In contrast to chronic modifications of the diet, acute changes (maintaining or altering diets for 24 hours) did not alter interdigestive enzyme output, but adaptation of postprandial pancreatic enzyme secretion occurred. ${ }^{24}$

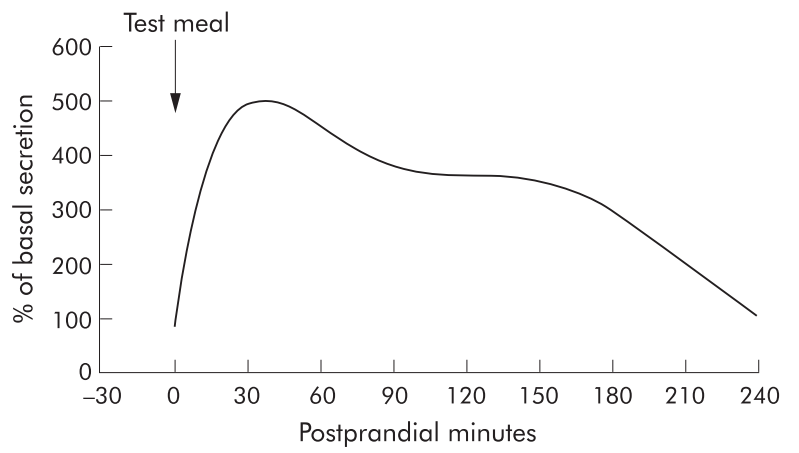

Figure 2 Digestive pancreatic enzyme response to a regular meal. Enzyme delivery into the duodenum increases rapidly and reaches maximal values within the first postprandial hour or even within 20-30 minutes postprandially. Following peak output, enzyme secretion decreases to almost stable secretory rates at lower levels until about 3-4 hours postprandially depending on the size of the meal. The interdigestive range is reached again at the end of the digestive period..$^{7-13}$

\subsubsection{Influence of physical properties}

Apart from caloric content and nutrient composition, physical properties of a meal also affect pancreatic secretion. Enzyme response to a solid meal is more sustained compared with an identical meal which has been homogenised. ${ }^{8}$ This is partly due to slower gastric emptying of the solid compared with the homogenised meal which leads to prolonged stimulation of enzyme output. In addition, increased gastric acid secretion and, consequently, increased duodenal acid delivery in response to a solid meal may also cause a higher pancreatic secretory response. ${ }^{8}$

Due to better applicability in intubation studies many investigators have used semiliquid, homogenised meals and have shown an overall similar pattern for postprandial pancreatic enzyme secretion compared with solid meals with maximal secretory rates early postprandially, lower, yet stable or slowly declining secretion for about 2-3 hours followed by a fast decrease into the interdigestive range. ${ }^{9}{ }^{18} 25-27$

Other physical properties of a meal such as volume, osmolality, and temperature may also influence pancreatic enzyme secretion, either directly or by altering gastric emptying. Dooley et al report a stepwise increase in pancreatic amylase and bicarbonate secretion in response to duodenal perfusion with increasing flow rates of saline $(0.2$ to $3.2 \mathrm{ml} /$ min). Increasing osmolality of a duodenally perfused mannitol solution from $370 \mathrm{mosmol} / \mathrm{kg}$ to $520 \mathrm{mosmol} / \mathrm{kg}$
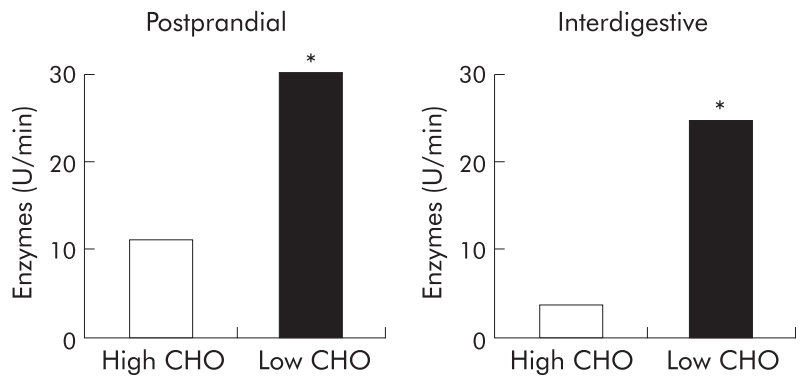

Figure 3 Effect of chronic ingestion of diets with varying nutrient composition in healthy volunteers. Following ingestion of a diet low in carbohydrate content (10\%) and high in fat content $(40 \%)$ for four weeks, postprandial enzyme output was about twice as high as following a high carbohydrate (80\%), low fat (10\%) diet (geometric means, ANOVA: ${ }^{*} \mathrm{p}<0.05$ ). Interdigestive pancreatic enzyme output was about four times higher with the low carbohydrate, high fat diet. Thus, chronic ingestion of a high fat diet is associated with higher enzyme outputs than a carbohydrate rich diet. ${ }^{24}$ 
also increased enzyme secretion, but no further increase was seen with higher osmolality. ${ }^{28}$ The authors conclude that the human duodenum contains receptors for volume (or distension) and osmolality that stimulate pancreatic enzyme and bicarbonate secretion. By contrast, Holtmann et al report a close yet inverse correlation between the osmolality of duodenally perfused nutrient solutions within a much lower range (24-290 mosmol) and enzyme secretion. Whether and why there may be differential responses of human pancreatic exocrine secretion to hypo- and iso-osmotic duodenal chyme on the one hand and hyperosmotic chyme on the other hand still needs to be established. It appears that gastric emptying-which is one major regulator of pancreatic exocrine secretion-is not affected by osmolality of ingested liquids in the range $200-400 \mathrm{mosmol} / \mathrm{kg} .{ }^{29}$ By contrast, gastric emptying was found to be delayed in some ${ }^{30}{ }^{31}$ but not all ${ }^{32}$ studies when meal temperature markedly deviated from body temperature. This may indirectly reduce or postpone stimulation of pancreatic exocrine secretion by nutrients entering the duodenal lumen. Direct effects of duodenal chyme temperature on pancreatic secretion may be of less physiological relevance because of the reservoir function of the stomach in which the meal will usually regain body temperature before being emptied.

\subsubsection{Influence of age and gender}

Whether pancreatic secretion is gender related and decreases in the elderly is controversial. Tiscornia et al showed an increase in amylase and lipase secretion in men aged over 45 years and a decrease in flow and bicarbonate output in women of the same age but no differences among younger men and women. ${ }^{33}$ Laugier et al reported a slight decrease in bicarbonate and enzyme secretion after the third decade, but even in subjects older than 80 years a less than $20-30 \%$ decrease in secretion was expected, which is far from being clinically significant. ${ }^{34}$ Other authors observed no reduction ${ }^{35}$ or a more marked reduction of pancreatic exocrine function (by about $45 \%$ ), ${ }^{36}$ particularly of bicarbonate secretion ${ }^{37}$ in elderly people. Gaia et al showed that fluid secretion, bicarbonate, and enzyme output were about $20 \%$ higher in men compared with women, but when flow and output values were related to body surface these differences were no longer apparent. ${ }^{38}$ There are no studies available addressing the influence of female sexual hormones or different stages of the menstrual cycle on pancreatic exocrine secretion. Furthermore, the influences of age and gender on pancreatic secretion have only been tested by exogenous stimulation. ${ }^{33}{ }^{34}$ Therefore it remains unclear whether they are of relevance postprandially.

\subsubsection{Total pancreatic secretion}

Because of interference with meal proteins, duodenal protein output cannot be used as a measure of total pancreatic enzyme secretion following ingestion of regular meals. To overcome this problem some authors added outputs of individual enzymes in order to estimate total pancreatic secretion. Following ingestion of a defined diet for four weeks ( 10 or $25 \%$ protein, 40 or $25 \%$ fat, $50 \%$ carbohydrates), combined amylase, lipase, and trypsin output was about $90 \mathrm{U} / \mathrm{min}^{*} \mathrm{~kg}$ interdigestively and $210-250 \mathrm{U} / \mathrm{min}^{*} \mathrm{~kg}$ postprandially. ${ }^{24}$

On the other hand, the problem of interference between meal and endogenous proteins can be circumvented by application of a meal without protein component. Under these conditions duodenal protein delivery is totally derived from endogenous sources and mainly from pancreatic enzymes. Following a pure carbohydrate meal containing $50 \mathrm{~g}$ rice starch, duodenal protein concentration during the eight hours postprandial period was $5.9 \mathrm{mg} / \mathrm{ml}$ and cumulative postprandial duodenal protein delivery $4.6 \mathrm{~g}$. Maximal duodenal protein delivery was achieved one hour postprandially and reached $30 \mathrm{mg} / \mathrm{min} .{ }^{39}$ However, this meal is likely to be a submaximal stimulant of pancreatic exocrine secretion.

\subsubsection{Secretion of individual enzymes}

In physiological studies measuring pancreatic enzyme response to solid or homogenised meals with normal nutrient composition and a caloric content of 300 to about $600 \mathrm{kcal}$, trypsin and lipase activities were analysed most frequently, amylase was also measured in several studies, but there is little information on chymotrypsin output. Such studies were chosen as the basis for analysis of literature data on digestive enzyme outputs and intraluminal enzyme activities. Enzymatic activities were directly measured in intestinal chyme. Enzyme outputs (or flow rates), on the other hand, were calculated from intraduodenal volume flow and enzyme activities (volume flow $\times$ enzyme activity for a given interval). In order to facilitate comparison of data from different studies, enzyme activities and outputs have been transferred to $\mathrm{U} / \mathrm{ml}$ and $\mathrm{U} / \mathrm{min}$, respectively. However, it has to be taken into account that varying methods were chosen for measurement of enzyme activities and hardly anybody indicated to have used FIP, Ph Eur, or BP units which impairs comparability of data.

Moreover, the data given below are derived from measurements under optimised assay conditions which are not achieved in vivo. Instead, Carriere et al report that in vivo, the specific activities of gastric and pancreatic lipase on meal triglycerides estimated from production of free fatty acids were about two orders of magnitude lower than those measured under optimised assay conditions in vitro. ${ }^{40}$ It is likely that this is also true for amylase and proteases but this has not been investigated.

\subsubsection{Intraduodenal enzyme flow rates}

In general, pancreatic enzymes are secreted approximately in parallel. Digestive secretion of all enzymes follows the above described pattern (fig 2) with a short phase of maximal enzyme secretion and a three to sixfold increase above interdigestive levels of lipase, ${ }^{12} 1841$ amylase, ${ }^{21} 4243$ and tryp$\sin ^{711254243}$ This is followed by a sustained increase in enzyme output, three to fourfold above preprandial values. ${ }^{711} 12182542$

In some studies, a more than tenfold stimulation of enzyme secretion even by low caloric meals has been described. ${ }^{1021}$ This may be due to preferential application of the test meal during phases of low interdigestive enzyme secretion (phase I or early phase II). ${ }^{44}$

Overall, mean interdigestive pancreatic lipase secretion was about $1000 \mathrm{U} / \mathrm{min}^{12}{ }^{18} 4145$ maximal postprandial enzyme output was about $3000-6000 \mathrm{U} / \mathrm{min}^{12}{ }^{1841}$ and $2000-$ $4000 \mathrm{U} / \mathrm{min}^{12}{ }^{18}{ }^{41}$ were secreted for a longer period of time (table 1 ).

Interdigestive amylase ouput varied from about $50^{21} 46-48$ to $250 \mathrm{U} / \mathrm{min}^{42}{ }^{43} 49$ Postprandially, 500-1000 U/min ${ }^{42} 434650$ or even $2000 \mathrm{U} / \mathrm{min}^{51}$ were maximally secreted and about $500 \mathrm{U} / \mathrm{min}$ were delivered to the duodenum for a longer period of time (table 1).21 434650

For trypsin, data are less homogenous, possibly because of methodological differences. In most studies, interdigestive trypsin output ranged from about $50 \mathrm{U} / \mathrm{min}^{112142}$ to 100 U/min. ${ }^{7} 1012145253$ However, some investigators report a trypsin output of less than $20 \mathrm{U} / \mathrm{min}^{25}$ and others about 500-1000 $\mathrm{U} / \mathrm{min}^{43}{ }^{54}$ interdigestively. Accordingly, maximal and sustained postprandial trypsin outputs also vary widely. The majority of investigators report maximal postprandial levels of about $200 \mathrm{U} / \mathrm{min}^{7114253}$ to $1000 \mathrm{U} / \mathrm{min}^{8}{ }^{12} 150 \mathrm{U} / \mathrm{min}^{7114253}$ to about $500 \mathrm{U} / \mathrm{min}^{82151}$ were stably released into the 
Table 1 Duodenal enzyme outputs

\begin{tabular}{llll}
\hline & Interdigestive & $\begin{array}{l}\text { Early/maximal } \\
\text { postprandial }\end{array}$ & $\begin{array}{l}\text { Late/mean } \\
\text { postprandial }\end{array}$ \\
\hline Lipase (U/min) & 1000 & $3000-6000$ & $2000-4000$ \\
Amylase (U/min) & $50-250$ & $500-1000$ & 500 \\
Trypsin (U/min) & $50-100$ & $200-1000$ & $150-500$ \\
\hline $\begin{array}{l}\text { Data are derived from studies using test meals with 300-600 kcal. } \\
\text { References are given in the text. }\end{array}$
\end{tabular}

duodenum for two hours or longer, depending on the test meal administered (table 1).

\subsubsection{Duodenal enzyme activities}

Most investigators present duodenal enzyme outputs but not direct data for intraduodenal enzyme activities. These can be calculated if duodenal volume flow rates are given. However, because volume flow is influenced by perfusion rates which vary from about $0 \mathrm{ml} / \mathrm{min}^{42}$ to $5 \mathrm{ml} / \mathrm{min}^{10}$ or even $10 \mathrm{ml} / \mathrm{min}^{45}$ in individual studies, enzyme activities measured in aspirated samples are less comparable than enzyme outputs.

The following data for intraluminal enzyme activities have been derived from studies without marker perfusion ${ }^{42} 515556$ or with low marker perfusion rates ( $3 \mathrm{ml} / \mathrm{min}$ or less). ${ }^{12} 1826$ In these studies, interdigestive lipase activity ranged from $100^{42}$ to $400 \mathrm{U} / \mathrm{ml}^{18}$ Postprandially, intraluminal lipase activity increased markedly; however, there were minor differences between early and mean postprandial enzyme activities compared with differences between enzyme outputs, and maximal enzyme activities were invariably not reached during the first postprandial hour. This is probably because increased volume flow contributes considerably to the early postprandial output peak. Bozkurt et al, who collected duodenal juice completely without marker perfusion, report an interdigestive duodenal volume flow of $2 \mathrm{ml} /$ $\mathrm{min}, 5.3 \mathrm{ml} / \mathrm{min}$ early postprandially, and $2.3 \mathrm{ml} / \mathrm{min}$ from 30-120 minutes postprandially. ${ }^{42}$ Another study using a perfusion rate of $3 \mathrm{ml} / \mathrm{min}$ reports interdigestive duodenal flow rates of 3-4 ml/min and a rather stable volume flow of 5-6 ml/min for about two hours postprandially, followed by a slow decline to interdigestive values. ${ }^{50}$ Maximal postprandial duodenal lipase activity ranged from roughly $500 \mathrm{U} / \mathrm{ml}^{12} 4251$ to $1500 \mathrm{U} / \mathrm{ml}^{18}{ }^{18}{ }^{55}$ mean lipase acitvity during the major part of the postprandial period ranged from $400-500^{12} 4251$ or $1000 \mathrm{U} / \mathrm{ml}^{18}{ }^{50}{ }^{55}$ Data for amylase and trypsin show a similar pattern and are given in table 2 (references are included).

\subsection{7 $\mathrm{pH}$ and bicarbonate in vivo ( $24 \mathrm{~h})$ and in vitro} (aspirates)

In duodenal aspirates of healthy subjects, interdigestive $\mathrm{pH}$ is 6-7. Following ingestion of a normal meal, duodenal $\mathrm{pH}$ is around 6 early postprandially, drops towards 5-5.5 during the second and third postprandial hour, and reaches preprandial values at the end of the digestive period. ${ }^{811} 1255$ These data are reported homogenously in all studies investigating $\mathrm{pH}$ in aspirates of duodenal chyme. Recent in vivo measurements of intraduodenal $\mathrm{pH}$ by 24 hour $\mathrm{pH}$ monitoring are generally in line with previous findings, but report slightly lower $\mathrm{pH}$ values. ${ }^{57}{ }^{58}$

\subsubsection{Bile acids}

Basal bile acid output (about $10-20 \mu \mathrm{mol} / \mathrm{min})^{71145}$ is increased markedly by meal ingestion (three to sixfold). ${ }^{71}$ Similar to pancreatic enzyme secretion, peak bile acid output is followed by a period of stable or slowly declining biliary secretion, although the difference between peak and plateau bile acid output tends to be greater than between respective enzyme outputs. ${ }^{11}$ Overall, there are fewer data on postprandial bile acid output than expected, because many investigators chose bilirubin output as a measure of biliary secretion. Moreover, in this review only studies with simultaneous measurement of pancreatic and biliary secretion have been taken into account.

\subsubsection{Initiation and termination of digestive enzyme response}

Sight, smell, and taste of food initiate the cephalic phase of digestive pancreatic enzyme response. Cephalic stimulation is mediated by the vagal cholinergic system and may induce about half-maximal enzyme secretion rates. ${ }^{59}$ The subsequent gastric phase accounts for a smaller part of the overall enzyme output and is probably mediated by gastropancreatic reflexes which are activated by gastric distension. The quantitatively most important intestinal phase is induced by the entry of chyme into the duodenum. Gastric acid, free fatty acids, essential amino acids and carbohydrates within the duodenum initiate the intestinal phase of the digestive pancreatic exocrine response and maintain stimulation during the digestive period. Late postprandially, however, pancreatic enzyme output declines to interdigestive values, although the proximal small intestine is still exposed to substantial nutrient concentrations. This is probably not due to inhibitory mechanisms induced by duodenal nutrient exposure-for example, release of somatostatin ${ }^{60}$ or pancreatic polypeptide. ${ }^{61}$ The liberation of these inhibitory mediators coincides with the release of stimulatory hormones. Therefore, duodenal hormonal inhibitors are generally assumed to be modulators of the magnitude of the digestive response rather than its duration. Another potential mechanism might be desensitisation of pancreatic responsiveness as a result of persistent duodenal nutrient exposure. However, there is no evidence that prolonged duodenal perfusion with constant rates of nutrients decreases pancreatic responsiveness to endogenous stimulation. ${ }^{16}$ Therefore inhibitory mechanisms activated predominantly in the late postprandial period are more likely to mediate the termination of digestive pancreatic enzyme secretion in the presence of duodenal nutrient exposure. Candidate hormones are peptide YY (PYY) and glucagon-like peptide-1 (GLP-1). These peptides are released from the distal intestinal mucosa in response to a meal or intraileal nutrients (fig 4). ${ }^{2062-66}$

Ileal perfusion of lipids inhibits secretory and motor functions of upper gastrointestinal organs both in the interdigestive state ${ }^{67}$ and during weak or moderate endogenous stimulation (fig 5). ${ }^{1768-72}$ In addition, there are several studies suggesting comparable inhibitory effects of

Table 2 Enzyme activities in duodenal juice

\begin{tabular}{llll}
\hline & Interdigestive & Early/maximal postprandial & Late/mean postprandial \\
\hline Lipase $(\mathrm{U} / \mathrm{ml})$ & $100-400$ & $500-1500$ & $400-1000$ \\
Amylase $(\mathrm{U} / \mathrm{ml})$ & $100^{50}-150^{42}$ & $150^{50}-300^{42} 51$ & $150^{18} 5051-300^{42}$ \\
Trypsin $(\mathrm{U} / \mathrm{ml})$ & $20-50^{42} 51$ & $80^{26} 4251-180^{12}$ & $60-100^{26} 4251-150^{12}$
\end{tabular}

Data are derived from studies using test meals with 300-600 kcal and using no or only low marker perfusion rates $(\leqslant 3 \mathrm{ml} / \mathrm{min})$. References for lipase are given in the text. 

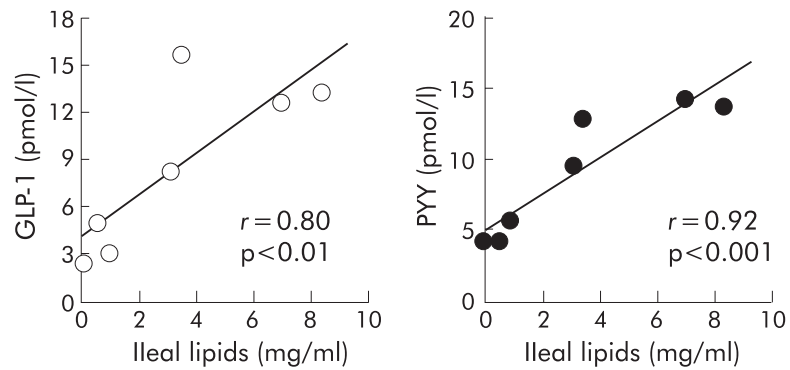

Figure 4 lleal lipid exposure dose dependently releases glucagon-like peptide-1 (GLP-1) and peptide YY (PYY) in healthy humans. ${ }^{20}$

equicaloric amounts of carbohydrates, especially glucose (fig 5). ${ }^{17} 6773$ By contrast, perfusion of protein or protein hydrolysates has no ${ }^{17} 74^{75}$ or only weak inhibitory effects, ${ }^{70}$ although the effect on pancreatic enzyme secretion remains largely to be determined. Under physiological circumstances, considerable amounts of nutrients pass the small intestine unabsorbed. This phenomenon is referred to as "physiological malabsorption". Up to $20 \%$ of a carbohydrate meal may reach the terminal ileum ${ }^{76}$ and following ingestion of a mixed meal ileal lipid concentrations of up to about $10 \mathrm{mg} / \mathrm{ml}$ were measured..$^{57} 78$ There are fewer data on physiological malabsorption of proteins because it has been difficult to differentiate between dietary and endogenous proteins. A recent study using labeled egg protein suggests that about $6 \%$ of cooked and $35 \%$ of raw egg protein escape digestion and absorption in the small intestine in healthy humans. ${ }^{78}$ The amount of non-absorbed proteins was even higher in patients receiving gastric acid suppression therapy, probably because gastric digestion plays a substantial role in overall protein assimilation. ${ }^{79}$

Ingestion of a low caloric and easily digestible test meal resulted in much lower intraileal glucose and lipid concentrations (about $2 \mathrm{mg} / \mathrm{ml}$ and $1 \mathrm{mg} / \mathrm{ml}$, respectively) than would be expected after ingestion of a normal meal. ${ }^{18}$ Nevertheless, ileal nutrient concentration corresponded to up to about $25 \%$ of maximal duodenal values and remained stable for almost four hours, whereas duodenal nutrient concentration peaked one hour postprandially, was maintained at increased levels for about two hours and rapidly

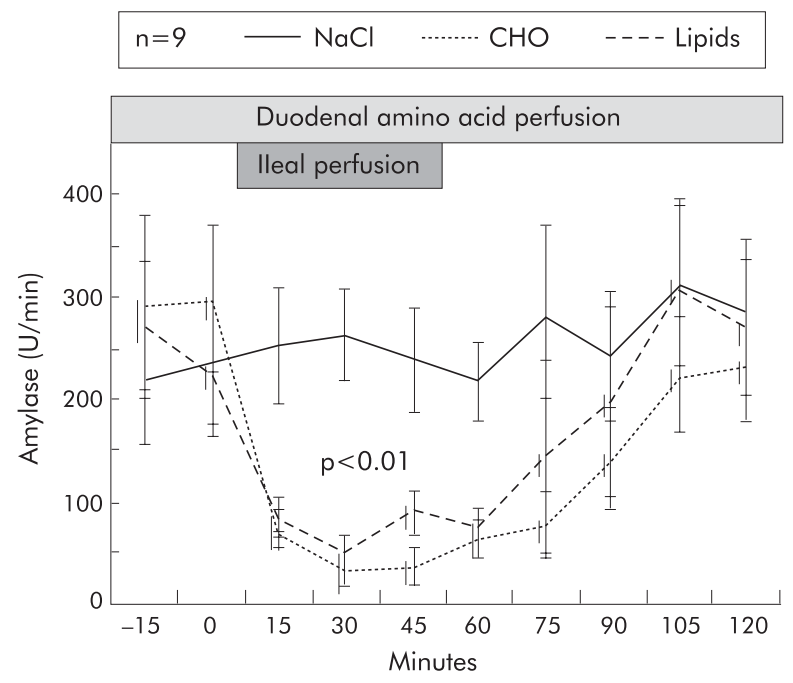

Figure 5 Inhibition of endogenously stimulated pancreatic enzyme secretion by ileal perfusion of carbohydrates (CHO) and lipids in healthy humans. ${ }^{7}$

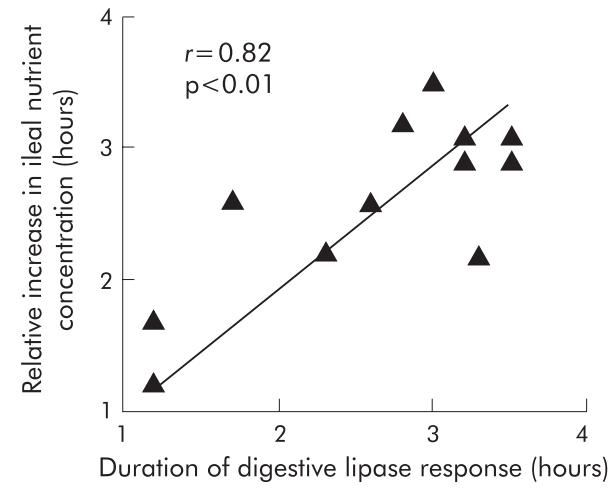

Figure 6 Correlation between the duration of digestive lipase secretion and the time of the relative increase in ileal nutrient concentration in healthy humans. ${ }^{18}$

decreased thereafter. The resulting relative increase in late postprandial ileal nutrient exposure correlated tightly with the termination of the digestive pancreatic secretory response (fig 6). Therefore, the ileum appears to contribute to the regulation of the transition from the fed to the subsequent fasting state. Stimulatory and inhibitory mechanisms induced by nutrients both in the proximal and distal small bowel may interact to co-regulate pancreatic exocrine secretion during the functional interface between the late postprandial and the subsequent interdigestive period.

\subsection{Pancreatic response to protein diets}

\subsubsection{Enzyme secretion}

The protein component of a meal contributes markedly to induction of the digestive pancreatic enzyme response. Overall, mixed amino acids have the same effect on pancreatobiliary secretions compared with polymeric protein solutions.$^{80}$ However, the stimulatory effect of dietary protein on pancreatic exocrine secretion appears to depend on adequate protein digestion ${ }^{81}$ and stimulatory potency is limited to certain essential amino acids: phenylalanine, valine, methionine, and tryptophane increased trypsin secretion (300-180\% compared with $\mathrm{NaCl}$ ), whereas isoleucine, leucine, lysine, threonine, and other amino acids did not. ${ }^{82}$ Even low doses of intraduodenally perfused essential amino acids have a stimulatory effect on pancreatic enzyme secretion. Graded intraduodenal essential amino acid perfusion at $0,62.25,122.5,225$, and $450 \mu \mathrm{mol} / \mathrm{min}$ dosedependently increased trypsin and chymotrypsin outputs. In these experiments, at least $225 \mu \mathrm{mol} / \mathrm{min}$ were needed to significantly increase protease output above basal levels. ${ }^{49}$ If only essential amino acids with stimulatory potency were perfused, even $150 \mu \mathrm{mol} / \mathrm{min}$ induced a sustained twofold increase in amylase secretion $(53 \mathrm{U} / \mathrm{min} \quad v \quad 85 \mathrm{U} / \mathrm{min}) .{ }^{48}$ Constant duodenal perfusion of essential amino acids at a higher dose $(800 \mu \mathrm{mol} / \mathrm{min})$ caused a short lived (<30 min) peak trypsin output (basal: $25 \mathrm{U} / \mathrm{min}$, peak: $160 \mathrm{U} / \mathrm{min}$ ) followed by a stable $50 \%$ maximal enzyme output (about $120 \mathrm{U} / \mathrm{min}$ ) throughout amino acid perfusion (>5 hours). ${ }^{16}$

Doubling the protein content of an otherwise unchanged low caloric test meal also doubled cumulative lipase output. ${ }^{83}$ However it has to be taken into account that these meals had different caloric loads which were within the range of dosedependent stimulation of enzyme output. ${ }^{13}$

\subsection{Pancreatic response to lipid diets 2.4.1 Enzyme secretion}

Lipids are the strongest stimulants of pancreatic enzyme secretion; thus, administration of a diet with a high fat content for four weeks was associated with higher enzyme 
output compared with diets rich in carbohydrates or proteins. $^{24}$

Duodenal free fatty acids rather than triglycerides appear to be responsible for the release of cholecystokinin (CCK) and subsequent stimulation of enzyme output in humans. ${ }^{84} 85$ Duodenal perfusion of fatty acids (oleic acid) at graded doses $(0,50,100,200$, and $400 \mu \mathrm{mol} / \mathrm{min})$ dose dependently increased amylase output $(0.7,1.15,1.24,1.4$, and $1.7 \mathrm{kU} /$ min respectively). Even the lowest dose of $50 \mu \mathrm{mol} / \mathrm{min}$ significantly stimulated enzyme secretion. Overall pancreatic enzyme response paralleled plasma CCK plasma concentrations. ${ }^{45}$

Apart from the dose of fatty acids delivered to the duodenum, fatty acid chain length has a major influence on pancreatic enzyme response: glycerol did not influence enzyme secretion, increasing fatty acid chain length augmented pancreatic responses. ${ }^{58}$ Accordingly, medium chain triglycerides administered to the proximal jejunum did not increase enzyme secretion in contrast to equicaloric amounts of long chain fatty acids. ${ }^{86}$ Furthermore, the terminal carboxy group of the fat molecule appears to be of importance because oleic acid had a much stronger stimulatory effect on pancreatic secretion than oleyl alcohol. ${ }^{45}$ On the other hand, fat droplet size appears to have no major effect on lipase output: Armand et al showed that a lipid emulsion with small droplets $(0.7 \mu \mathrm{m})$ was digested more efficiently in the upper gastrointestinal tract than a coarse emulsion $(10 \mu \mathrm{m})$ but gastric and pancreatic lipase activities were similar with both emulsions and overall fat assimilation was unchanged. ${ }^{87}$

Trypsin output in response to a mixed, fat rich meal (580 kcal, 60\% fat) was within the range observed for meals with regular nutrient composition (plateau output: 400$500 \mathrm{U} / \mathrm{min}){ }^{.52}$ These findings may imply that within a certain range caloric content plays a major role for determination of pancreatic enzyme response than the proportion of individual nutrient components.

\subsection{2 $\mathrm{pH}$ and bicarbonate in vivo ( $24 \mathrm{~h})$ and in vitro (aspirates)}

Graded duodenal fatty acid perfusion (0, 50, 100, 200, and $400 \mu \mathrm{mol} / \mathrm{min})$ dose dependently increased bicarbonate output $\left(13,17.3,10.2,66.9^{*}, 92.3^{*} \mu \mathrm{mol} / \mathrm{min}\right.$ respectively $\left({ }^{*} \mathrm{p}<0.05 \vee 0 \mu \mathrm{mol} / \mathrm{min}\right)$. However, fatty acids are a weaker stimulant of bicarbonate secretion compared with enzyme secretion. Stimulation started at a dose of $200 \mu \mathrm{mol} / \mathrm{min}$ and paralleled secretin release. ${ }^{45}$ There appear to be no studies measuring duodenal $\mathrm{pH}$ in response to lipid meals.

\subsubsection{Bile acids}

The bile acid response to graded doses of duodenal fatty acids parallels pancreatic enzyme response and CCK release. Infusion of $50,100,200$, and $400 \mu \mathrm{mol} / \mathrm{min}$ oleic acid significantly and dose dependently increased bile acid output compared with basal levels $(85,70,89,99, v 23.5 \mu \mathrm{mol} /$ min). ${ }^{45}$ The bile acid response to a fat rich liquid meal (580 kcal, 60\% fat) paralleled the pancreatic enzyme response, apart from the fact that plateau bile acid output during the second and third postprandial hour was lower than plateau trypsin output in relation to respective peak output rates. ${ }^{52}$

\subsection{Pancreatic response to carbohydrate diets 2.5.1 Enzyme secretion}

Carbohydrates are weaker stimulants of pancreatic enzyme secretion compared with proteins and lipids. ${ }^{1}$ Most investigators report a marked but short lived increase in enzyme output induced by carbohydrate meals followed by a fast decline ${ }^{41} 83100 \mathrm{~g}$ glucose dissolved in $500 \mathrm{ml}$ water increased basal lipase output ( $800 \mathrm{U} / \mathrm{min}$ ) about threefold (2600 U/ min). However, one hour postprandially lipase output had already returned to preprandial values. By contrast, a liquid mixed meal with similar caloric content increased lipase secretion for more than two hours. ${ }^{41}$ On the other hand, test meals containing either $100 \mathrm{~g}$ of glucose alone or $100 \mathrm{~g}$ of glucose and $35 \mathrm{~g}$ of protein, induced similar, though overall submaximal trypsin responses. ${ }^{88}$

Layer et al investigated the effect of a pure rice starch meal on protein and enzyme output and on intraluminal protein concentration and enzyme activities. These data are given in table $3 .{ }^{39}$

In those studies cited above, liquid monomeric or polymeric carbohydrate solutions were used. Therefore, the lower digestive pancreatic enzyme response to carbohydrate meals may depend in part on faster gastric emptying of the carbohydrate solution compared with either fat containing liquid test meals or solid meals.

\subsubsection{Bile acids}

Bile acid output was significantly stimulated three to fourfold by $100 \mathrm{~g}$ of glucose alone or $100 \mathrm{~g}$ of glucose and $35 \mathrm{~g}$ of protein. ${ }^{88}$

\subsection{Ratios of enzymes}

\subsubsection{Ratios of pancreatic enzymes}

In general, output of pancreatic enzymes into the duodenum occurs in parallel and this becomes evident from most studies which analysed two or more enzymes.7 1243465053 Overall, postprandial lipase:amylase ratio and lipase:trypsin ratio are approximately 3-6/1 and 5-10/1, respectively (compare tables 1 and 2). This means that in terms of catalytic units as defined under optimised conditions in vitro, a three to sixfold excess of lipolytic activity in comparison with amylase and a five to tenfold excess of lipolytic activity in comparison with trypsin is released into the duodenum. It does not automatically imply that the ability of human intestinal contents to digest lipids is higher than the ability to digest proteins or carbohydrates. However, only very few investigators adressed the relations between pancreatic enzymes directly and systematically. Such studies show that under

Table 3 Release of pancreatic enzymes in response to a pure carbohydrate meal and fate of enzymes during small intestinal transit*. ${ }^{39}$

\begin{tabular}{|c|c|c|c|c|c|c|}
\hline & \multicolumn{2}{|l|}{ Duodenum } & \multicolumn{2}{|l|}{ Jejunum } & \multicolumn{2}{|l|}{ lleum } \\
\hline & Concentration & Output & Concentration & Output & Concentration & Output \\
\hline Protein $(\mathrm{mg} / \mathrm{ml} / \mathrm{g})$ & 5.9 & 4.6 & 3.5 & 2.2 & 5.1 & 1.5 \\
\hline Lipase (U/ml/kU) & 220 & 177 & $29+$ & $13+$ & & $2 \dagger$ \\
\hline Amylase (U/ml/kU) & 943 & 538 & $1201 \dagger$ & $456+$ & $2215^{*}$ & $400+$ \\
\hline Trypsin (U/ml/kU) & 117 & 66 & 136 & $43 \dagger$ & 126 & $15 \dagger$ \\
\hline \multicolumn{7}{|c|}{$\begin{array}{l}\text { *Data refer to protein and enzyme concentrations and outputs during the postprandial period which was defined as } \\
\text { time span between first appearance and delivery of }>95 \% \text { of the meal marker to each intestinal site ( } 219 \text { minutes } \\
\text { in the duodeum, } 251 \text { minutes in the jejunum, and } 257 \text { minutes in the ileum). } \\
t p<0.05 v \text { duodenum. }\end{array}$} \\
\hline
\end{tabular}




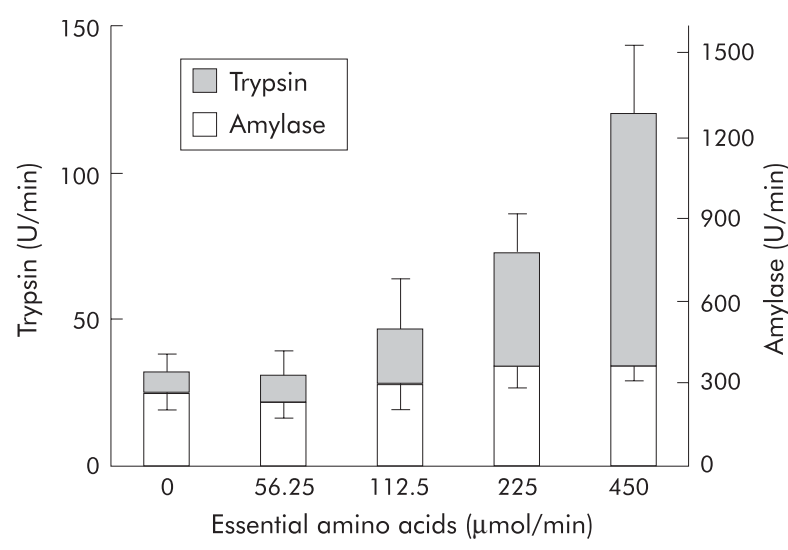

Figure 7 Differential effects of graded duodenal nutrient perfusion on protease and amylase outputs in healthy humans. Essential amino acids at doses up to $450 \mu \mathrm{g} / \mathrm{min}$ dose dependently stimulated trypsin but had no effect on amylase output $\left({ }^{*} p<0.05\right) .{ }^{49}$

experimental conditions-that is, during weak duodenal stimulation $^{49}$ and during low dose ileal nutrient perfusion pancreatic amylase seems to be less susceptible to stimulatory and inhibitory mediators, respectively, compared with trypsin and lipase (fig 7). ${ }^{50} 69$ This led to alterations in amylase:protease and amylase:lipase ratios which may occur physiologically at the very beginning and at the end of the digestive period. Although the concept of non-parallel pancreatic enzyme secretion is mostly debated in humans, the group of Morisset has published data showing individual regulation of each pancreatic enzyme under experimental conditions in rats. $^{89-92}$

In addition, there is evidence that chronic dietary habits may influence enzyme ratios in humans. Intraindividually, the ratio between amylase and lipase is not influenced acutely by the fat content of a meal. By contrast, interindividually there is a correlation between body weight and the amylase:lipase ratio- the heavier the subjects were, the lower this ratio was. Therefore, long time dietary differences might influence enzyme composition with relative dominance of amylase in lighter subjects and of lipase in heavier subjects. ${ }^{80}$ Theoretically, high fat diets in heavier subjects might not only cause increased overall enzyme secretion ${ }^{24}$ but specifically increase lipase secretion.

\subsubsection{Ratios of pancreatic and non-pancreatic digestive enzymes}

The ratio between pancreatic and non-pancreatic enzymes changes postprandially. Following infusion of a standard semiliquid test meal $(375 \mathrm{kcal})$ into the stomach, intraduodenal pancreatic lipase activity plateaued at $200 \mu \mathrm{g} / \mathrm{ml}$ (equivalent to $1600 \mathrm{U} / \mathrm{ml}$ ) until $60 \%$ of the meal were emptied from the stomach. Afterwards, pancreatic lipase activity decreased to $50 \mu \mathrm{g} / \mathrm{ml}$ or $400 \mathrm{U} / \mathrm{ml}$. By contrast, gastric lipase activity in duodenal chyme was low during the early postprandial period (about $10 \mu \mathrm{g} / \mathrm{ml}$ ) and increased late postprandially (up to $90 \mu \mathrm{g} / \mathrm{ml}$ ). Consequently, the ratio between pancreatic and gastric lipase decreased postprandially from $8.4(\mathrm{wt} / \mathrm{wt})$ during the first postprandial hour to 1.6 during the third hour. ${ }^{55}$ Globally, during the whole digestive period, gastric lipase hydrolysed $17.5 \%$ of the triglyceride acyl chains (10\% intragastrically, $7.5 \%$ within the duodenal lumen)..$^{55}$

Likewise, salivary amylase occurs as a sharp peak late postprandially in duodenal juice, leading to a marked decrease in the ratio between pancreatic and salivary amylase. Throughout the digestive period, salivary amylase comprises about $15 \%$ of total amylase output. ${ }^{53}$
2.7 Fate of enzymes during small intestinal transit

Following ingestion of $50 \mathrm{~g}$ pure rice starch $(<300 \mathrm{mg}$ fat and protein) only about $8 \%, 85 \%$, and $64 \%$ of lipase, amylase, and trypsin, respectively, reached the mid-jejunum, whereas $1 \%, 74 \%$, and $22 \%$ of lipase, amylase, and trypsin respectively, reached the terminal ileum (table 3 ). This means that lipase activity is almost completely lost during small intestinal transit in the absence of its substrate. Compared with lipase activity, lipase immunoreactivity was preserved significantly longer. Vice versa, trypsin activity survived small intestinal transit better than trypsin immunoreactivity. Consequently, complete structural integrity of the molecule may not be essential for its proteolytic activity. ${ }^{39}$

Following ingestion of a mixed meal ${ }^{50}$ or duodenal perfusion of graded doses of mixed nutrients ${ }^{93}$ similar amounts of amylase reached the terminal ileum, whereas considerably higher amounts of lipase (20-25\% of duodenal lipase) survived small intestinal transit. In vitro and in vivo survival of pancreatic enzymes is enhanced by the presence of nutrients, in particular of the respective substrate..$^{509} 94$ Proteases, especially chymotrypsin, play a major role in the destruction of lipolytic activity during aboral small intestinal transit. ${ }^{3}$ Interestingly, the protective effect of nutrients on degradation of lipase was as high as the effect of protease inhibition. ${ }^{95}$

\subsection{Summary}

Current knowledge about the physiological pancreatic exocrine response to a meal can be summarised as follows:

Pattern and magnitude of digestive pancreatic enzyme response have been described consistently by several authors. In response to an ordinary meal or application of individual nutrients, there is a short phase of maximal enzyme secretion which means a three to sixfold increase above interdigestive levels of all major enzymes. This is followed by a three to fourfold sustained increase in enzyme output. Secretory rates return to the interdigestive range late postprandially (see 2.2).

The degree and the duration of the digestive enzyme response are determined by the caloric content, nutrient composition, and physical properties of the meal: Meals containing about $500 \mathrm{kcal}$ appear to be sufficient to induce the maximal enzyme response (see 2.2.1). Lipids are the strongest stimulants of pancreatic enzyme secretion and chronic administration of a diet with a high fat content is permanently associated with higher enzyme output compared with diets rich in carbohydrates or proteins. Duodenal free fatty acids rather than triglycerides appear to be responsible for the release of CCK and subsequent stimulation of enzyme output in humans. The stimulatory potency of proteins is limited to the essential amino acids phenylalanine, valine, methionine, and tryptophane. Carbohydrates are weaker stimulants than lipids and proteins. Maximal postprandial enzyme output to carbohydrate solutions is comparable to lipid and protein diets tested in various studies, however, the latter cause a more sustained increase in enzyme output. The relevance of faster gastric emptying of liquid and semiliquid carbohydrate meals has not been clarified, so far. This would require circumventing gastric emptying by duodenal perfusion of individual nutrient solutions (for example, equicaloric and/or same molar concentrations of fatty acids, essential amino acids with stimulatory potency and glucose) (see 2.2.2 and 2.3-2.5).

Enzyme response to a solid meal is more sustained compared with an identical meal which has been homogenised. This is partly due to slower gastric emptying of the solid compared with the homogenised meal which leads to prolonged stimulation of enzyme output. In addition, increased gastric acid secretion and, consequently, increased 
duodenal acid delivery in response to a solid meal may also cause higher pancreatic secretory response. The effects of other physical properties of a meal, such as osmolality and temperature, have so far not been clarified (see 2.2.3).

It is controversial whether pancreatic secretion is gender related and decreases in the elderly. In any case, differences in pancreatic exocrine secretion among women and men on the one hand and young and elderly adults on the other hand are probably small and clinically unimportant. The influence of female sexual hormones or different stages of the menstrual cycle on pancreatic exocrine secretion have not been investigated, so far (see 2.2.4).

There are only a few studies addressing total digestive pancreatic enzyme output. It can be estimated by duodenal protein delivery if the test meal does not contain proteins because under these circumstances duodenal proteins are totally derived from endogenous sources and mainly from pancreatic enzymes. Following submaximal digestive stimulation by a pure rice starch meal, duodenal protein concentration during the postprandial period is about $6 \mathrm{mg} / \mathrm{ml}$ and cumulative postprandial duodenal protein delivery $4.6 \mathrm{~g}$. Maximal duodenal protein delivery is achieved one hour postprandially and reaches $30 \mathrm{mg} / \mathrm{min}$ (see 2.2 .5 ).

In physiological studies, individual digestive enzymes have been analysed more frequently, in particular trypsin and lipase. Amylase was also measured in several studies, but there is astonishingly little information on chymotrypsin output. Duodenal enzyme outputs (see table 1) are easier to compare among the different studies than intraluminal enzyme activities (see table 2), because the latter are more profoundly influenced by methodological differences, particularly by marker perfusion. Overall, mean interdigestive pancreatic lipase, amylase, and trypsin outputs are about 1000, 50-250, and 50-100 U/min, respectively. Maximal postprandial outputs reach about 3000 to $6000 \mathrm{U} / \mathrm{min}$ for lipase, 500-1000 U/min for amylase, and 200-1000 U/min for trypsin. Thereafter, $2000-4000 \mathrm{U} / \mathrm{min}$ of lipase, $500 \mathrm{U} / \mathrm{min}$ of amylase, and $150-500 \mathrm{U} / \mathrm{min}$ of trypsin are stably released into the duodenum for two hours or longer, depending on the test meal administered (see 2.2.6).

Nutrients within the duodenal lumen are the most important stimulators of the pancreatic exocrine response and maintain enzyme secretion throughout the digestive period. However, the distal small intestine also participates in the regulation of the pancreatic response to a meal. Late postprandially, stimulatory and inhibitory mechanisms induced by nutrients both in the proximal and distal small bowel seem to interact to co-regulate pancreatic exocrine secretion during the functional interface between the late postprandial and the subsequent interdigestive period (see 2.2.9).

In general, output of pancreatic enzymes into the duodenum occurs in parallel and this becomes evident from most studies which analysed two or more enzymes. Postprandial lipase:amylase ratio and lipase:trypsin ratio are approximately 3-6/1 and 5-10/1, respectively (see tables 1 and 2). However, there appear to be no studies addressing this question directly and systematically. Moreover, under experimental conditions-that is, during weak duodenal stimulation and during low dose ileal nutrient perfusion, pancreatic amylase seems to be less susceptible to stimulatory and inhibitory mediators, respectively, compared with trypsin and lipase. This leads to alterations in amylase:protease and amylase:lipase ratio which may occur physiologically at the very beginning and at the end of the digestive period (see 2.6).

Postprandially, the ratio between pancreatic and nonpancreatic enzymes in duodenal juice changes markedly. The ratio between pancreatic and gastric lipase decreases from 8.4 (wt/wt) during the first postprandial hour to 1.6 during the third hour. Likewise, salivary amylase occurs as a sharp peak late postprandially in duodenal juice, leading to a marked decrease in the ratio between pancreatic and salivary amylase (see 2.6).

During small intestinal transit, lipase activity is most susceptible to destruction and is almost completely lost following a carbohydrate meal. If subjects ingest a mixed meal and following duodenal perfusion of mixed nutrient solutions, significantly higher amounts-that is, about $20 \%$ of duodenal lipase reach the terminal ileum in active form (see 2.7).

\subsection{PATHOPHYSIOLOGY OF PANCREATIC EXOCRINE SECRETION}

The crucial importance of pancreatic exocrine function is reflected by the detrimental malabsorption which occurs as a consequence of untreated pancreatic exocrine insufficiency and may be due to different diseases. ${ }^{296}$ In chronic pancreatitis, which is the most common cause of pancreatic exocrine insufficiency, intraluminal availability of pancreatic enzymes decreases because of destruction of functioning pancreatic parenchyma causing insufficient amounts of enzymes to be synthesised and secreted into the duodenum in response to ingestion of a meal. Other, virtually pancreatic causes of intraluminal enzyme deficiency include: cystic fibrosis, pancreatic resections, and pancreatic carcinoma. However, even in the absence of (primary) pancreatic disease, there are other pathophysiological mechanisms which may also cause intraluminal lack of enzymatic activity and maldigestion. Periampullary tumours, for instance, may obstruct the main pancreatic duct and impair secretion of pancreatic juice despite normal synthetic capacity. In coeliac sprue, on the other hand, reduced endogenous stimulation is the main cause of decreased pancreatic exocrine secretion. Patients with Zollinger-Ellison syndrome may suffer from maldigestion due to intraluminal inactivation of enzymes, particularly lipase, caused by duodenal hyperacidity. Gastrointestinal surgery-for example, gastrectomy and Roux-en-Y anastomosis-may impair coordination between secretory and motor functions and thereby induce maldigestion and malabsorption (fig 8). ${ }^{97-101}$

Further understanding of the pathophysiological mechanisms is needed for optimising enzyme replacement therapies, because in most patients luminal lipid digestion cannot be completely normalised by currently available enzyme preparations. ${ }^{5} 102103$ Moreover, it has to be taken into account that in states of chronic intraluminal enzyme deficiency, complex and interacting alterations of secretory, motor, and endocrine functions may contribute to symptoms which may even precede overt malabsorption. ${ }^{3}{ }^{104}$

This chapter will focus on pancreatic responses to a normal diet and to administration of individual food components in patients with pancreatic diseases (that is, acute and chronic pancreatitis, pancreatic cancer, pancreatic surgery, and cystic fibrosis) as well as non-pancreatic diseases associated with intraluminal lack of pancreatic enzymes (that is, coeliac disease, diabetes mellitus, Crohn's disease, gastric surgery, short bowel syndrome, and Zollinger-Ellison syndrome). Other evidence of pancreatic involvement and dysfunction in these diseases-for example, pancreatic response to exogenous stimulation-will also be discussed, in particular if sufficient data on endogenously stimulated pancreatic secretion are lacking. On the other hand, the influence on other organs apart from the pancreas by the diseases under discussion will only be reviewed if they influence pancreatic function or the degree of dysfunction tolerated without nutrient maldigestion and malabsorption. 


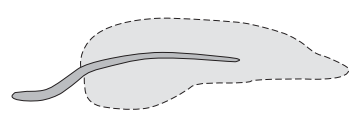

\author{
Loss of functioning parenchyma \\ - Chronic pancreatitis \\ - Cystic fibrosis \\ - Pancreatic tumours \\ - Pancreatic resections
}

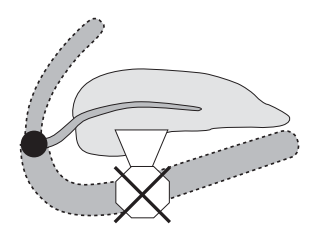

Decreased secretion despite intact parenchyma

- Obstruction of pancreatic duct (tumour of the papilla)

- Decreased endogenous stimulation (coeliac disease, Crohn's

disease?, diabetes mellitus?)

- Intraluminal inactivation (Zollinger Ellison syndrome, tetrahydrolipstatin)

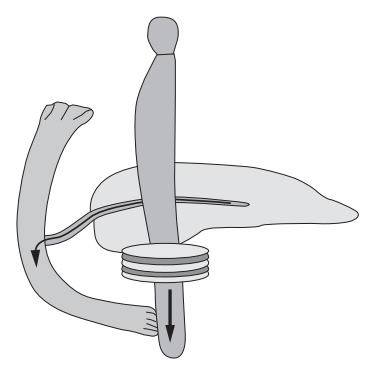

\title{
Postcibal asynchromy
}

- Gastric resections

- Short bowel syndrome

- Crohn's disease, diabetes mellitus

\subsection{Chronic pancreatitis}

Chronic pancreatitis is the most common cause of pancreatic exocrine insufficiency. Although pancreatic exocrine function may already decrease during the early stages of the disease because of loss of functioning parenchyma, overt malabsorption is a late complication in most patients ${ }^{4}$ because of the large reserve capacity of the exocrine pancreas. ${ }^{105}$ It is widely accepted that steatorrhoea and creatorrhoea do not occur until secretion of the respective digestive enzymes is decreased below $5-10 \%$ of normal. ${ }^{2}{ }^{105}$

In consequence, patients with suspected chronic pancreatitis may show a broad spectrum of pancreatic function ranging from normal enzyme output to "compensated" (mild to moderate) exocrine insufficiency - that is, enzyme output less than normal but sufficient to prevent nutrient malabsorption and "decompensated" (severe) exocrine insufficiency with clinical steatorrhoea.

The fact that patients with variable degrees of pancreatic exocrine insufficiency have been investigated is probably one of the main reasons for variable findings in studies on pancreatic exocrine function in chronic pancreatitis ${ }^{106} 107$ showing approximately a $40-90 \%$ or even $99 \%$ reduction of enzyme release compared with healthy humans (table 4). ${ }^{12}{ }^{97}{ }^{104-114}$ On the other hand, in most studies patients with varying aetiologies of chronic pancreatitis, for example alcoholic and idiopathic, ${ }^{104}$ have been included. The different natural courses of chronic pancreatitis suggest that pancreatic exocrine function is preserved longer and consequently exocrine insufficiency may generally be milder in "early onset" idiopathic chronic pancreatitis compared with alcoholic and "late onset" idiopathic chronic pancreatitis. However, direct comparisons of enzyme and bicarbonate outputs in patients with varying aetiologies of chronic pancreatitis have hardly been performed, so far. For alcoholic and tropical chronic pancreatitis, Sarles et al demonstrated that both show similar biochemical modifications of pancreatic juice including protein output. ${ }^{115}$

\subsubsection{Interdigestive pancreatic enzyme output}

Interdigestive pancreatic enzyme output is lower in patients with chronic pancreatitis compared with healthy controls. ${ }^{108} 117$ In respective studies, interdigestive cycling was
Figure 8 Pathomechanisms causing intraluminal pancreatic enzyme deficiency. preserved, but the time between cycling peaks of enzyme secretion was shortened in chronic pancreatitis and peak enzyme outputs were no longer related to the migrating motor complex (MMC) as observed in healthy humans. In chronic pancreatitis, only about half of the phase III activity fronts were associated with a secretory peak compared with more than $90 \%$ in healthy volunteers. This means that chronic pancreatitis not only decreases interdigestive pancreatic enzyme secretion but also interrupts coordination among interdigestive cyclic phenomena (see 2.2).

\subsubsection{Pancreatic response to mixed meals}

DiMagno et al investigated pancreatic enzyme output in response to a mixed meal in patients with chronic pancreatitis, steatorrhoea, and creatorrhoea-that is, severe pancreatic exocrine insufficiency. ${ }^{12}$ In chronic pancreatitis patients, digestive lipase output was about $2.5 \mathrm{IU} / \mathrm{min}$ which was less than $0.2 \%$ of normal $(3000 \mathrm{IU} / \mathrm{min}$ ). Oral pancreatin (eight times $3.5 \mathrm{kU}$ of lipase per meal) increased duodenal lipase to reach about $1 \%$ of normal which is obviously still far below the minimum of 5 to $10 \%$ of normal needed to prevent steatorrhoea. Similarly, Layer et al investigated digestive responses to a $300 \mathrm{kcal}$ semiliquid meal in patients with severe pancreatic exocrine insufficiency (that is, SC test results $<5 \%$ of normal) in comparison to healthy volunteers. ${ }^{104}$ Oro-ileal intubation and aspiration of aliquots of chyme further allowed estimation of intestinal nutrient absorption. Severe exocrine insufficiency was associated with considerable maldigestion and malabsorption: in chronic pancreatitis patients, about $40 \%$ of nutrients $(487 \mathrm{~kJ}$ of $1257 \mathrm{~kJ}$ ) were delivered to the terminal ileum compared with about $5 \%$ of nutrients $(69 \mathrm{~kJ})$ which were physiologically malabsorbed in healthy humans. In these chronic pancreatitis patients, proportions of individual nutrients in ileal chyme reflected those administered in the meal. Thus, it appears that malabsorption of lipids, proteins, and carbohydrates was roughly equal. Physiological malabsorption in healthy volunteers remained unaltered when enzymes (30 kU of lipase) were substituted together with the test meal. By contrast, in chronic pancreatitis patients, enzyme supplementation (pancreatin powder containing $30 \mathrm{kU}$ of 
Table 4 Pancreatic exocrine function in chronic pancreatitis

\begin{tabular}{|c|c|c|c|c|c|}
\hline & Stimulus & Trypsin & Lipase & Amylase & Other \\
\hline Brugge et al, $1985^{108}$ & CCK & \multicolumn{4}{|l|}{$10 \%$} \\
\hline Conwell et al, 2002 & CCK & & \multicolumn{3}{|c|}{$50 \% / 23 \% / 13 \% *$} \\
\hline Conwell et al, $2003^{114}$ & CCK & & \multicolumn{3}{|c|}{$25 \%$} \\
\hline DiMagno et al, $1973^{105}$ & EAA & $20 \%$ & \multicolumn{3}{|l|}{$15 \%$} \\
\hline DiMagno et al, $1973^{105}$ & CCK & $10 \%$ & \multicolumn{3}{|l|}{$10 \%$} \\
\hline DiMagno et al, $1977^{12}$ & Mixed meal & $<1 \%$ & \multicolumn{3}{|l|}{$<1 \%$} \\
\hline Funakoshi et al, $1990^{109}$ & $\begin{array}{l}\text { Mixed meal } \\
\text { (intra- } \\
\text { jejunally) }\end{array}$ & & & $2 \%$ & $30 \%(\mathrm{HCO} 3-)$ \\
\hline Hoeden et al, $1976^{110}$ & $\mathrm{~S}+\mathrm{C}$ & \multirow{4}{*}{$35 \%$} & \multirow{4}{*}{$\begin{array}{l}20 \% \\
25 \% \dagger\end{array}$} & \multirow[t]{2}{*}{$10 \%$} & \multirow{3}{*}{$\begin{array}{l}65 \% \text { (HCO3-) } \\
30 \%(\mathrm{PL})\end{array}$} \\
\hline Ihse et al, $1977^{97}$ & Lundh meal & & & & \\
\hline Karlsborg et al, $1997^{116}$ & Lundh meal & & & $30 \%(\mathrm{PL})$ & \\
\hline Layer et al, $1997^{104}$ & $\mathrm{~S}+\mathrm{C}$ & & & & \multirow{2}{*}{$\begin{array}{l}2 \%+\text { (enzyme not } \\
\text { specified) } \\
25 \% \text { (PL) } \\
40 \% \text { (HCO3-) }\end{array}$} \\
\hline Makela et al, $1998^{111}$ & S & & & $30 \%$ & \\
\hline Mizuno et al, $1985^{107}$ & $\mathrm{~S}+\mathrm{P}$ & $60 \% / 15 \% \ddagger$ & $60 \% / 10 \% \ddagger$ & $60 \% / 15 \% \ddagger$ & $\begin{array}{l}40 \% / 5 \% \ddagger(\mathrm{El}) \\
60 \% / 10 \% \ddagger(\mathrm{CT})\end{array}$ \\
\hline Rogos et al, $1987^{112}$ & EAA & $50 \%$ & $35 \%$ & $45 \%$ & \\
\hline Rogos et al, $1987^{112}$ & $\mathrm{~S}+\mathrm{CCK}$ & $50 \%$ & $35 \%$ & $55 \%$ & \\
\hline \multicolumn{6}{|c|}{$\begin{array}{l}\text { Enzyme output in per cent of normal in response to various stimuli in patients with chronic pancreatitis. Data are } \\
\text { partly derived from figures and therefore rounded. } \\
\mathrm{CCK} \text {, cholecystokinin; EAA, essential amino acids; } \mathrm{S} \text {, secretin; } \mathrm{C} \text {, cerulean; } \mathrm{P} \text {, pankreozymin; } \mathrm{HCO}_{3} \text {, bicarbonate; } \\
\mathrm{PL} \text {, phospholipase; El, elastase; } \mathrm{CT} \text {, chymotrypsin } \\
{ }^{*} \mathrm{Mild} / \text { moderate/advanced chronic pancreatitis. } \\
\text { †Of lower limit of normal. } \\
\text { †Mild/advanced exocrine insufficiency. }\end{array}$} \\
\hline
\end{tabular}

lipase, $24 \mathrm{kU}$ of amylase, and $2 \mathrm{kU}$ of proteases) reduced malabsorption to $227 \mathrm{~kJ}$ - that is, by $50 \%$ (fig 9). ${ }^{104}$

In healthy volunteers, duodenal nutrients have a higher stimulatory potency compared with jejunal (see 2.2.9). In chronic pancreatitis, however, neither oral nor jejunal application of nutrients increased enzyme outputs, ${ }^{12}{ }^{109}$ at least not in severe exocrine insufficiency. ${ }^{12}$ The effects of duodenal versus jejunal nutrient perfusion in chronic pancreatitis have not been compared, so far.

Ihse et al investigated pancreatic enzyme response to the Lundh test meal in 474 unselected patients including 42 patients with chronic pancreatitis. ${ }^{97}$ Depending on which enzyme the diagnosis was based, $80 \%$ to $90 \%$ of chronic pancreatitis patients showed varying degrees of pancreatic exocrine insufficiency (that is, lipase activity $<185 \mathrm{U} / \mathrm{ml}$, phospholipase activity $<10 \mathrm{U} / \mathrm{ml}$, trypsin activity $<37 \mathrm{U} / \mathrm{ml}$ ).

Addition of wheat bran or pectin to a Lundh meal further reduced intraluminal activities of endogenous as well as exogenously applied enzymes by $40 \%$ to $60 \% .{ }^{118}$

Moreover, there is evidence that in chronic pancreatitis digestive enzyme output is not only reduced, but that the typical biphasic pattern of digestive enzyme release with an early postprandial peak followed by a decrease and a plateau

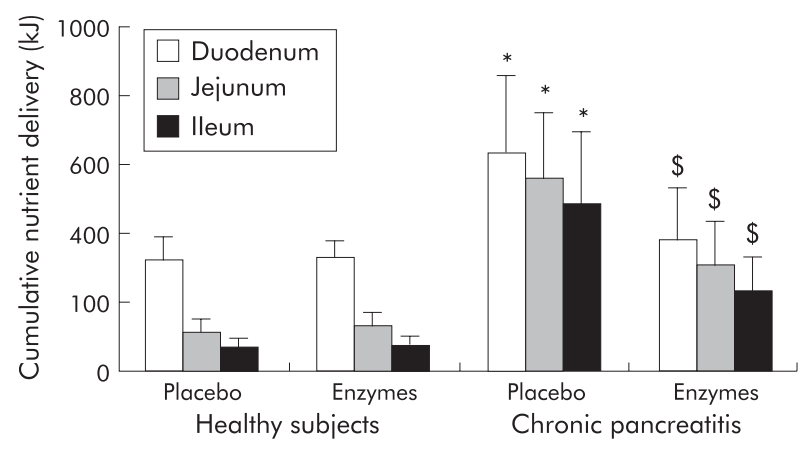

Figure 9 Nutrient malabsorption with and without enzyme supplementation in healthy subjects $(n=14)$ and patients with chronic pancreatitis $(n=12) .{ }^{104}$ phase (see fig 2) is almost lost. Instead, no or only a weak initial peak of intraduodenal enzyme activities was observed following the Lundh test meal in 47 patients with chronic pancreatitis. ${ }^{119}$

Overall, there are only a few studies investigating pancreatic exocrine response to mixed meals in chronic pancreatitis. Most of these have been performed as Lundh tests which include ingestion of a semiliquid, low caloric, easily digestible meal ( $15 \mathrm{~g}$ milk protein, $18 \mathrm{~g}$ corn oil, $40 \mathrm{~g}$ glucose, and $300 \mathrm{ml}$ water; total $250.5 \mathrm{kcal}$, compare above) and it has to be kept in mind that this does not reflect normal Western diet. Compared with healthy subjects, pancreatic exocrine response to endogenous stimulation is decreased by $65 \%$ to more than $99 \%$ (table 4 ), probably depending on which patients are investigated..$^{12} 97104105109116118120$

To prevent lipid malabsorption, lipase output has to exceed $5-10 \%$ of normal. ${ }^{105}$ Accordingly, in patients with virtually no enzyme secretion, it has been shown that administering sufficient enzymes into the duodenum and thus increasing lipase activities above $5 \%$ of normal is associated with abolition of steatorrhoea. ${ }^{121}$ The threshold activity that has to be exceeded throughout the digestive period is 40$60 \mathrm{IU} / \mathrm{ml}$ of lipase. ${ }^{2}{ }^{122}$ Taking normal ranges of lipase output and intraluminal lipase activity into account (see tables 1 and 2) and provided that postprandially nutrients will enter the duodenum for roughly four hours, a cumulative quantity of $25000-50000 \mathrm{U}$ of exogenous lipase is required intraduodenally for digestion of a regular meal (5\% of 2000-4000 $\mathrm{U} / \mathrm{min}$ required for 240 minutes: $2000 \mathrm{U} / \mathrm{min}^{*} 0.05^{\star} 240$ minutes $=24000 \mathrm{U}, 4000 \mathrm{U} / \mathrm{min}^{*} 0.05^{*} 240$ minutes $=$ $48000 \mathrm{U})$. Obviously, far higher doses of lipase supplements need to be administered orally, probably because of partial acidic destruction of enzymes particularly from non-enteric coated preparations and/or delayed, that is, partial jejunal release from modern, enteric coated preparations. ${ }^{122}$ As shown above, orally administered lipase at a dose of 28000 IU only raised duodenal lipase to $1 \%$ of normal and did not normalise fat digestion. ${ }^{12}$ This suggests that with this specific enzyme preparation about 10 times more (that is, $280000 \mathrm{IU})$ may still be required. However, it remains to be 
clarified whether this holds true for modern enzyme supplements, too.

\subsubsection{Pancreatic response to protein, lipid, and carbohydrate diets}

There are even fewer data on pancreatic exocrine response to individual food components in chronic pancreatitis. DiMagno et al compared pancreatic enzyme response to exogenous stimulation by CCK at a maximal stimulatory dose and to endogenous stimulation by essential amino acids ( $78 \mathrm{mM})$. In healthy volunteers, enzyme response to endogenous stimulation was weaker compared with exogenous stimulation by CCK. By contrast, in chronic pancreatitis, pancreatic exocrine response to both forms of stimulation was very low (about $10-20 \%$ of normal) but equal. ${ }^{105}$ Rogos et al also showed markedly reduced bicarbonate and enzyme secretion (about 50\%) in response to duodenal essential amino acids compared with healthy volunteers. ${ }^{112}$

Literature research revealed only one study investigating the effect of duodenal fat perfusion on enzyme release in chronic pancreatitis: this study suggests that cumulative CCK release in response to duodenal free fatty acids is greater than to undigested triglycerides even in patients with severe pancreatic exocrine insufficiency according to the secretincerulein test. However, enzyme release was increased by duodenal nutrient exposure only in patients with moderate insufficiency. In contrast, the physiological enzyme response to duodenal free fatty acids was abolished in the patients with severe exocrine insufficiency and lowest residual secretory capacity. ${ }^{84}$

Similar to their effects on intraluminal enzyme activities in response to a mixed meal, pectin and wheat bran reduced cumulative ${ }^{14} \mathrm{C}$-exhalation following ingestion of a pure lipid meal ( $100 \mathrm{ml}$ Intralipid) together with $1.5-2 \mu \mathrm{Ci}{ }^{14} \mathrm{C}$-triolein by about $30 \% .{ }^{118}$ Moreover, dietary fibre inhibits pancreatic lipase activity by more than $50 \%$ in vitro. ${ }^{123}$ Thus, the decrease in digestive efficacy induced by intraluminal availability of pectin or wheat bran is probably induced by interactions between dietary fibres and activity of pancreatic enzymes rather than interactions between nutrients and fibres.

There appear to be no studies designed to investigate the effect of pure carbohydrate meals on pancreatic exocrine secretion in chronic pancreatitis, so far. Moreover, there are only indirect data on carbohydrate malabsorption following ingestion of a pure carbohydrate meal: using $\mathrm{H}_{2}$ breath tests and intestinal intubation studies, respectively, Ladas et al ${ }^{124}$ and Layer $e^{2}$ al $^{125}$ reported about $1 \%$ carbohydrate malabsorption in healthy volunteers following ingestion of 50-100 g rice starch. By comparison, about $10 \%$ malabsorption were observed in chronic pancreatitis patients. ${ }^{124}$ Conversely, Hiele et al demonstrated that starch malabsorption occurred only when amylase secretion was $10 \%$ of normal or less. ${ }^{126}$ Data obtained by oro-ileal intubation and direct measurement of carbohydrate content in intestinal juice samples suggest that about $80 \%$ of carbohydrates are absorbed despite nearly complete experimental inhibition of amylase activity in healthy volunteers. ${ }^{125}$ Accordingly, even complete loss of amylase secretion in severe pancreatic exocrine insufficiency may reduce small intestinal carbohydrate digestion and absorption by only about $20 \%$, although it remains unclear whether the degree of carbohydrate malabsorption is load dependent. Anyway, a considerable proportion of malabsorbed carbohydrates will be metabolised by the colonic flora and will not occur in stool. ${ }^{127-129}$ On the one hand, this represents a salvage mechanism by which considerable amounts of energy are gained. On the other hand, microbial metabolism of carbohydrates leading to production of gas and short chain fatty acids may contribute to symptoms such as diarrhoea, flatulence, and abdominal pain. The issue is

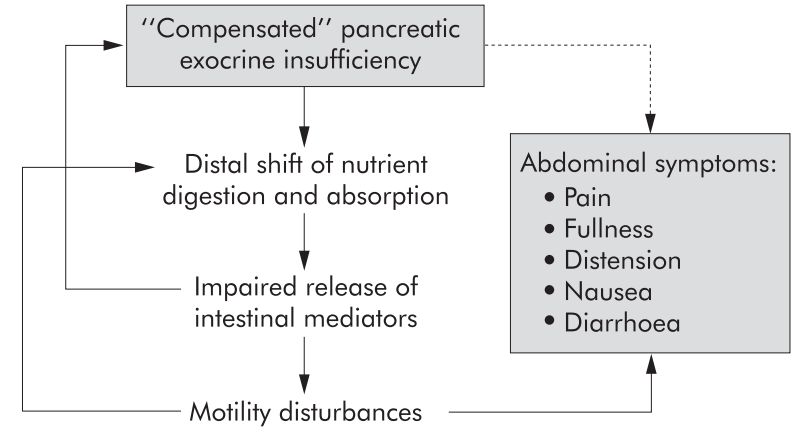

Figure 10 Potential pathophysiological role of "compensated" pancreatic exocrine insufficiency for abdominal symptoms: in patients with mildly to moderately decreased exocrine function a distal shift of nutrient digestion and absorption may lead to impaired release of intestinal mediators. This, in turn may cause motility disturbances inducing abdominal symptoms and it may aggravate exocrine insufficiency. Accordingly, abdominal symptoms would not be a consequence of increased loss of nutrients but of a disturbance of the integrated regulation of gastrointestinal secretory and motor functions.

further complicated by the fact that the rate of starch digestion by pancreatic amylase differs considerably, depending on starch species and/or its processing. ${ }^{76}{ }^{130}$

Therefore, it remains open whether in chronic pancreatitis different nutrients have the same rank order of stimulatory potency as observed in healthy humans (that is, lipids $>$ protein $>$ carbohydrates; see 2.3-2.5). Moreover, the effects of different caloric content and of physical properties of a meal have not been investigated in chronic pancreatitis patients. Potential differences would probably be of minor clinical importance in patients with decompensated or severe pancreatic exocrine insufficiency in whom enzyme substitution is needed under all circumstances to achieve sufficient nutrient digestion and absorption. By contrast, in patients with compensated pancreatic exocrine insufficiency such differences might influence integrated regulation of gastrointestinal secretory and motor functions and thereby determine whether patients develop gastrointestinal symptoms (fig 10). ${ }^{104}$ Although this hypothesis has not been tested in a specific experimental design, it is supported by several studies showing disturbed release of regulatory mediators and of upper gastrointestinal functions in response to experimental nutrient exposure of the distal small intestine ${ }^{6369104131}$ and, most importantly, by studies showing correction or amelioration of gastrointestinal disturbances and/or symptoms by enzyme supplementation in chronic pancreatitis patients without overt steatorrhoea. ${ }^{104} 132133$

\subsubsection{Pancreatic response to exogenous stimulation} Most investigators performed various modifications of the secretin (S) or secretin cerulein (SC) test to examine pancreatic exocrine function in chronic pancreatitis. On the one hand, exogenous stimulation has the advantage of allowing estimation of the residual secretory capacity of the pancreas. On the other hand, alterations of gastrointestinal motor functions and of release of neurohormonal mediators in response to endogenous stimulation are neglected in these studies but are of importance for the pancreatic exocrine response to a regular meal as well as for development of symptoms.

As expected, chronic pancreatitis patients generally showed reduced bicarbonate and enzyme responses to exogenous stimulation (decreased by $40 \%$ to more than 98\% compared with healthy controls; see table 4). ${ }^{104} 105107108110111134$ Unlike healthy controls, they demonstrated a progressive reduction in secretion during 
constant exogenous stimulation with secretin and cerulein for 90 minutes. ${ }^{135}$ Whereas in healthy volunteers enzyme and bicarbonate secretion were higher and more stable during the final 30 minutes compared with previous periods, in chronic pancreatitis patients the outputs for the final 30 minutes were significantly lower than those of the preceding intervals. These findings suggest that enzyme and bicarbonate secretion are exhaustible in chronic pancreatitis. However, the comparability of the available data is hampered by inclusion of patients with varying aetiologies and degrees of pancreatic exocrine insufficiency, different modes of stimulation (secretin, CCK or its analogue cerulein, alone or in combination) for varying periods of time, as well as different doses of stimulatory agents.

DiMagno et al investigated pancreatic exocrine response to CCK in 16 healthy subjects and 16 patients with chronic pancreatitis. Infusion of CCK at a maximal stimulatory dose induced mean lipase and trypsin outputs of about $250 \mathrm{U} / \mathrm{min}$ and $60 \mathrm{U} / \mathrm{min}$, respectively, in chronic pancreatitis patients, which was about $15-20 \%$ of normal. Nutrient malabsorption, that is, steatorrhoea and creatorrhoea, only occurred in patients in whom secretion of the respective digestive enzyme was below $10 \%$ of normal (that is, less than $167 \mathrm{U} / \mathrm{min}$ of lipase and $43 \mathrm{U} / \mathrm{min}$ of trypsin during stimulation with CCK). ${ }^{105}$

Klass et al compared enzyme release in response to exogenous and endogenous stimulation in chronic pancreatitis and showed that peak trypsin output during the SC test correlated best with mean trypsin output during a Lundh test. ${ }^{120}$ Moreover, secretin infusion alone revealed pancreatic exocrine insufficiency in $85 \%$ of nearly 200 patients with definite or probable chronic pancreatitis. ${ }^{136}$ These data are in good agreement with the rate of exocrine insufficiency diagnosed in chronic pancreatitis by the Lundh test. ${ }^{97}$

In general, the degree of impairment of pancreatic exocrine function in chronic pancreatitis patients compared with healthy controls in response to exogenous stimulation was found to be similar to that observed in response to nutrients (table 4). ${ }^{105}$

\subsubsection{Pancreatic exocrine function and morphological evidence of chronic pancreatitis}

In patients with morphological evidence of chronic pancreatitis but with unknown pancreatic exocrine function, Brugge et al observed no increase in duodenal protein output in response to $40 \mathrm{ng} / \mathrm{kg} / \mathrm{h}$ CCK octapeptide. By contrast, in healthy volunteers protein output was almost doubled. ${ }^{108}$ Rogos et al showed a 40-60\% reduction of bicarbonate and enzyme output in response to a modified SC test compared with controls. ${ }^{112}$ Vice versa, Hardt et al observed that pathological faecal elastase- 1 concentrations at a cutoff point of $200 \mu \mathrm{g} / \mathrm{g}$ had a positive predictive value of more than $95 \%$ for pancreatic duct alterations in more than 200 patients undergoing endoscopic retrograde cholangiopancreatography (ERCP), though sensitivity of elastase-1 measurements was low $(45 \%) .{ }^{137}$ In addition, comparison of the results of the secretin test with ERP findings in 192 chronic pancreatitis patients revealed parallel results in about $75 \%$, whereas impairment of exocrine function and morphologic alterations did not occur in parallel in about $25 \%$, predominantly in patients with non-calcifying chronic pancreatitis ${ }^{136}$ Similarly, Lankisch et al observed parallel SC test and ERCP findings in $64 \%$ of 202 chronic pancreatitis patients, abnormal results in both tests but different degrees of severity in $21 \%$, and totally non-parallel results in $15 \% .{ }^{138}$ A normal ERCP but abnormal SC test was observed in seven patients, that is, in about $3 \%$. This means that pancreatic exocrine insufficiency without morphological alterations is rare, yet possible, as also shown by case reports. ${ }^{139}$
A recent study examined dilation of the main pancreatic duct in chronic pancreatitis patients and healthy volunteers in response to intravenous secretin by dynamic ultrasonography. Patients with definite or probable chronic pancreatitis had a lower maximal to basal duct diameter ratio than healthy subjects and this ratio correlated with bicarbonate output. ${ }^{140}$ Thus, the authors suggest that ultrasonographic findings might reflect pancreatic exocrine function and might be used for diagnosis.

\subsubsection{Pancreatic enzyme pattern}

Hoeden et al performed an SC test in 30 control subjects and 34 chronic pancreatitis patients. They observed that amylase output was decreased to $10 \%$ of normal whereas bicarbonate output was less markedly reduced and was still about $40 \%$ of normal. ${ }^{110}$ Harada et al collected pure pancreatic juice in eight control subjects and 12 patients with chronic pancreatitis for 20 minutes after application of secretin and for a further 10 minutes following CCK. Maximal bicarbonate concentration and chymotrypsinogen output were decreased in all chronic pancreatitis patients and appeared to be most susceptible followed by maximal lipase output and peak chymotrypsinogen concentration. Amylase was slightly less affected. ${ }^{141}$ In contrast, Mizuno et al observed that exogenously stimulated chymotrypsin and lipase release were reduced to a similar extent in mild and severe disease, and that both were reduced slightly more than trypsin and amylase in severe disease but that elastase output was the most affected by pancreatic disease including chronic pancreatitis. ${ }^{107}$ Yet, there are further studies suggesting that lipase secretion is most susceptible to chronic pancreatitis and is impaired earlier and more severely compared with secretion of other enzymes. ${ }^{97} 142$ In particular, DiMagno et al showed that in most of 17 patients with chronic alcoholic pancreatitis, lipase output was reduced to a slightly greater extent compared with trypsin output. On the other hand, there were only two patients with lipase output below and trypsin output above $10 \%$ of normal associated with steatorrhoea but not creatorrhoea. ${ }^{142}$ However, regression curves drawn from these data suggest that in chronic alcoholic pancreatitis lipase secretion may reach the critical threshold of $10 \%$ of normal 5-10 years before trypsin output. ${ }^{2}$ Similarly, Ihse et al showed a significantly reduced lipase: trypsin ratio in 42 patients with chronic pancreatitis compared with 133 healthy controls. ${ }^{97}$

Taken together, there are single studies suggesting that amylase, ${ }^{110}$ chymotrypsin, ${ }^{141}$ or elastase ${ }^{107}$ secretion may be impaired earlier and/or more severely in chronic pancreatitis compared with secretion of other components of pancreatic juice whereas two studies show that lipase secretion is particularly susceptible. ${ }^{97}{ }^{141}{ }^{142}$ Still, there is only one study comparing release of all major pancreatic hydrolases - that is, lipase, amylase, trypsin, and chymotrypsin-in chronic pancreatitis. ${ }^{107}$ Furthermore, varying sensitivity and accuracy of enzyme assays hamper comparability. Thus, it has not been fully clarified whether secretion of all pancreatic enzymes is reduced more or less in parallel in chronic pancreatitis or whether secretion of an individual enzyme, especially lipase, is particularly susceptible.

\subsubsection{Pathophysiological mechanisms contributing to steatorrhoea}

From a clinical point of view, steatorrhoea remains the most prominent digestive malfunction in pancreatic exocrine insufficiency: it may be associated with malabsorption of the lipid soluble vitamins A, D, E, and $\mathrm{K}$, it is usually more severe, and develops several years before overt malabsorption of protein or starch. ${ }^{25} 143$ The earlier disturbance of fat absorption is caused by several interacting mechanisms: 
Firstly, the question of whether the capacity of the pancreas to synthesise and secrete lipase is impaired earlier and more severely in the course of chronic pancreatitis compared with other enzymes has been extensively discussed above. Theoretically, in the same patient, a decrease in lipase secretion to less than ( $5 \%$ to) $10 \%$ of normal may cause steatorrhoea for several years earlier, while protease output may be maintained in a range between $10-20 \%$ of normal which is supposed to be sufficient to prevent protein malabsorption. ${ }^{12}{ }^{142}$

Secondly, pancreatic bicarbonate secretion, which serves to protect pancreatic enzymes from denaturation by gastric acid, is also diminished in exocrine pancreatic insufficiency (see 3.2.6). Low intraduodenal $\mathrm{pH}$ dramatically reduces lipase activity (only $50 \%$ activity at $\mathrm{pH} 7$ compared with $\mathrm{pH} 9$ ). In severe exocrine pancreatic insufficiency intraduodenal $\mathrm{pH}$ falls to around 4, particularly late postprandially. ${ }^{12}$ Lipase is very susceptible to acidic destruction ${ }^{12}$ and, therefore, the small residual quantities of lipase secreted into the duodenum may be inactivated. ${ }^{1}$ In addition, bile acids are precipitated by low intraduodenal $\mathrm{pH}$ levels and lipid absorption is compromised further. ${ }^{144}$

Thirdly, lipase degradation within the small intestinal lumen occurs more rapidly than destruction of other enzymes $^{39}$ due to its greater instability against proteolysis. ${ }^{94}{ }^{95}$ This means that, compared with other enzymes, lipase activity is available for a shorter period of time during small intestinal transit in healthy individuals ${ }^{39} 9395$ as well as in patients with exocrine pancreatic insufficiency. ${ }^{122}$

Fourthly, extrapancreatic lipolytic enzymes, which have been shown to be entirely of gastric origin, ${ }^{145}$ contribute only little to overall lipid digestion in humans..$^{40} 55$ 145-148 There is evidence that in pancreatic exocrine insufficiency the relative importance of gastric lipase for lipid digestion is increasedthat is, gastric lipase may digest more than $50 \%$ instead of roughly $20 \%$ of dietary fat. ${ }^{55}$ However, most studies available suggest that secretion of gastric lipase cannot be upregulated to compensate for the loss of pancreatic lipase. ${ }^{145} 149$ By contrast, a recent study by Carriere et al showed a three to fourfold increase in gastric lipase output. Astonishingly, intragastric lipolysis levels did not increase accordingly, but even tended to be lower than in healthy volunteers (4.8\% (SD $1.2 \%) v 7.3 \%$ (5.9\%) of meal triglycerides converted into free fatty acids and monoglycerols). This seemingly paradoxical effect was potentially due to lower intragastric $\mathrm{pH}$ or accelerated gastric emptying and reduced time for digestion. ${ }^{104} 120150$ Furthermore, there are contradictory data whether in chronic pancreatitis gastric lipase secretion is increased adequately in response to physiological stimuli (that is, gastrin or cephalic stimulation). ${ }^{151-153}$ Within the intestinal brush border, there are no triglyceride digesting enzyme systems. Consequently, adequate lipid digestion within the small intestinal lumen depends on the interaction of pancreatic lipase and its cofactors-that is, colipase and bile acids. A decrease in pancreatic lipolytic activity cannot be compensated sufficiently by other mechanisms. By contrast, protein digestion is maintained even if virtually all luminal pancreatic proteolytic activity is blocked under experimental conditions because protein digestion is initiated by intragastric proteolytic activity and continued by the intestinal brush border peptidases. It has to be remembered, however, that small intestinal protein malabsorption in chronic pancreatitis may be considerably underestimated because maldigestion and malabsorption are measured in the faeces and there is rapid hindgut fermentation of any unabsorbed protein. Similarly, in the absence of pancreatic amylase activity, starch digestion is delayed, but can be achieved to about $80 \%$ by salivary amylase and by brush border oligosaccharidases. $^{143}$ Furthermore, a considerable proportion of malabsorbed carbohydrates is metabolised by the colonic flora and does not occur in stool. ${ }^{127-129}$

Lastly, there is evidence that biliary secretion may be particularly susceptible to and impaired by inhibitory influences of ileal nutrient exposure as expected in pancreatic exocrine insufficiency. ${ }^{131}$ Decreased release of bile acids may further compromise lipid digestion and absorption.

\subsubsection{Bicarbonate output and duodenal $\mathrm{pH}$}

In chronic pancreatitis, the chronic inflammatory process does not only destroy pancreatic acini but also the ductal tissue and thereby impairs bicarbonate secretion. Decreased bicarbonate secretion eventually results in decreased duodenal $\mathrm{pH}$. This is of importance not only because neutral to basic intraluminal $\mathrm{pH}$ is a prerequisite for optimal activity of digestive enzymes, ${ }^{154}$ but also because pancreatic enzymes, in particular lipase, can be inactivated irreversibly by acidic $\mathrm{pH}$ (that is, $\mathrm{pH}<4$ ). ${ }^{12}$ This further compromises lipid digestion and is true for both residual endogenous enzyme secretion and therapeutic enzyme supplementation. Most investigators concentrated on measuring outputs of digestive enzymes in chronic pancreatitis but bicarbonate output may also be used as a marker of pancreatic exocrine dysfunction. ${ }^{141}$ However, those studies which compared enzyme and bicarbonate output in chronic pancreatitis suggest that bicarbonate secretion may be preserved longer than enzyme secretion and, thus, may be less sensitive. ${ }^{109-111}$

DiMagno et al showed that in chronic pancreatitis postprandial duodenal $\mathrm{pH}$ was lower than in healthy subjects and reached the threshold for lipase inactivation (that is, $\mathrm{pH} 4$ ) late postprandially. By contrast, interdigestive and early postprandial duodenal $\mathrm{pH}$ were within the physiological range. ${ }^{12}$ Accelerated gastric emptying may contribute to low intraduodenal $\mathrm{pH}$ in chronic pancreatitis. ${ }^{104}{ }^{120}$ Its relative contribution has not been estimated, so far, but the observations that late gastric emptying was accelerated in particular ${ }^{104}$ and that duodenal $\mathrm{pH}$ was particularly low in chronic pancreatitis patients late postprandially ${ }^{12}$ underline the potential importance of disturbed gastric emptying in chronic pancreatitis. On the other hand, direct measurements showed no statistically significant difference between duodenal acid delivery in chronic pancreatitis patients with varying degrees of pancreatic exocrine insufficiency compared with five healthy controls despite accelerated gastric emptying in patients. ${ }^{120}$

Gastric acidity also appears to be associated with pancreatic exocrine function: Bovo et al observed an earlier drop in intragastric $\mathrm{pH}$ postprandially in patients with decompensated compared with compensated pancreatic exocrine insufficiency. ${ }^{155}$ Moreover, there was a positive correlation between median postprandial $\mathrm{pH}$ and lipase output. If gastric contents were not aspirated completely, this may not only be explained by the association between the degree of pancreatic exocrine insufficiency and the drop of intragastric $\mathrm{pH}$ but also by acidic destruction of lipase intraduodenally. Following a low caloric, low fat meal $(300 \mathrm{ml}$ chocolate milk, $5 \%$ protein, $5 \%$ carbohydrates, $1.5 \%$ fat, $660 \mathrm{~kJ}$ ), a poor correlation between continuously measured (in vivo) jejunal $\mathrm{pH}$ values and $\mathrm{pH}$ in jejunal aspirates (in vitro) was observed in chronic pancreatitis patients and healthy controls. ${ }^{144}$ However, from the experimental protocol it does not become clear whether $\mathrm{pH}$ of aspirates was measured adequately. Only for in vivo measurements, a longer period with $\mathrm{pH}$ below 4 was demonstrated in decompensated pancreatic exocrine insufficiency. Moreover, it was shown in this study that the fraction of bile acids in the micellar phase of duodenal contents correlated with duodenal $\mathrm{pH}$ and the fraction of fat solubilised. Accordingly, acidic bile acid precipitation 
probably plays a major role for steatorrhoea in chronic pancreatitis. $^{144} 156$

\subsubsection{Summary}

Taken together, in an unselected group of patients with chronic pancreatitis $80 \%$ to $90 \%$ show some degree of pancreatic exocrine insufficiency and mean pancreatic exocrine function is reduced by about $50 \%$ to $80 \%$ compared with healthy volunteers. In about $65 \%$ to $75 \%$ of patients, morphological alterations and functional impairment occur in parallel. Pancreatic exocrine insufficiency without morphological alterations is rare (less than $5 \%$ ), yet possible.

There is evidence that the pancreatic enzyme pattern is altered in chronic pancreatitis, but it is controversial which component of pancreatic juice is most susceptible. Two studies suggest an earlier and stronger impairment of lipase secretion compared with secretion of other enzymes. The observation that lipid malabsorption is the most important digestive dysfunction in chronic pancreatitis is further explained by impaired bicarbonate output, which causes more rapid and complete inactivation of lipase and bile acid precipitation within the acidic duodenum, by greater susceptibility of lipase against proteolytic destruction, by low effectiveness of compensating enzyme systems, and by potent inhibition of biliary output in response to malabsorbed nutrients. Moreover, faecal nutrient excretion is considerably influenced by fermentation of carbohydrates and protein by colonic bacteria.

Apart from an overall reduction in enzyme release, the physiological biphasic postprandial pattern and differential responsiveness to varying degrees of endogenous and exogenous stimulation appear to be lost in chronic pancreatitis. In decompensated chronic pancreatitis with less than $5 \%$ of normal enzyme output, about $40 \%$ of nutrients of an easily digestible low caloric meal are malabsorbed and enter the colon. Proximal small intestinal enzyme activities can be increased and maldigestion can be decreased by enzyme supplementation. However, even with clinically established doses of pancreatin ( $28 \mathrm{kU}$ of lipase) duodenal lipase delivery remains far below the physiological range and lipid malabsorption cannot be normalised

\subsection{Acute pancreatitis}

Data from animal studies have shown that the exocrine function of the pancreas during acute pancreatitis is decreased. ${ }^{157-162}$ For methodological and ethical reasons, only the interdigestive, non-stimulated exocrine function could be determined in humans during the acute phase of the disease. Interdigestive pancreatic exocrine secretion was shown to be variable (normal in most cases, decreased or increased in individuals) in the early phase of mild to moderate acute pancreatitis ${ }^{163} 164$ and was adequately reduced by glucagon and cimetidine. ${ }^{164}$

It is controversial whether (recurrent) acute pancreatitis has long term effects on pancreatic exocrine function. During the subacute phase and during reconvalescence, reduced pancreatic exocrine function was shown in all patients investigated even by less sensitive indirect pancreatic function tests (PABA test). ${ }^{165} 166$ By contrast, patients who had recovered from an attack of acute pancreatitis two to six years before showed normal results in this test. ${ }^{165}$ More sensitive measurements of stimulated enzyme synthesis and turnover in 10 patients with acute pancreatitis two to 29 months after the most recent attack showed non-parallel changes with decreased total protein and amylase but preserved trypsin synthesis and turnover. The authors suggest that there may be continuing acinar cell malfunction and specifically impaired amylase synthesis following acute pancreatitis. ${ }^{167}$ Similarly, Bozkurt et al observed mostly mild to moderate pancreatic exocrine insufficiency in $80-85 \%$ of 53 patients who had recovered from their first attack of necrotising acute pancreatitis. Functional impairment persisted for at least 18 months, though severe forms appeared to be less frequent in the long term group (6\%) compared with a group of patients investigated after four weeks $(26 \%) .{ }^{168}$ Boreham and Ammori found a similar rate of pancreatic exocrine insufficiency-that is, $86 \%$ in patients recovering from necrotising acute pancreatitis. In general, development of exocrine insufficiency correlated strongly with the extent of pancreatic necrosis and the severity of pancreatic endocrine insufficiency (fig 11). During the four week observation period, there was no recovery of exocrine function in patients with necrotising disease. ${ }^{169}$ Further investigations by Seidensticker et al, including patients with less severe forms of acute pancreatitis up to 156 months after the acute attack, showed normal pancreatic exocrine function and a normal ERCP in $50 \%$ of patients. Functional impairment with $(n=4)$ or without $(\mathrm{n}=1)$ morphological alterations was observed in $13 \%$ of patients. Interestingly, all of these patients later developed chronic pancreatitis. ${ }^{170}$

\subsubsection{Summary}

In summary, little is known about the secretory capacity of the pancreas during the acute phase of acute pancreatitis and ethical reasons will probably prevent such investigations. During the subacute phase (the first few weeks following an acute attack), pancreatic exocrine function appears to be regularly impaired and a considerable percentage of patients with necrotising disease may show severe exocrine insufficiency. Depending on the severity of acute pancreatitis and the degree of pancreatic necrosis, pancreatic exocrine function recovers step by step, but in a subset of patients exocrine insufficiency may last for several months or may even persist permanently.

\subsection{Pancreatic cancer}

Obstruction of the pancreatic duct by tumours of the head of the pancreas, ongoing destruction of the normal pancreas by tumour growth, and loss of pancreatic tissue following surgical procedures frequently cause pancreatic exocrine insufficiency in pancreatic carcinoma. Studies in patients with pancreatic carcinoma describing the quantitative relations between the length of opacified main pancreatic duct obtained at ERCP and the secretory capacity of the exocrine pancreas revealed that secretion did not decrease until more than $60 \%$ of the total length was obstructed. As the site of pancreatic cancer further approached the duodenum, enzyme secretion decreased in an exponential fashion (fig 12). ${ }^{171}$ Ihse
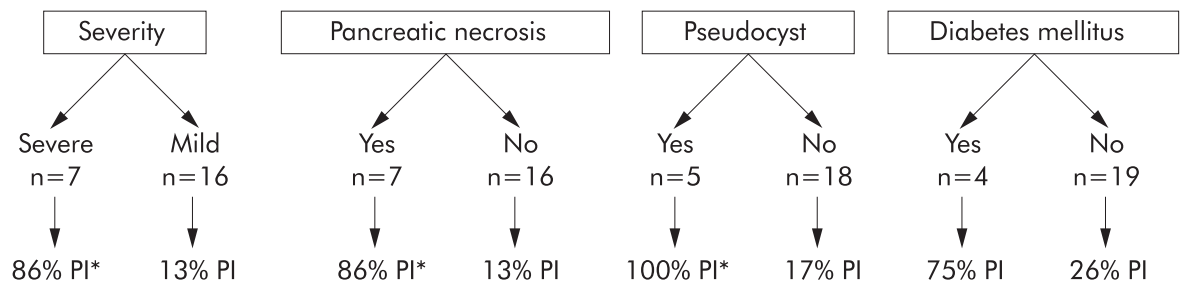

Figure 11 Incidence of pancreatic exocrine insufficiency (PI) in 23 patients recovering from acute pancreatitis depending on severity of disease and presence of complications. ${ }^{169}$ ${ }^{*} \mathrm{p}=0.002$ mild $v$ severe or absence $v$ presence of symptoms. 


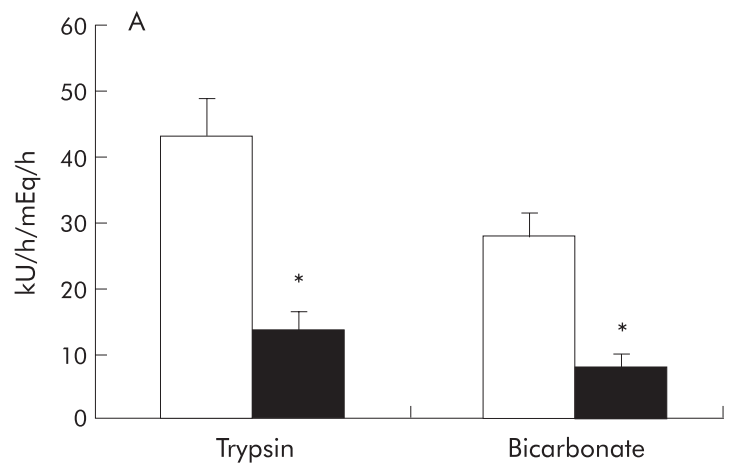

et al performed a Lundh test in 474 unselected patients including 25 with pancreatic carcinoma. Of these, depending on the enzyme analysed, 80-90\% showed exocrine insufficiency. Furthermore, a significant decrease in lipase:trypsin and lipase:phospholipase ratios and loss of the typical biphasic secretory pattern were observed..$^{97}$ These findings suggest that similar to chronic pancreatitis, pancreatic cancer not only decreases pancreatic exocrine secretion but may also alter enzyme pattern. The rate of exocrine insufficiency observed in this study matches well with data obtained by Perez et al showing malabsorption in $85 \%$ of patients with pancreatic cancer. ${ }^{172}$ In 14 preoperative patients with pancreatic tumours, and 13 patients who had undergone pancreatduodenectomy more than five years ago, an indirect pancreatic function test-the ${ }^{13} \mathrm{C}$-trioctanoin breath testrevealed impaired lipid digestion and absorption in all cases. Not surprisingly, direct measurement of pancreatic exocrine secretion by the secretin test showed pathological results in 13 out of 14 patients preoperatively and in four out of five postoperatively. ${ }^{173}$

\subsubsection{Summary}

Overall, there is a limited number of studies revealing exact information about pancreatic exocrine function in patients with pancreatic cancer. This is probably due to the poor prognosis of these patients which limits reasonable investigations. Available evidence suggests exocrine dysfunction and malabsorption in $80-90 \%$ of patients potentially associated with loss of the normal secretory pattern. The site and degree of ductal obstruction appear to be major determinants of residual pancreatic exocrine secretion.

\subsection{Cystic fibrosis}

In cystic fibrosis, an autosomal recessive defect of the gene that encodes for the cystic fibrosis transmembrane regulator (CFTR), a cyclic AMP regulated chloride channel impairs water secretion of exocrine glands including the pancreas. ${ }^{174}$ Highly concentrated and viscous pancreatic juice blocks the pancreatic ducts leading to acinar atrophy, fibrosis, fatty replacement, and inspissation of secretions in ducts and acini. ${ }^{175}$ More recent data suggest that acidification of luminal contents of pancreatic tissue, due to disturbed bicarbonate release, may be an important mechanism leading to defects in apical trafficking of zymogen granules and of solubilisation of enzymes with subsequent cytological alterations. ${ }^{176}$ Even if compared with controls matched for pancreatic exocrine function as defined by trypsin secretion, cystic fibrosis patients secrete significantly less fluid (mean water secretion $3.35 \mathrm{ml} / \mathrm{kg} / \mathrm{h} v 9.74 \mathrm{ml} / \mathrm{kg} / \mathrm{h}$ in controls) and their pancreatic secretions are hyperconcentrated. ${ }^{177}$ Moreover, a significant linear correlation was observed between protein output and volume secretion in cystic fibrosis patients only,

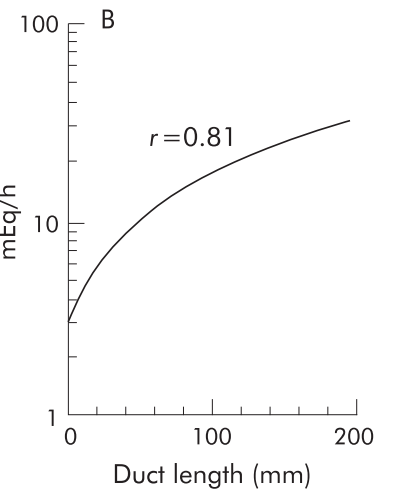

Figure 12 (A) Trypsin and bicarbonate response to CCK are significantly decreased in patients with pancreatic cancer ( $n=17$, black bars) compared with controls $(n=17$, open bars). (B) Bicarbonate output in response to CCK is significantly correlated with (remaining) length of pancreatic duct for combined pancreatic cancer and control groups $\left({ }^{*} p<0.05\right) .{ }^{171}$

suggesting that fluid secretion may be a rate limiting factor in protein output. ${ }^{177}$ Pancreatic exocrine insufficiency of varying degrees was observed in $55-100 \%{ }^{176-181}$ of patients. Weizman et al demonstrated reduced enzyme output in all of 18 cystic fibrosis patients compared with mean output of healthy subjects. However, only in seven out of 18 -that is, $39 \%-$ was it severe enough to cause steatorrhoea. ${ }^{180}$ Similarly, Walkowiak et al reported some degree of pancreatic exocrine insufficiency in all of 28 cystic fibrosis patients investigated by the secretin cholecystokinin test; in 20 of these (about $70 \%)$ it was severe and, thus, presumably associated with malabsorption. ${ }^{181}$ Most recent studies agree that (severe) pancreatic exocrine insufficiency occurs in more than $80 \%$ of cystic fibrosis patients. ${ }^{176} 182183$ Differing results might be explained by the varying age of the subjects investigated because some studies report increase in frequency and degree of pancreatic involvement over time, particularly during the first months and years of life. ${ }^{184}$ Others, however, already found pancreatic involvement in 85-95\% of one year old children in various populations. ${ }^{182}$ Moreover, the probability of pancreatic insufficiency depends on the underlying gene defect (particularly high in patients with $\Delta$ F508 mutation). ${ }^{185}{ }^{186}$ In general, patients who carry two "severe" gene mutations develop pancreatic insufficiency, whereas those who carry at least one "mild" mutation usually remain pancreatic sufficient (fig 13). These represent about $10 \%$ of patients. ${ }^{183}$ However, the latter does not exclude pancreatic insufficiency. ${ }^{187}$

Pancreatic enzymes involved in lipid digestion such as lipase, colipase, and phospholipase were decreased in parallel in children with cystic fibrosis. ${ }^{188}$ Impaired pancreatic lipase secretion might in part be compensated by a moderate increase in gastric lipase activity and intragastric lipolysis. ${ }^{189}$

Duodenal pancreatic enzyme output in response to a meal or meal components has rarely been studied in cystic fibrosis, probably because of the invasive character of these investigations and the young age of most patients. Augarten et al examined serum lipase levels before and after pancreatic stimulation by a Lundh meal in 36 cystic fibrosis patients with severe pancreatic exocrine insufficiency, eight patients with mild disease and normal exocrine function, and 17 healthy individuals. The authors claim that consistently low lipase levels suggested a severely affected insufficient pancreas; normal basal levels followed by a linear rise peaking 30 minutes after the meal reflected normal exocrine function. Increased lipase levels not influenced by the meal were found in five out of eight patients with mild disease and were interpreted as an ongoing destructive process in the pancreas which will eventually result in conversion from pancreatic sufficiency to pancreatic insufficiency. ${ }^{190}$ However, these conclusions appear premature and findings have so far not been confirmed. 


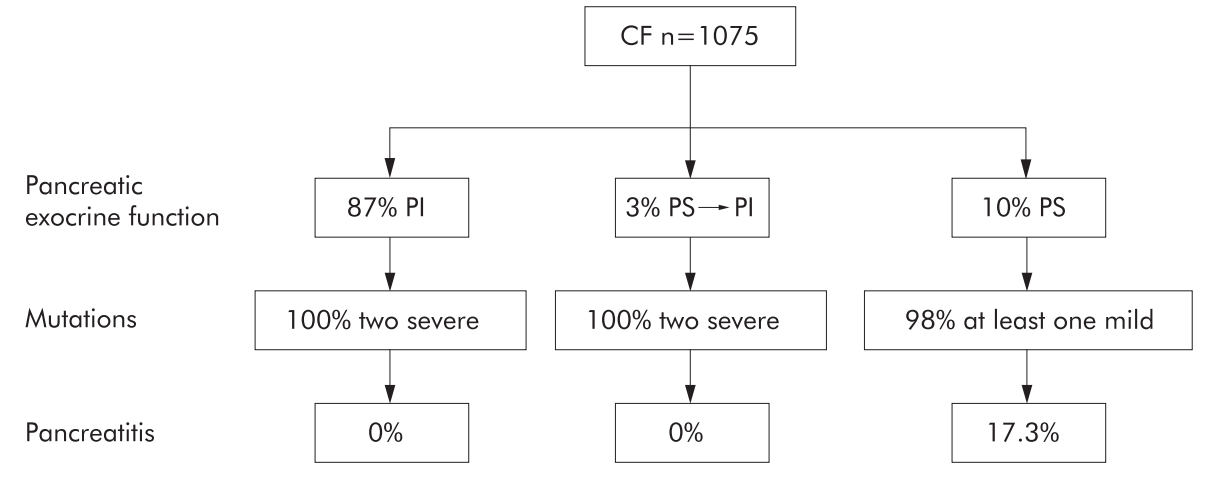

Figure 13 About $10 \%$ of patients with cystic fibrosis remain pancreatic sufficient (PS), 3\% develop pancreatic insufficiency during the course of the disease (PS $\rightarrow \mathrm{PI}$ ) and $87 \%$ show pancreatic exocrine insufficiency at diagnosis (PI). All patients with PI or PS $\rightarrow \mathrm{Pl}$ in whom complete genotype analysis could be performed showed severe CFTR gene mutations on both alleles. By contrast, almost all patients with PS had at least one mild mutation. Only patients with PS appear to be at risk of developing (recurrent) acute pancreatitis. ${ }^{183}$
Similarly, the number of studies on nutrient digestion and absorption is limited. In an early study, average fat absorption was found to be $46 \%$ of the amount ingested in 12 children without pancreatic enzyme supplementation, $67 \%$ in response to $5 \mathrm{~g}$ pancreatin four times daily and $71 \%$ in response to $15 \mathrm{~g}$ pancreatin. ${ }^{191}$ With modern therapeutic strategies using more recently developed pancreatin preparations nutrient absorption can be increased, ${ }^{192}{ }^{193}$ although seldom normalised. ${ }^{194}$

One reason for this presumably is that even modern pancreatic enzyme supplements do not fully imitate physiological intraluminal enzyme activities. ${ }^{122}$ On the other hand, further disturbances of gastrointestinal secretory and motor functions apart from pancreatic insufficiency-that is, alterations of gastrointestinal $\mathrm{pH}$, motility, and transit-are observed in cystic fibrosis and may additionally compromise assimilation of nutrients. ${ }^{150}$

Basal and stimulated gastric acid secretion were reported to be greater in cystic fibrosis than in healthy controls, but this was contradicted by others and did not affect interdigestive or postprandial gastric $\mathrm{pH} .{ }^{150}$ Fasting and postprandial duodenal $\mathrm{pH}$ were $1-2 \mathrm{pH}$ units lower in cystic fibrosis patients (range 3-6 postprandially) than in control subjects (range 5-7 postprandially), probably mainly due to reduced pancreatic bicarbonate secretion. ${ }^{150}$ Whether impaired duodenal bicarbonate release contributes to low intraluminal $\mathrm{pH}$ is not clarified, yet. $\mathrm{PH}$ of luminal contents in the more distal small intestine of cystic fibrosis patientsthat is, in the jejunum and ileum-was seldomly measured and was reported to be slightly lower or similar to that in healthy subjects. ${ }^{150}$ Increasing intraluminal $\mathrm{pH}$ by treatment with omeprazole improves fat absorption in enzyme treated patients. ${ }^{193} 195196$ This may not only be due to better survival of exogenous enzyme preparations but also to improved conditions for lipolysis by endogenous gastric lipase. ${ }^{197}{ }^{198}$ In cystic fibrosis patients with severe pancreatic exocrine insufficiency gastric lipase accounted for about $90 \%$ of total lipolytic activity at the ligament of Treitz ${ }^{199}$ as opposed to 7\% in healthy volunteers. ${ }^{200}$

Available data suggest that gastric emptying of liquid meals is normal or accelerated in cystic fibrosis. ${ }^{150}$ Gastric emptying of solids, which is more susceptible to impairment, was not adequately investigated in these patients, so far. Taylor et al report a discrepancy between the gastric emptying of microspheres (supposed to simulate modern enzyme preparation) and a standard pancake and baked beans test meal. The half time of gastric emptying of 103 minutes appears to be within the normal range; unfortunately, however, no normal values were given by these investigators. ${ }^{201}$ Symonds et al found similar gastric emptying of solids in children with cystic fibrosis and healthy controls using the 13C-octanoic acid breath test. Remarkably, those patients with slow gastric emptying had less improvement of fat digestion and absorption than patients with a high gastric emptying velocity. ${ }^{202}$

Small intestinal motility has never been measured directly in a group of cystic fibrosis patients; instead, several investigators studied orocecal transit using the lactulose $\mathrm{H}_{2}$ breath test and observed prolonged orocecal transit times compared with healthy controls. ${ }^{203-205}$ This is at variance with what we observed in chronic pancreatitis patients ${ }^{104}$ and may be due to cystic fibrosis specific small intestinal motility disturbances. However, altered colonic flora caused by chronic use of antibiotics to combat respiratory infections likely decreases reliability of the lactulose $\mathrm{H}_{2}$ breath test and questions these findings. Increased plasma levels of motilin, enteroglucagon, neurotensin, and PYY in cystic fibrosis ${ }^{150} 206$ may at least in part account for gastrointestinal motor dysfunction and may also impair gastrointestinal secretory functions. Overall, disturbances of gastrointestinal motility and of release of regulatory mediators may aggravate maldigestion and malabsorption in cystic fibrosis.

\subsubsection{Summary}

In conclusion, a well characterised hereditary defect of electrolyte and water secretion induces major morphological alterations of the pancreas in the majority of patients with cystic fibrosis leading to functional impairment. According to recent studies severe pancreatic exocrine insufficiency is observed in more than $80 \%$ of patients. Nutrient digestion and absorption is markedly increased by enzyme supplementation with or without suppression of gastric acid secretion; however, it is rarely normalised. This may in part be due to the fact that in cystic fibrosis further disturbances of gastrointestinal secretory and motor functions-that is, alterations of gastrointestinal $\mathrm{pH}$, motility, and transitadditionally compromise assimilation of nutrients.

\subsection{Gastrointestinal surgery}

\subsubsection{Pancreatic resections}

Major pancreatic resection naturally decreases pancreatic secretory capacity and it depends on the original disease process and on the type and extent of resection whether patients develop maldigestion and malabsorption. Following middle segment pancreatectomy, a novel technique reported recently for conserving pancreatic tissue, none of 10 patients operated on because of benign pancreatic tumours of the neck or body of the pancreas required pancreatic enzyme supplements postoperatively. ${ }^{207}$ Drainage procedures, ${ }^{208-210}$ segmental resection, ${ }^{211}$ and duodenum preserving pancreatic head resection (DPPHR $)^{212-216}$ did not decrease pancreatic exocrine function compared with preoperative values. Even in patients followed up for up to 26 years after DPPHR, the rate of patients requiring enzyme supplementation postoperatively remained more or less stable. ${ }^{217}$ Drainage procedures with or without (minor) resections were even found to 
be associated with improvement of exocrine function in a subset of patients. ${ }^{209} 210$ By contrast, following conventional pancreatoduodenectomy or pylorus preserving pancreatoduodenectomy (PPPD) patients showed about a $20 \%$ decrease in the PABA test or decreased faecal chymotrypsin. ${ }^{212} 213$ In the latter patient group, insufficient weight gain despite intake of regular amounts of pancreatin was shown to be associated with decreased pancreatic exocrine function postoperatively. ${ }^{218}$

Children with previously normal exocrine function operated on because of nesidioblastosis generally showed normal pancreatic enzyme activities and bicarbonate concentrations following a $75 \%$ pancreatectomy. Even a $95 \%$ pancreatectomy was tolerated without clinically significant exocrine failure in six out of seven patients. ${ }^{219}$ These findings underline the enormous functional reserve capacity of the healthy exocrine pancreas.

On the other hand, short term effects of pancreatic head resection appear to depend on the preoperative findings: residual pancreatic exocrine function after operation was associated with the preoperative degree of pancreatic fibrosis $^{220}$ and pancreatic exocrine function deteriorated early postoperatively ${ }^{221}$ only in a group of patients with markedly dilated pancreatic duct but not in those with normal duct diameter. Within 12-31 months, pancreatic exocrine function recovered to preoperative levels in both groups. ${ }^{221}$ Progression of the underlying disease accounted for failure of both exocrine and endocrine functions on long term follow up following partial pancreatic resections. ${ }^{208}$

Moreover, in patients with preexisting chronic pancreatitis, the percentage of patients with steatorrhoea was increased from $3.7 \%$ to $19 \%$ by $40-80 \%$ distal resection, from $9.0 \%$ to $37.6 \%$ by $80-95 \%$ distal resection and from 5.2 to $55 \%$ by Whipple's operation. ${ }^{222}$ The average faecal loss of fat following a $80-95 \%$ distal resection in patients ingesting $100 \mathrm{~g}$ fat per day was $26.4 \mathrm{~g} / \mathrm{d}$ (normal: less than $5-7 \mathrm{~g} / \mathrm{d}$ ), that is, the coefficient of fat absorption in these patients was reduced to $73.6 \%{ }^{222}$ compared with greater than $93-95 \%$ in healthy humans. ${ }^{2}$

Residual lipid digestion in spite of almost complete loss of pancreatic exocrine tissue is probably due to gastric lipase (see 2.6.2).

It has to be kept in mind, however, that most of the favourable data on the effects of partial pancreatic resection on pancreatic exocrine function cited above have been obtained by rather crude methods which only allow reliable diagnosis of severe pancreatic exocrine insufficiency. ${ }^{223}$ Data from animal experiments using direct measurements of pancreatic protein, enzyme, and bicarbonate output in pancreatic juice showed decreased secretion in response to endogenous and exogenous stimulation in partially pancreatectomised dogs and in rats following extensive resections. ${ }^{224-226}$ Human studies describing the quantitative relations between the length of opacified pancreatic duct obtained at ERCP and the secretory capacity of the exocrine pancreas revealed that $40 \%$ of the gland (pancreatic head) can secrete enzymes and bicarbonate at normal rates. ${ }^{171}$

\subsubsection{Gastric resections}

Not only surgical procedures of the pancreas but also partial or total gastrectomy may be associated with intraluminal lack of pancreatic enzymes postprandially, ${ }^{97} 98100101$ mainly because of asynchrony between gastric emptying of the meal and discharge of bile and pancreatic enzymes into the small intestine (postcibal asynchrony). As digestive products are stronger endogenous stimulators of CCK release and of pancreatic secretion than macronutrients, ${ }^{85}$ postcibal asynchrony is also associated with decreased endogenous stimulation (fig 8).

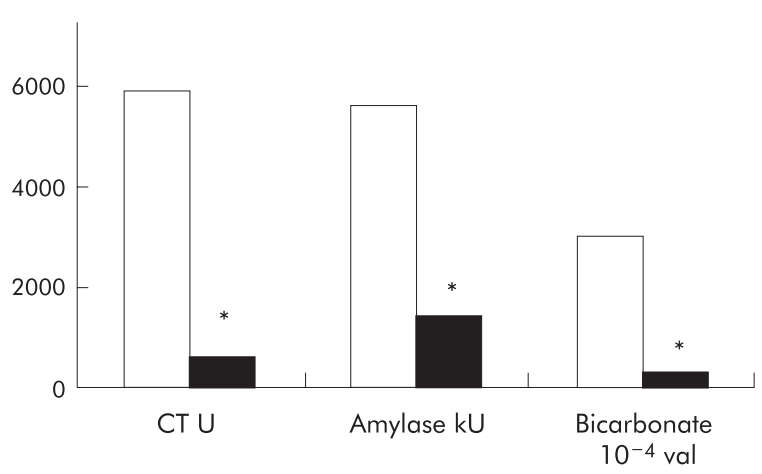

Figure 14 Median enzyme and bicarbonate output in patients before (open bars) and three months after (black bars) total gastrectomy due to gastric cancer. Preoperatively, all patients had normal pancreatic exocrine function. Median output of all parameters in response to direct stimulation by secretin and cerulein was markedly and significantly decreased postoperatively $\left({ }^{*} p<0.01\right) . .^{98}$

There is evidence however, that further mechanisms may contribute to pancreatic insufficiency following gastric surgery. Friess et al investigated 15 patients undergoing total gastrectomy due to gastric cancer. ${ }^{98}$ A secretin cerulein test was performed preoperatively and endocrine responses to a test meal were measured. In nine patients, both tests were repeated postoperatively. All patients had normal pancreatic function preoperatively. Postoperatively, all patients were assessed as having severe pancreatic exocrine insufficiency and secretion of pancreatic juice, trypsin, chymotrypsin, and amylase was reduced by $70-90 \%$ (fig 14). These findings cannot be explained by postcibal asynchrony but suggest "direct" pancreatic influences. Furthermore, pancreatic insufficiency was more severe than described in previous studies. ${ }^{100} 101$ The authors attribute severe impairment of pancreatic exocrine function to the extensive denervation of the pancreas because of lymph node dissection and truncal vagotomy. The latter has been shown to cause mild to moderate pancreatic exocrine insufficiency (reduction of secretin stimulated trypsin and lipase outputs by $50-60 \%$ ) by itself. 227228

Heptner et al observed primary pancreatic exocrine insufficiency following gastric resection for various reasons in only $30 \%$ of patients. By contrast, the Pankreolauryl test (Tremmler Pharma GmbH \& CO KG, Marburg, Germany), an indirect pancreatic function test which allows estimation of intraluminal digestion of a test meal, was abnormal in $90 \%$ of these patients postoperatively, probably as a result of interacting pathomechanisms ("primary" insufficiency, postcibal asynchrony, decreased endogenous stimulation, fig 8). ${ }^{100}$

\subsubsection{Short bowel syndrome}

Following extensive small bowel resections, reduced endogenous stimulation and postcibal asynchrony may lead to intraluminal pancreatic enzyme deficiency and may thereby reduce nutrient absorption. Therefore, administration of pancreatin preparations is encouraged by several authors ${ }^{229}$ although there are no controlled studies demonstrating a positive effect of enzyme supplementation therapy. Theoretically, application of unprotected pancreatic enzymes together with gastric acid suppression therapy should enable gastric digestion of nutrients with increased delivery of digestive products to the small bowel. Because of the superior stimulatory capacity of peptides, amino acids, and free fatty acids compared with macronutrients, conditions for nutrient absorption should be improved by increased endogenous pancreatic enzyme secretion, delayed gastric emptying, and small intestinal transit as well as mucosal hypertrophy (fig 15). 


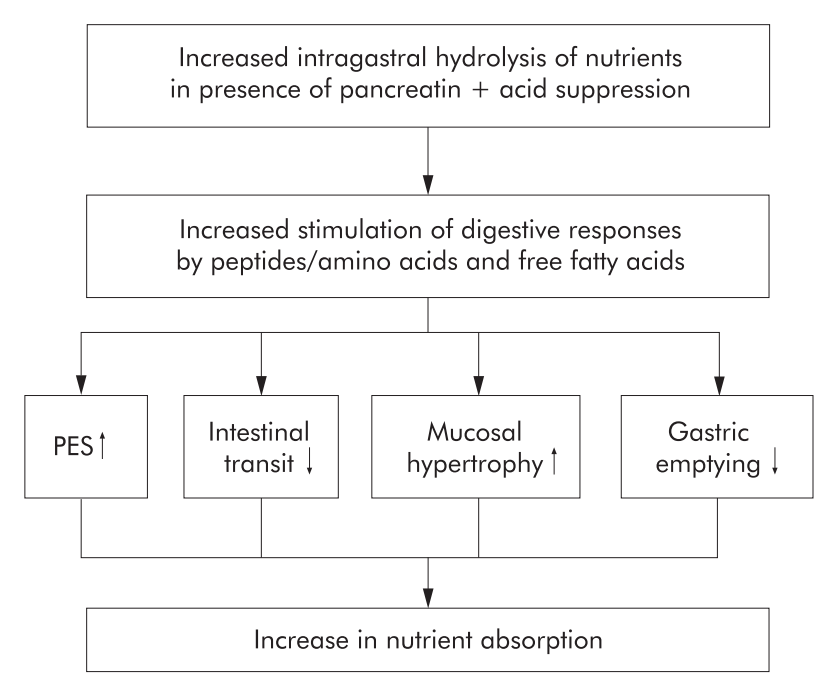

Figure 15 Theoretical effect of pancreatic enzyme supplementation in short bowel syndrome (PES, pancreatic enzyme secretion). Application of unprotected pancreatic enzymes together with gastric acid suppression therapy should enable gastric digestion of nutrients with increased delivery of digestive products to the small bowel. Because of the superior stimulatory capacity of peptides, amino acids, and free fatty acids compared with macronutrients, conditions for nutrient absorption should be improved by increased endogenous pancreatic enzyme secretion, delayed gastric emptying, and small intestinal transit as well as mucosal hypertrophy.

\subsubsection{Summary}

Major pancreatic resections naturally decrease pancreatic secretory capacity and it depends on the original disease process and on the type and extent of resection whether patients develop maldigestion and malabsorption. Human studies suggest that $40 \%$ of the gland proximal to an obstruction can secrete enzymes and bicarbonate at normal rates. In patients with previously normal pancreatic function, even a 90-95\% resection of the pancreas is generally tolerated without clinical signs of severe pancreatic exocrine insufficiency - that is, without overt malabsorption. By contrast, in patients with preexisting chronic pancreatitis, the percentage of patients with steatorrhoea is markedly increased by less extensive distal resections. In general, drainage procedures, segmental resections and DPPHR are less likely to reduce pancreatic exocrine function compared with conventional pancreatoduodenectomy and PPPD.

Not only pancreatic resections but also partial or total gastrectomy and short bowel syndrome may be associated with intraluminal lack of pancreatic enzymes postprandially, mainly because of asynchrony between intestinal delivery of the meal and discharge of digestive secretions including pancreatic enzymes into the duodenum (postcibal asynchrony). In patients operated on because of malignant disease, extensive denervation of the pancreas including vagotomy contributes to pancreatic dysfunction.

\subsection{Coeliac disease}

Pancreatic exocrine dysfunction is observed in a subset of patients with coeliac sprue although it is generally assumed that the pancreas is not involved. ${ }^{230}$ In coeliac disease patients, decreased release of stimulatory mediators, in particular $\mathrm{CCK}^{231} 232$ from the atrophic proximal small intestinal mucosa explains diminished endogenous stimulation $^{233}$ and asynchrony between transit of the meal and discharge of bile and pancreatic enzymes into the small intestine (fig 8). It is assumed that these pathomechanisms interact and lead to intraluminal lack of digestive enzymes and maldigestion despite normal secretory capacity of the pancreas. ${ }^{233} 234$ Accordingly, DiMagno et al observed equal enzyme output during exogenous stimulation with CCK in healthy volunteers and coeliac patients, whereas in the latter, enzyme output was decreased by more than $50 \%$ during endogenous stimulation with essential amino acids. ${ }^{233}$

In untreated coeliac patients, pancreatic exocrine insufficiency was observed in $15-40 \% .{ }^{97}{ }^{235-240}$ In most cases, insufficiency was mild to moderate. In less than $10 \%$ of patients pancreatic secretion was below $10 \%$ of normal-that is, severely impaired. ${ }^{237} 238$ Generally, pancreatic exocrine insufficiency is limited to patients with mucosal damage and reversed by restitution of the intestinal mucosa after initiation of gluten free diet. ${ }^{230} 235239$ There is even evidence that pancreatic function is indirectly related to the degree of damage of the duodenal and jejunal mucosa in coeliac disease. ${ }^{230}{ }^{234}$ Moreover, recent findings suggest that exocrine pancreatic secretion is decreased in villous atrophy regardless of the underlying disease. ${ }^{241}$ Accordingly, abnormal pancreatic function was found in about $65 \%$ of patients with untreated tropical sprue using an indirect test and probably was also due to low pancreatic neurohormonal stimulation because of intestinal damage. ${ }^{242}$

However, in contrast to what has been discussed above, several more recent studies report decreased pancreatic exocrine response to exogenous stimulation in coeliac disease. ${ }^{232} 235-237240243$ Severe exocrine insufficiency with residual enzyme secretion rates below $10 \%$ of normal was rare (about $8 \%$ of patients), but subnormal values for one or more pancreatic enzymes were observed in nearly one third of patients. ${ }^{237}$ These findings question the concept that lack of endogenous stimulation and postcibal asynchrony due to mucosal damage are the only causes of pancreatic dysfunction in coeliac disease. Instead, they might point to coexisting pancreatic disease and may explain failure of dietary treatment (gluten free diet) in a subset of patients. $^{232} 233235-238240243-246$

Caroccio et al divided 52 coeliac disease patients into three groups according to their weight/height ratio $(<3$ rd percentile, $4-10$ th percentile, $>10$ th percentile). They observed no differences in enzyme outputs between these groups and concluded that mild to moderate pancreatic exocrine insufficiency is rather frequent in coeliac disease patients, but possibly completely independent of the nutritional status and probably of little clinical importance. ${ }^{237}$ By contrast, the same group observed a faster weight gain in coeliac patients receiving enzyme substitution together with a gluten free diet compared with patients receiving the diet only during the first 30 days of therapy. ${ }^{236}$ In addition, they reported a positive correlation between faecal chymotrypsin at diagnosis of coeliac disease and weight gain within the first 60 days of therapy. ${ }^{243}$ Consequently, faecal chymotrypsin could predict weight recovery within the first two months after diagnosis of coeliac disease and low faecal chymotrypsin could be used to select patients who probably benefit from enzyme treatment. ${ }^{243}$ It remains unclear why low chymotrypsin was not correlated with low body weight at diagnosis ${ }^{237}$ but with slow weight gain during gluten free diet. ${ }^{243}$

Another interesting and so far unexplained finding is that the pattern of pancreatic exocrine secretion (for example, ratios among pancreatic enzymes) appears to be altered in coeliac patients. ${ }^{97} 232240$ Lipase secretion was found to be decreased whereas trypsin secretion remained more or less stable leading to a decrease in the lipase:trypsin ratio.

\subsubsection{Summary}

Taken together, mostly mild to moderate pancreatic exocrine insufficiency is observed in up to $40 \%$ of patients with coeliac disease. Impairment of pancreatic exocrine function is mainly due to decreased release of stimulatory mediators by the 
diseased upper intestinal mucosa leading to reduced enzyme and bicarbonate secretion and postcibal asynchrony of secretory and motor functions. Still, it remains unclear whether these are the only pathomechanisms or whether there may be direct pancreatic insufficiency in a subset of patients. At least in children with coeliac disease, low faecal chymotrypsin might be used to select patients who would probably benefit from enzyme treatment during the first few weeks of therapy.

\subsection{Diabetes mellitus}

In diabetic patients, marked morphological alterations of the exocrine pancreas are observed. ${ }^{100}{ }^{247-252}$ Compared with healthy controls, the pancreas of patients with diabetes was smaller, ${ }^{247}$ mainly caused by involution of the exocrine tissue. ${ }^{249}$ Atrophy particularly affected the pancreatic body ${ }^{249}$ and was more pronounced in insulin dependent diabetes mellitus patients (IDDM) compared with non-insulin dependent diabetics (NIDDM). ${ }^{248-250}$ Diabetics treated with, but not fully dependent on, insulin showed intermediate reductions in pancreatic size. ${ }^{249}$ It is controversial as to whether morphological alterations correlate with the duration or the age at onset of the disease. ${ }^{247} 250253$ Histopathological alterations were more pronounced in IDDM and included pancreatic fibrosis, ${ }^{253-255}$ fatty infiltration, ${ }^{253}$ and intra- and peri-insular inflammatory infiltrates in IDDM. $.^{251-253} 256-258$ Lymphocytic insulitis, a predominant characteristic of IDDM, disappeared after the beta cells had been totally destroyed. ${ }^{258}$

In addition to morphological alterations, a considerable proportion of patients with diabetes mellitus show mild to moderate impairment of bicarbonate and enzyme secretion. In IDDM, a strong correlation was observed between pancreatic volume measured by computed tomography and exocrine function-that is, patients with small pancreata had low exocrine function. This correlation was only weak in NIDDM..$^{259}$ Moreover, prevalence of pancreatic exocrine insufficiency is particularly high in IDDM and ranges between about 40 to $80 \%$ in these patients. ${ }^{260-268}$ For these investigations various modifications of the secretin pankreozymin test or faecal elastase-1 measurements were applied. Our own study in 12 IDDM patients confirmed that overall pancreatic enzyme secretion was decreased, however, the degree of impairment varied among different enzymes

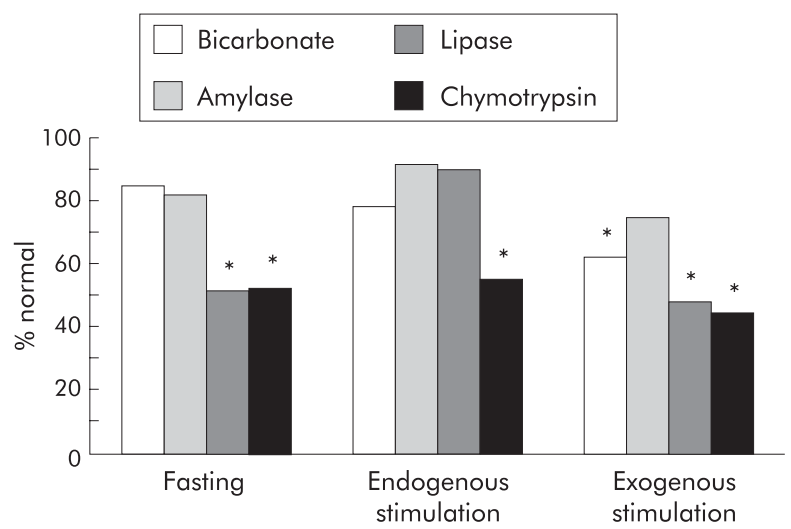

Figure 16 Exocrine pancreatic insufficiency in type I diabetes mellitus: differential susceptibility of individual enzymes to endogenous and exogenous stimulation. Amylase output was normal in the interdigestive state, during moderate endogenous and maximal exogenous stimulation. Diminished fasting lipase output increased regularly in response to endogenous but not to exogenous stimulation. Chymotrypsin output was most susceptible and was decreased under all experimental conditions. $^{262}$ (fig 16): amylase output was normal in the interdigestive state during moderate endogenous and maximal exogenous stimulation. Diminished fasting lipase output increased regularly in response to endogenous but not to exogenous stimulation. Apparently, chymotrypsin output was most susceptible and was decreased under all experimental conditions. Consequently, pancreatic enzyme pattern appears to be altered in response to different stimuli in IDDM. Chymotrypsin secretion may be most susceptible to IDDM associated disturbances. ${ }^{262}$ In contrast, we observed markedly decreased amylase output in response to maximal exogenous stimulation in a mixed group of IDDM and NIDDM patients without clinical evidence of pancreatic exocrine insufficiency. ${ }^{269}$

In NIDDM patients, the prevalence of pancreatic exocrine insufficiency estimated by various modifications of the secretin pankreozymin test or faecal elastase-1 measurements is somewhat lower and ranges between 15\% and $73 \%{ }^{260} 263267268270$ In the subgroup of patients with diarrhoea and peripheral neuropathy, however, all patients showed impaired exocrine function with amylase and bicarbonate secretion amounting to about $40 \%$ of healthy controls in response to endogenous and exogenous stimulation. ${ }^{271}$

Most of the studies performed so far have been limited to small numbers of patients due to relatively time and cost consuming tests of pancreatic functions and/or invasive methods. ${ }^{260-262} 271$ Although a significantly increased prevalence of pancreatic exocrine insufficiency in diabetic patients was observed in all studies, this difference may also have been biased by selection of patients that were more prone to diabetic complications, including pancreatic dysfunction. Only a few studies have used unselected patients of diabetes mellitus registries. ${ }^{264} 270$ These studies suggest relatively low frequencies of impaired pancreatic exocrine function in IDDM (26\%) and NIDDM.(12\%) However, faecal elastase-1 measurements as used in these studies are less sensitive compared with direct and invasive pancreatic function testing. ${ }^{272}$

The pathophysiological mechanisms leading to pancreatic exocrine insufficiency in diabetes mellitus are not fully elucidated. ${ }^{273}$ The disturbance of acinar-islet interactions with imbalance of stimulatory (insulin) 261 $^{274-279}$ and inhibitory (glucagon, somatostatin) ${ }^{60} 280-285$ islet hormones (fig 17) is probably one of the main reasons for pancreatic exocrine dysfunction but does not explain it sufficiently. Further pathomechanisms include pancreatic fibrosis due to angiopathy, ${ }^{255} 267$ autoimmune mechanisms, ${ }^{286-288}$ autonomic neuropathy, ${ }^{271}{ }^{289-292}$ and altered release of gastrointestinal regulatory mediators. ${ }^{293-296}$

As pancreatic exocrine insufficiency is usually only mild to moderate and will not lead to clinically overt steatorrhoea in the majority of patients concerned, clinical relevance of pancreatic exocrine impairment in these patients is questionable. However, patients with diabetes mellitus frequently suffer from a wide range of abdominal symptoms which markedly contribute to impairment of quality of life. ${ }^{297} 298$ At least some of these symptoms, such as pain and diarrhoea, may be attributable in part to (compensated) pancreatic exocrine insufficiency (fig 10) and might respond to enzyme treatment. Consequently, potential beneficial effects of enzyme supplementation on abdominal symptoms in diabetes mellitus warrant clinical studies. On the other hand, potential adverse effects of enzyme supplementation on glucose homeostasis need to be monitored carefully. ${ }^{299}$

\subsubsection{Summary}

Diabetes mellitus is associated with morphological and functional impairment of the exocrine pancreas. This appears to be more extensive in patients with IDDM in whom 


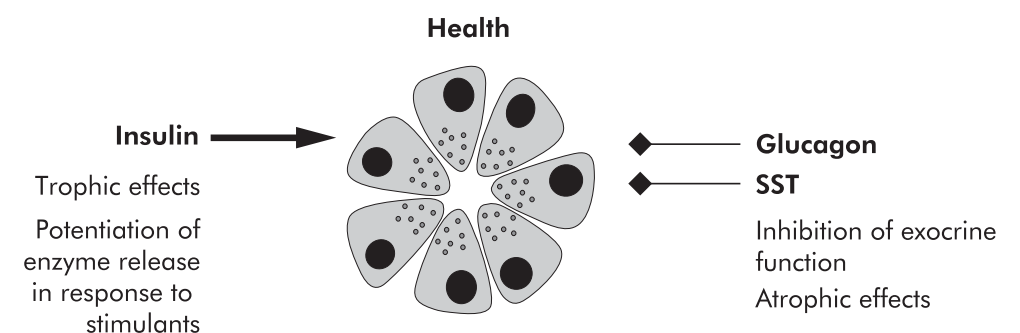

Figure 17 Imbalance of stimulatory and inhibitory pancreatic islet hormones in diabetes mellitus. ${ }^{273}$

Halo phenomenon

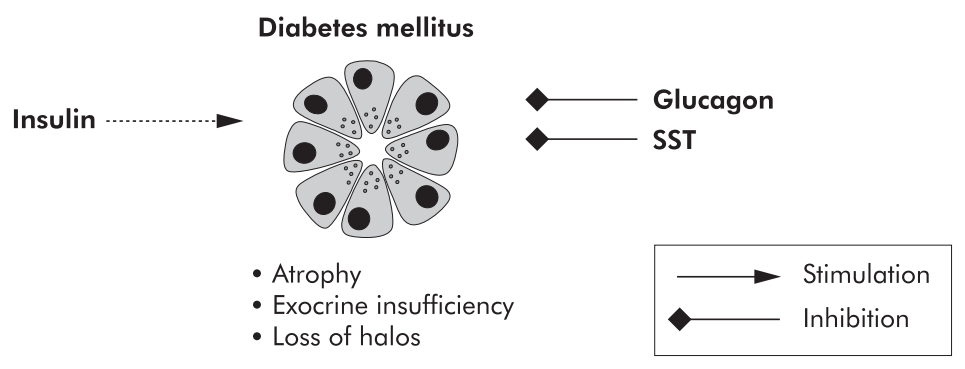

prevalence of mostly mild to moderate pancreatic exocrine insufficiency ranges between about 25-80\%. In NIDDM patients, the prevalence of pancreatic exocrine insufficiency is somewhat lower and ranges from $15-73 \%$. It has to be taken in mind, however, that most of these data are derived from small groups of selected patients who are probably more prone to diabetic complications, including pancreatic exocrine dysfunction. Valid population based data on the frequency of pancreatic exocrine insufficiency in diabetes mellitus are scarce, so far. Anyway, exocrine insufficiency is usually mild to moderate and not associated with overt steatorrhoea. Thus, clinical relevance of pancreatic exocrine impairment in these patients may be questionable. However, patients with diabetes mellitus frequently suffer from a wide range of abdominal symptoms which markedly contribute to impairment of quality of life and might in part be caused by a distal shift of nutrient digestion and absorption as observed in mild to moderate pancreatic exocrine insufficiency. ${ }^{298}$

\subsection{CROHN'S DISEASE}

Pancreatic involvement-that is, pancreatic autoantibodies $^{300} 301$ or increased levels of pancreatic enzymes in plasma ${ }^{302}$ - has been documented in up to $40 \%$ of patients with Crohn's disesase. Increased frequency of pancreatic pathology in Crohn's disease is partly explained by disease associated well known risk factors such as increased incidence of gall stones, duodenal involvement at the papilla of Vater, and adverse reactions to drugs, for example azathioprine. ${ }^{303}$ Still, there are numerous patients with alterations of pancreatic function and/or morphology without these risk factors in whom pathophysiological mechanisms are not completely understood. A high incidence of pancreatic fibrosis (15 out of 36 patients) was described in an autopsy study. ${ }^{304}$ Moreover, in $8.7 \%$ of Crohn's disease patients without clinical evidence of pancreatic insufficiency, morphological alterations of the pancreatic ducts were observed by ERCP. ${ }^{302}$

There are few studies investigating pancreatic exocrine function in Crohn's disease to date. Mostly mild to moderate exocrine insufficiency was observed in $5-15 \%$ of patients in response to exogenous s $^{302}{ }^{305-307}$ or endogenous s $^{3008} 309$ stimulation. In 143 Crohn's disease patients amylase and lipase outputs in response to a Lundh test meal were decreased by 15-20\% compared with healthy volunteers. Enzyme secretion was not associated with duration of the disease, age, nutritional status, medication, or previous bowel surgery, but patients with ileal disease and mild activity had higher secretion rates compared with other locations and higher disease activity. ${ }^{308}$ Similarly, in our own recent study, duodenal perfusion with essential amino acids increased protease secretion in healthy subjects three to fourfold compared with interdigestive values. By contrast, protease secretion did not increase in Crohn's disease patients, neither in response to this moderate endogenous stimulus nor in response to exogenous stimulation by a modified secretin cerulein test. Additionally, integration between pancreatic secretory and intestinal motor functions was disturbed. ${ }^{307}$ Endogenous stimulation caused exaggerated release of GLP-1 and PYY in patients with inflammatory bowel disease compared with healthy volunteers. ${ }^{310}$ This may in part explain reduced response to duodenal amino acids because both of these gastrointestinal hormones were shown to inhibit pancreatic exocrine secretion. ${ }^{311-313}$

Mild to moderate exocrine insufficiency as observed in most patients affected would not be expected to cause clinical symptoms - that is, no steatorrhoea in subjects with an otherwise healthy digestive system. ${ }^{105}$ It might be speculated, however, that in Crohn's disease patients with reduced absorptive capacity due to small intestinal resections, extensive inflammation, or scars and/or motility disturbances, lesser degrees of pancreatic insufficiency might suffice to induce symptoms. Accordingly, selected patients might benefit from enzyme supplementation.

\subsubsection{Summary}

Altogether, some signs of pancreatic pathology are observed in up to $40 \%$ of patients with Crohn's disease and decreased pancreatic exocrine function as assessed by routine pancreatic function tests occurs in 5-15\%. Moreover, patients with Crohn's disease as a group show a decreased enzyme response to endogenous stimulation compared with healthy controls. Apart from disease associated risk factors for pancreatic disease such as increased incidence of gall stones, duodenal involvement at the papilla of Vater, and adverse reactions to drugs, impairment of pancreatic exocrine function may be a consequence of direct pancreatic affection. Moreover, disturbed regulation of pancreatic secretion in particular, and disturbed integration among gastrointestinal secretory and motor functions in general may explain 
decreased digestive enzyme and bicarbonate output. In patients with reduced absorptive capacity lesser degrees of pancreatic insufficiency than usually expected might suffice to induce symptoms.

\subsection{Zollinger-Ellison syndrome}

Zollinger-Ellison syndrome is an uncommon disease and reports about pancreatic exocrine insufficiency in these patients are rare. Still, it is of major pathophysiological interest because a distinct mechanism causes intraluminal lack of pancreatic enzyme activity: $5-10 \%$ of Zollinger-Ellison syndrome's patients have been reported to present with diarrhoea and steatorrhoea. This is in part due to gastrin induced high volume secretion as well as mucosal inflammation, partial villus atrophy, and bile salt precipitation caused by exposure to excessive amounts of gastric acid. Moreover, low duodenal $\mathrm{pH}$ induces acidic destruction of pancreatic enzymes within the intestinal lumen despite normal secretory capacity (fig 8). ${ }^{314}$ This, in turn means that a large volume of acid duodenal juice during investigations of suspected pancreatic steatorrhoea may indicate ZollingerEllison syndrome. ${ }^{314}$

\subsection{CLINICAL CONSEQUENCES 4.1 The physiological goal}

In states of disturbed, that is, mainly diminished pancreatic exocrine function, an ideal therapy would achieve complete restoration of quantity, composition, and availability of luminal enzymatic activity. The healthy human pancreas adopts its exocrine secretory response to the size, nutrient composition, and physical properties of a meal. As a prerequisite there is a complex regulatory interplay among nutrient delivery to the duodenum and pancreatic exocrine secretion. Ingestion of an "ordinary" meal induces a transient phase of maximal enzyme output resulting in a three to sixfold increase above interdigestive outputs of all major enzymes. This is followed by a three to fourfold increase in enzyme output which is sustained for several hours; degree and duration of the digestive enzyme response are higher and longer, respectively, in response to high caloric and solid meals compared with liquid meals with low caloric content. Moreover, different macromolecules have varying stimulatory potency-lipids are the strongest stimulants followed by proteins and carbohydrates.

During small intestinal transit, enzymatic activities of all major pancreatic hydrolases decrease but at greatly different rates: lipase activity is most susceptible to destruction, and only about $20 \%$ or less of duodenal lipase may reach the terminal ileum in active form compared with about $70 \%$ of amylase.

Thus, the available evidence suggests that for perfectly mimicking physiological conditions a pancreatic enzyme preparation would need to:

- be delivered to the duodenum together with the meal;

- induce highest duodenal enzyme delivery during the first postprandial hour reaching $3000 \mathrm{U} / \mathrm{min}$ of lipase, 500 $\mathrm{U} / \mathrm{min}$ of amylase, and $200 \mathrm{U} / \mathrm{min}$ of trypsin;

- thereafter, allow stable duodenal enzyme delivery at lower rates for more than two hours;

- show a decrease in enzymatic activity during small intestinal transit by about $80 \%$ for lipase, $60 \%$ for proteases, and $30 \%$ for amylase.

\subsection{Insufficient luminal enzyme activity}

Due to the high reserve capacity of the exocrine pancreas and because other enzymatic and non-enzymatic mechanisms may at least partly substitute for the loss of pancreatic enzymes, clinically significant malabsorption is prevented at intraduodenal enzyme activities that reach only $5-10 \%$ of physiological postprandial levels.

However, under these threshold conditions, nutrient digestion and absorption is slowed temporally and shifted aborally into the distal small intestine with significant regulatory consequences for gastrointestinal motor and secretory functions. ${ }^{3}{ }^{104}$ Further, it can be assumed that abdominal symptoms in a subgroup of patients with pancreatic insufficiency arise at least in part from these regulatory dysfunctions. This explains the favourable symptomatic response of some patients to enzyme treatment for pain, even in the absence of steatorrhoea. In conclusion, pancreatin supplementation may not only be indicated in patients with overt malabsorption due to severe pancreatic exocrine insufficiency but may also be of therapeutic value in a subset of patients with milder forms of pancreatic exocrine insufficiency.

\subsection{Indications for enzyme supplementation therapy} Chronic pancreatitis is the most frequent and relevant indication for pancreatin supplementation therapy. In an unselected group of patients with chronic pancreatitis 80-90\% show some degree of pancreatic exocrine insufficiency but in most patients, severe pancreatic exocrine insufficiency with overt steatorrhoea is a late event in the course of the disease. Once overt malabsorption has occurred, patients definitely need pancreatic enzyme supplementation therapy. However, it has to be taken in mind that in a fundamental study about 30 years ago DiMagno et al observed duodenal lipase delivery of only about $1 \%$ of normal even with clinically established doses of pancreatin $(28 \mathrm{kU}$ of lipase per meal). Correspondingly, lipid malabsorption could not be normalised in these patients. ${ }^{12}$ These studies were performed with unprotected pancreatin and modern acid resistant microsphere preparations probably achieve considerably higher intraluminal enzyme activities. Still, even today, refractory steatorrhoea despite high doses of pancreatin is a frequent problem in enzyme supplementation therapy.

As discussed above, a therapeutic trial may also be indicated in chronic pancreatitis patients without overt malabsorption but with abdominal symptoms which cannot be attributed to the inflammatory process itself but may be due to regulatory disturbances.

During the first few weeks following onset of acute pancreatitis, pancreatic exocrine function appears to be regularly impaired and a high proportion of patients with necrotising disease may show severe exocrine insufficiency. Milder forms of pancreatic exocrine insufficiency usually recover step by step but particularly patients with expanded necrosis may need pancreatin therapy for a prolonged period of time.

Severe pancreatic exocrine dysfunction and malabsorption occur in $80-90 \%$ of patients with pancreatic cancer. Site and degree of ductal obstruction appear to be major determinants of residual pancreatic exocrine secretion in these patients. In view of the poor prognosis of these patients and the impact of nutritional status on quality of life and survival indication for pancreatin therapy should be administered generously.

Depending on the genetic background cystic fibrosis is associated with pancreatic exocrine insufficiency in the vast majority of patients. Patients presenting with steatorrhoea and/or other symptoms of malabsorption definitely need pancreatic enzyme supplementation therapy. Pancreatin supplementation has been shown to markedly improve nutrient digestion and absorption though it is rarely normalised. This may in part be due to the fact that in cystic fibrosis further disturbances of gastrointestinal secretory and motor 
functions - that is, alterations of gastrointestinal $\mathrm{pH}$, motility, and transit-additionally compromise assimilation of nutrients. Administration of ultra high doses of pancreatin preparations was associated with development of fibrosing colonopathy and should therefore be avoided.

Pancreatic resections naturally decrease pancreatic secretory capacity and it depends on the original disease process and on the type and extent of resection whether patients develop maldigestion and malabsorption. In patients with previously normal pancreatic function, even a 90-95\% resection of the pancreas is generally tolerated without clinical signs of severe pancreatic exocrine insufficiency. By contrast, in patients with pre-existing chronic pancreatitis, the percentage of patients with steatorrhoea is markedly increased by less extensive distal resections. Thus, pancreatic exocrine function needs to be monitored carefully postoperatively, particularly in patients who are at increased risk of developing severe pancreatic exocrine insufficiency. Naturally, high doses of pancreatin with every meal are needed following total pancreatectomy. Moreover, all patients with overt malabsorption following limited pancreatic resections need enzyme therapy.

Partial or total gastrectomy and short bowel syndrome may also be associated with intraluminal lack of pancreatic enzymes postprandially, mainly because of postcibal asynchrony - that is, dissociation between intestinal delivery of nutrients and discharge of digestive secretions. In patients operated on because of malignant disease, extensive denervation of the pancreas including vagotomy contributes to pancreatic dysfunction. Thus, pancreatic exocrine function should be measured in patients with symptoms of malabsorption following gastric or extensive small bowel resections. Indirect tests may be preferred because they reflect digestive action of endogenous enzymes under the patient's pathological conditions. Pancreatin supplementation therapy should be initiated in those patients with documented exocrine insufficiency.

Mostly mild to moderate pancreatic exocrine insufficiency is observed in up to $40 \%$ of patients with coeliac disease. Impairment of pancreatic exocrine function is mainly due to decreased release of stimulatory mediators by the diseased upper intestinal mucosa and to postcibal asynchrony of secretory and motor functions. Still, in a subset of patients, the pancreas itself may also be affected. At least in children with coeliac disease, low faecal enzyme concentrations might be used to select patients who would probably benefit from enzyme treatment during the first few weeks of dietary therapy.

Diabetes mellitus is associated with morphological and functional impairment of the exocrine pancreas. Mostly mild to moderate pancreatic exocrine insufficiency is observed in about $25-80 \%$ of patients with IDDM and in $15-73 \%$ with NIDDM. Severe pancreatic exocrine insufficiency associated with overt steatorrhoea which obviously necessitates enzyme therapy affects only a minority of these patients. However, patients with diabetes mellitus frequently suffer from a wide range of abdominal symptoms which markedly contribute to impairment of quality of life and might in part be caused by a distal shift of nutrient digestion and absorption as observed in mild to moderate pancreatic exocrine insufficiency. ${ }^{298}$ In such patients, a therapeutic trial with enzyme preparations may be justified but necessitates close control of blood glucose.

In Crohn's disease decreased pancreatic exocrine insufficiency as assessed by routine pancreatic function tests occurs in $5-15 \%$ of patients. Mostly, mild to moderate exocrine insufficiency is observed which would not be expected to cause clinical symptoms - that is, no steatorrhoea in subjects with an otherwise healthy digestive system. It might be speculated, however, that in Crohn's disease patients with reduced absorptive capacity due to small intestinal resections, extensive inflammation, or scars and/or motility disturbances, lesser degrees of pancreatic insufficiency might be enough to induce overt malabsorption. Accordingly, selected patients might benefit from enzyme supplementation. Moreover, a distal shift of nutrient digestion and absorption and consecutive regulatory disturbances may contribute to symptoms and might respond to enzyme treatment.

In Zollinger-Ellison syndrome intraluminal enzymes are destroyed by excessive amounts of gastric acid which leads to steatorrhoea in about $5-10 \%$ of patients. Thus, these patients need high doses of proton pump inhibitors and/or surgical therapy but usually do not benefit from enzyme supplementation.

\subsection{Therapeutic standards}

Modern pancreatic enzyme preparations consist of $\mathrm{pH}$ sensitive pancreatin microspheres. In order to reduce steatorrhoea to less than $15 \mathrm{~g}$ of fat per day, a minimal dose of $25000-50000 \mathrm{IU}$ of lipase per meal is required. In order to ensure release of enzymes throughout the digestive period it is recommended that for small meals or snacks, one tablet/ capsule should be swallowed with the start of the meal, and that for major meals a second dosage should be administered during the meal. ${ }^{315}$

Acid resistant coating of the microspheres protects exogenous enzymes from acidic denaturation in the stomach but allows disintegration and release of enzymes at about pH 5.5-6 which is achieved physiologically in the postprandial period. The small size of microspheres was chosen to enable simultaneous delivery of enzymes and meal nutrients to the duodenum because larger indigestible particles (exceeding about $2 \mathrm{~mm}$ in diameter) are retained within the stomach until the end of the digestive period. Microsphere preparations have been shown to be superior to equivalent doses of unprotected pancreatin powder and to acid resistant monolithic capsules or tablets. However, due to the physicochemical properties of the coating the microspheres may be somewhat retained in the stomach postprandially (in the lipophilic phase of the meal) (16 $^{316}$ and-more importantly-release of enzymes within the intestinal lumen does not occur instantly but is retarded particularly if intestinal $\mathrm{pH}$ is below the $\mathrm{pH}$ threshold cited above due to loss of bicarbonate secretion. ${ }^{122}$ Thus, nutrient digestion and absorption are shifted from the duodenum to the more distal small intestine. These appear to be the main reasons why lipid digestion and absorption cannot be normalised in a subset of patients with severe pancreatic exocrine insufficiency despite administration of high doses of modern enzyme preparations.

Following (total) gastrectomy and in patients with gastric acid suppression therapy due to other reasons, unprotected pancreatin powder should be preferred. On the other hand, application of proton pump inhibitors together with pancreatin powder may increase fat absorption in patients who do not respond adequately to standard enzyme treatment.

Moreover, failure of enzyme therapy to adequately improve steatorrhoea and other symptoms of exocrine insufficiency may be due to low patient compliance, intestinal infections or other disorders associated with malabsorption. These require specific diagnostic work up and therapeutic intervention. ${ }^{315}$

\subsection{Future developments}

Lipid malabsorption is regarded as the clinically most important malfunction in pancreatic exocrine insufficiency. Thus, investigations to optimise enzyme treatment have concentrated on supplementation of adequate amounts of lipolytic activity to the proximal small intestine. ${ }^{102}$ 
At present, adminstration of bacterial lipase, for example from Burkholderia plantarii, may be the most promising approach. This bacterial lipase has a high specific activity, is resistant to gastric acid and proteolytic enzymes, is not inhibited by bile acids, and is (at least in animal experiments) superior compared with porcine pancreatin in correcting fat malabsorption. ${ }^{317-319}$ On the other hand, no human dataeither experimental or clinical studies-are available to date.

Moreover, the human pancreatic lipase gene has been successfully transfected and expressed in vitro and in vivo. Significant production of human lipase was observed under all these conditions. ${ }^{320} 321$ These experiments suggest the possibility of future ectopic expression of human pancreatic lipase in the hepatobiliary system of patients with pancreatic exocrine insufficiency.

Furthermore, application of bioengineered, acid resistant human gastric lipase may offer treatment alternatives.

The primary goal of new developments is to achieve sufficient lipase activities within the upper small intestine in order to prevent lipid maldigestion and malabsorption. Thus, the galenic properties of optimised treatment alternatives should not only ensure high intraduodenal enzyme activities early postprandially but also a stable duodenal enzyme delivery for more than two hours. On the other hand, fibrosing colonopathy in cystic fibrosis patients treated with ultra high doses of pancreatin has been attributed to the exposure of the colon to high protease activities. It has remained controversial whether the enzyme content truly played a decisive pathogenetic role in these patients. Still, it cannot be excluded that the physiological decrease in enzymatic activity during small intestinal transit may be protective for the distal intestine.

\subsection{ACKNOWLEDGEMENTS}

This work is made possible by an educational grant by Solvay Pharmaceuticals, Hannover, Germany. The authors wish to thank Ulrike Melle, MD for literature review. Own cited studies were partly supported by the Deutsche Forschungsgemeinschaft, the EstherChristiansen-Stiftung, and the Anna-Lorz-Stiftung.

\section{Authors' affiliations}

J Keller, P Layer, Israelitic Hospital, University of Hamburg, Hamburg, Germany

We have no other competing financial interests.

Competing interest statement: Commercial interests of any company producing or selling pancreatin preparations may be affected by the conclusions of this review. In the past five years both authors have received financial support for research, educational and scientific consulting activities from various pharmaceutical companies producing and selling enzyme preparations including Solvay Pharmaceuticals, Hannover, who sponsored this review by educational grant. None of the authors has been employed by an organisation that may in any way gain or lose financially from the conclusions of our review. None of the authors holds any stocks or shares in an organisation that may in any way gain or lose financially from the conclusions of our review. Both authors have given medical opinion statements on the subject of our review - that is, pancreatic exocrine insufficiency.

\subsection{REFERENCES}

1 DiMagno EP, Layer P. Human exocrine pancreatic enzyme secretion. In: Go VL, ed. The pancreas: biology, pathobiology and diseases. New York: Raven Press, 1993:275-300.

2 DiMagno EP, Clain JE, Layer P. Chronic pancreatitis. In: Go VL, ed. The pancreas: biology, pathobiology and disease. New York: Raven Press, 1993:665-706.

3 Layer P, Keller J. Pancreatic enzymes: secretion and luminal nutrient digestion in health and disease. J Clin Gastroenterol 1999;28:3-10.

4 Layer P, Yamamoto H, Kalthoff L, et al. The different courses of early- and late-onset idiopathic and alcoholic chronic pancreatitis. Gastroenterology 1994; 107:1481-7

5 Kolbel C, Layer P, Hotz J, et al. [Effect of an acid protected, microencapsulated pancreatin preparation on pancreatogenic steatorrhea]. Med Klin 1986;81:85-6.
6 Keller J, Layer P. Circadian pancreatic enzyme pattern and relationship between secretory and motor activity in fasting humans. J Appl Physiol 2002;93:592-600

7 Fried M, Mayer EA, Jansen JB, et al. Temporal relationships of cholecystokinin release, pancreatobiliary secretion, and gastric emptying of a mixed meal. Gastroenterology 1988;95:1344-50

8 Malagelada JR, Go VL, Summerskill WH. Different gastric, pancreatic, and biliary responses to solid-liquid or homogenized meals. Dig Dis Sci 1979;24:101-10.

9 Miller L, Clain JE, Malagelada JR, et al. Control of human postprandial pancreatic exocrine secretion: a function of the gastroduodenal region. Dig Dis Sci 1979;24:150-4.

10 Owyang C, Louie DS, Tatum D. Feedback regulation of pancreatic enzyme secretion. Suppression of cholecystokinin release by trypsin. J Clin Invest 1986;77:2042-7

11 Cantor P, Mortensen PE, Myhre J, et al. The effect of the cholecystokinin receptor antagonist MK-329 on meal- stimulated pancreaticobiliary output in humans. Gastroenterology 1992;102:1742-51.

12 DiMagno EP, Malagelada JR, Go VL, et al. Fate of orally ingested enzymes in pancreatic insufficiency. Comparison of two dosage schedules. N Engl J Med 1977;296:1318-22.

13 Wisen O, Hellstrom PM, Johansson C. Meal energy density as a determinant of postprandial gastrointestinal adaptation in man. Scand J Gastroenterol 1993;28:737-43.

14 Brunner H, Northfield TC, Hofmann AF, et al. Gastric emptying and secretion of bile acids, cholesterol, and pancreatic enzymes during digestion. Duodenal perfusion studies in healthy subjects. Mayo Clin Proc 1974;49:851-60.

15 O'Keefe SJ, Lee RB, Anderson FP, et al. Physiological effects of enteral and parenteral feeding on pancreaticobiliary secretion in humans. Am J Physiol Gastrointest Liver Physiol 2003;284:G27-G36.

16 Malagelada JR, Go VL, DiMagno EP, et al. Interactions between intraluminal bile acids and digestive products on pancreatic and gallbladder function. $J$ Clin Invest 1973;52:2160-5.

17 Layer P, Peschel S, Schlesinger T, et al. Human pancreatic secretion and intestinal motility: effects of ileal nutrient perfusion. Am J Physiol 1990;258(2 Pt 1):G196-G201

18 Keller J, Runzi M, Goebell H, et al. Duodenal and ileal nutrient deliveries regulate human intestinal motor and pancreatic responses to a meal. Am J Physiol 1997:272(3 Pt 1):G632-G637.

19 Keller J, VanKrieken A, Goebell H, et al. Differential responses of pancreatic secretion and intestinal motility to graded ileal nutrient perfusion [abstract] Gastroenterology 1997;1 12:452.

20 Keller J, Franke A, Rippel K, et al. Termination of digestive pancreatic secretory and intestinal motor responses: importance of GLP-1 and PYY [abstract]. Digestion 1999;60:383.

21 Katschinski M, Dippel C, Reinshagen M, et al. Induction of the fed pattern of human exocrine pancreatic secretion by nutrients: role of cholecystokinin and neurotensin. Clin Investig 1992;70:902-8.

22 Holtmann G, Kelly DG, DiMagno EP. Nutrients and cyclical interdigestive pancreatic enzyme secretion in humans. Gut 1996;38:920-4.

23 Horowitz M, Edelbroek MA, Wishart JM, et al. Relationship between oral glucose tolerance and gastric emptying in normal healthy subjects. Diabetologia 1993;36:857-62.

24 Boivin M, Lanspa SJ, Zinsmeister AR, et al. Are diets associated with different rates of human interdigestive and postprandial pancreatic enzyme secretion? Gastroenterology 1990;99:1763-71.

25 Beglinger C, Fried M, Whitehouse I, et al. Pancreatic enzyme response to a liquid meal and to hormonal stimulation. Correlation with plasma secretin and cholecystokinin levels. J Clin Invest 1985;75:1471-6.

26 Dukehart MR, Dutta SK, Vaeth J. Dietary fiber supplementation: effect on exocrine pancreatic secretion in man. Am J Clin Nutr 1989;50:1023-8.

27 Vidon N, Pfeiffer A, Franchisseur C, et al. Effect of different caloric loads in human jejunum on meal-stimulated and nonstimulated biliopancreatic secretion. Am J Clin Nutr 1988;47:400-5.

28 Dooley CP, Valenzuela JE. Duodenal volume and osmoreceptors in the stimulation of human pancreatic secretion. Gastroenterology 1984;86:23-7.

29 Gisolfi CV, Summers RW, Lambert GP, et al. Effect of beverage osmolality on intestinal fluid absorption during exercise. J Appl Physiol 1998;85:1941-8.

30 Sun WM, Houghton LA, Read NW, et al. Effect of meal temperature on gastric emptying of liquids in man. Gut 1988;29:302-5.

31 Sun WM, Penagini R, Hebbard G, et al. Effect of drink temperature on antropyloroduodenal motility and gastric electrical activity in humans. Gut 1995;37:329-34.

32 McArthur KE, Feldman M. Gastric acid secretion, gastrin release, and gastric emptying in humans as affected by liquid meal temperature. Am J Clin Nutr 1989:49:51-4.

33 Tiscornia OM, Cresta MA, de Lehmann ES, et al. Effects of sex and age on pancreatic secretion. Int J Pancreatol 1986;1:95-118.

34 Laugier R, Bernard JP, Berthezene $P$, et al. Changes in pancreatic exocrine secretion with age: pancreatic exocrine secretion does decrease in the elderly. Digestion 1991;50:202-11.

35 Tiscornia OM. Human exocrine pancreatic response with different types of secretin. Influence of sex, age, and previous intraduodenal sorbitol infusion. Am J Gastroenterol 1978;69:166-75.

36 Vellas B, Balas D, Moreau J, et al. Exocrine pancreatic secretion in the elderly. Int J Pancreatol 1988;3:497-502.

37 Ishibashi T, Matsumoto $\mathrm{S}$, Harada $\mathrm{H}$, et al. [Aging and exocrine pancreatic function evaluated by the recently standardized secretin test]. Nippon Ronen lgakkai Zasshi 1991;28:599-605. 
38 Gaia E, Andriulli A, Tappero G, et al. Influence of sex and body size on pancreatic bicarbonate and enzyme output. J Clin Gastroenterol 1984;6:429-33

39 Layer P, Go VL, DiMagno EP. Fate of pancreatic enzymes during small intestinal aboral transit in humans. Am J Physiol 1986;251(4 Pt 1):G475-G480.

40 Carriere F, Renou C, Lopez V, et al. The specific activities of human digestive lipases measured from the in vivo and in vitro lipolysis of test meals. Gastroenterology 2000;1 19:949-60.

41 Fried M, Erlacher U, Schwizer W, et al. Role of cholecystokinin in the regulation of gastric emptying and pancreatic enzyme secretion in humans. Studies with the cholecystokinin- receptor antagonist loxiglumide. Gastroenterology 1991;101:503-11.

42 Bozkurt T, Adler G, Koop I, et al. Effect of atropine on intestinal phase of pancreatic secretion in man. Digestion 1988;41:108-15.

43 Czako L, Hajnal F, Nemeth J, et al. Effect of a liquid meal given as a bolus into the jejunum on human pancreatic secretion. Pancreas 1999: 18:197-202

44 Layer P, Chan AT, Go VL, et al. Human pancreatic secretion during phase II antral motility of the interdigestive cycle. Am J Physiol 1988;254(2 Pt 1):G249-G253

45 Olsen O, Schaffalitzky dMO, Cantor P. Fat and pancreatic secretion. Scand J Gastroenterology 1989;24:74-80.

46 Hildebrand P, Beglinger C, Gyr K, et al. Effects of a cholecystokinin receptor antagonist on intestinal phase of pancreatic and biliary responses in man. $J$ Clin Invest 1990;85:640-6.

47 Thimister PW, Hopman WP, Loualidi A, et al. Cholestyramine influences meal-stimulated pancreaticobiliary function and plasma cholecystokinin independent of gastric emptying and food digestion. Scand J Gastroenterol 1997;32:778-84.

48 Thimister PW, Hopman WP, van Roermund RF, et al. Inhibition of pancreaticobiliary secretion by loperamide in humans. Hepatology 1997:26:256-61.

49 Keller J, Daecke W, Goebell H, et al. Integrated secretory and motor responses to submaximal endogenous stimulation by essential amino acids [abstract]. Pancreas 1996;13:442.

50 Keller J. Postprandiale Regulation der Pankreasenzymsekretion und Dünndarmmotilität durch intraluminale Nährstoffe im proximalen und distalen Dünndarm. 1996.

51 Braganza JM, Herman K, Hine P, et al. Pancreatic enzymes in human duodenal juice-a comparison of responses in secretin pancreozymin and Lundh Borgstrom tests. Gut 1978;19:358-66.

52 MacGregor IL, Deveney C, Way LW, et al. The effect of acute hyperglycemia on meal-stimulated gastric, biliary, and pancreatic secretion, and serum gastrin. Gastroenterology 1976;70:197-202.

53 Fried M, Abramson S, Meyer JH. Passage of salivary amylase through the stomach in humans. Dig Dis Sci 1987;32:1097-103.

54 Schmidt WE, Creutzfeldt W, Schleser A, et al. Role of CCK in regulation of pancreaticobiliary functions and $\mathrm{GI}$ motility in humans: effects of loxiglumide. Am J Physiol 1991;260(2 Pt 1):G197-G206.

55 Carriere $F$, Barrowman JA, Verger $R$, et al. Secretion and contribution to lipolysis of gastric and pancreatic lipases during a test meal in humans. Gastroenterology 1993;105:876-88.

56 Skude G, Ihse I. Salivary amylase in duodenal aspirates. Scand J Gastroenterol 1976;11:17-20.

57 Gan KH, Geus WP, Lamers CB, et al. Effect of omeprazole $40 \mathrm{mg}$ once daily on intraduodenal and intragastric $\mathrm{pH}$ in $\mathrm{H}$. pylori-negative healthy subjects. Dig Dis Sci 1997; 42:2304-9.

58 Geus WP, Eddes EH, Gielkens HA, et al. Post-prandial intragastric and duodenal acidity are increased in patients with chronic pancreatitis. Aliment Pharmacol Ther 1999;13:937-43.

59 Anagnostides A, Chadwick VS, Selden AC, et al. Sham feeding and pancreatic secretion. Evidence for direct vagal stimulation of enzyme output. Gastroenterology 1984:87:109-14.

60 von der $\mathrm{O}$, Layer P, Wollny C, et al. Somatostatin 28 and coupling of human interdigestive intestinal motility and pancreatic secretion. Gastroenterology 1992; 103:974-81

61 Beglinger C, Taylor IL, Grossman MI, et al. Pancreatic polypeptide inhibits exocrine pancreatic responses to six stimulants. Am J Physiol 1984;246/3 P† 1):G286-G291.

62 Adrian TE, Ferri GL, Bacarese-Hamilton AJ, et al. Human distribution and release of a putative new gut hormone, peptide YY. Gastroenterology 1985;89:1070-7.

63 Layer P, Holst JJ, Grandt D, et al. Ileal release of glucagon-like peptide-1 (GLP-1). Association with inhibition of gastric acid secretion in humans. Dig Dis Sci 1995;40:1074-82.

64 Layer $\mathbf{P}$, Ohe M, Muller MK, et al. Effects of somatostatin on the exocrine pancreas. Scand J Gastroenterol 1991;26:129-36.

65 Savage AP, Adrian TE, Carolan G, ef al. Effects of peptide YY (PYY) on mouth to caecum intestinal transit time and on the rate of gastric emptying in healthy volunteers. Gut 1987;28:166-70

66 Wettergren A, Schioldager B, Mortensen PE, et al. Truncated GLP-1 (proglucagon 78-107-amide) inhibits gastric and pancreatic functions in man. Dig Dis Sci 1993;38:665-73.

67 Layer P, Schlesinger T, Groger G, et al. Modulation of human periodic interdigestive gastrointestinal motor and pancreatic function by the ileum Pancreas 1993:8:426-32.

68 Holgate AM, Read NW. Effect of ileal infusion of intralipid on gastrointestinal transit, ileal flow rate, and carbohydrate absorption in humans after ingestion of a liquid meal. Gastroenterology 1985;88:1005-11.
69 Keller J, Conrads H, Holst JJ, et al. The ratios between pancreatic secretory enzymes are modulated by physiologic ileal lipid concentrations [abstract]. Pancreas 1998;17:442.

70 Read NW, McFarlane A, Kinsman RI, et al. Effect of infusion of nutrient solutions into the ileum on gastrointestinal transit and plasma levels of neurotensin and enteroglucagon. Gastroenterology 1984;86:274-80.

71 Soper NJ, Chapman NJ, Kelly KA, et al. The 'ileal brake' after ileal pouchanal anastomosis. Gastroenterology 1990;98:111-16.

72 Spiller RC, Trotman IF, Adrian TE, et al. Further characterisation of the 'ileal brake' reflex in man-effect of ileal infusion of partial digests of fat, protein, and starch on jejunal motility and release of neurotensin, enteroglucagon, and peptide YY. Gut 1988;29:1042-51.

73 Jain NK, Boivin M, Zinsmeister AR, et al. Effect of ileal perfusion of carbohydrates and amylase inhibitor on gastrointestinal hormones and emptying. Gastroenterology 1989;96(2 Pt 1):377-87

74 Layer P, Groger G, Grandt D, et al. [The terminal ileum as a co-regulator of cyclic interdigestive pancreatic secretion in man]. Med Klin 1993;88(Suppl 1):15-17.

75 Welch IM, Cunningham KM, Read NW. Regulation of gastric emptying by ileal nutrients in humans. Gastroenterology 1988;94:401-4.

76 Levitt MD, Hirsh P, Fetzer CA, et al. H2 excretion after ingestion of complex carbohydrates. Gastroenterology 1987;92:383-9

77 Stephen AM, Haddad AC, Phillips SF. Passage of carbohydrate into the colon. Direct measurements in humans. Gastroenterology 1983;85:589-95.

78 Evenepoel P, Claus D, Geypens B, et al. Amount and fate of egg protein escaping assimilation in the small intestine of humans. Am J Physiol 1999;277(5 Pt 1):G935-G943

79 Evenepoel P, Claus D, Geypens B, et al. Evidence for impaired assimilation and increased colonic fermentation of protein, related to gastric acid suppression therapy. Aliment Pharmacol Ther 1998;12:1011-19.

80 Ekelund K, Johansson C. Output of bile and pancreatic enzymes after test meals with different fat content. Influence of body weight on pancreatic enzyme composition. Acta Physiol Scand 1980;110:161-5.

81 Thimister PW, Hopman WP, Sloots CE, et al. Role of intraduodenal proteases in plasma cholecystokinin and pancreaticobiliary responses to protein and amino acids. Gastroenterology 1996;110:567-75.

82 Go VL, Hofmann AF, Summerskill WH. Pancreozymin bioassay in man based on pancreatic enzyme secretion: potency of specific amino acids and other digestive products. J Clin Invest 1970;49:1558-64.

83 Ekelund K, Johansson C. Output of bilirubin and pancreatic enzymes in response to different liquid test meals in man. Scand J Gastroenterol 1975; 10:507-11.

84 Guimbaud R, Moreau JA, Bouisson M, et al. Intraduodenal free fatty acids rather than triglycerides are responsible for the release of CCK in humans. Pancreas 1997; 14:76-82.

85 Hildebrand P, Petrig C, Burckhardt B, et al. Hydrolysis of dietary fat by pancreatic lipase stimulates cholecystokinin release. Gastroenterology 1998; 114:123-9.

86 Symersky T, Vu MK, Frolich M, et al. The effect of equicaloric medium-chain and long-chain triglycerides on pancreas enzyme secretion. Clin Physiol Funct Imaging 2002;22:307-11.

87 Armand $M$, Pasquier $B$, Andre $M$, et al. Digestion and absorption of 2 fat emulsions with different droplet sizes in the human digestive tract. Am J Clin Nutr 1999;70:1096-106.

88 Fried $M$, Jansen JB, Harpole T, et al. Pancreatobiliary responses to an intragastric amino acid meal: comparison to albumin, dextrose, and maximal cholecystokinin stimulus. Gastroenterology 1989;97:1544-9.

89 Dagorn JC, Michel R, Morisset J. Nonparallel courses of intrapancreatic levels of exportable enzymes after a fatty meal. Proc Soc Exp Biol Med 1976;151:608-10.

90 Maouyo D, Morisset J. Amazing pancreas: specific regulation of pancreatic secretion of individual digestive enzymes in rats. Am J Physiol 1995;268(2 Pt 1):E349-E359.

91 Maouyo D, Guan D, Rivard N, et al. Modulation of the relationship between amylase and chymotrypsinogen secretion in atropine- and MK329-infused rats. Pancreas 1995:11:330-40.

92 Maouyo D, Morisset J. Modulation of pancreatic secretion of individual digestive enzymes in octreotide (SMS 201-995)-infused rats. Pancreas 1997; 14:47-57

93 Holtmann G, Kelly DG, Sternby B, et al. Survival of human pancreatic enzymes during small bowel transit: effect of nutrients, bile acids, and enzymes. Am J Physiol 1997;273(2 Pt 1):G553-G558.

94 Thiruvengadam R, DiMagno EP. Inactivation of human lipase by proteases. Am J Physiol 1988;255(4 Pt 1):G476-G481

95 Layer $\mathrm{P}$, Jansen JB, Cherian $\mathrm{L}$, et al. Feedback regulation of human pancreatic secretion. Effects of protease inhibition on duodenal delivery and small intestinal transit of pancreatic enzymes. Gastroenterology 1990;98:1311-19.

96 Layer PH, DiMagno EP. Natural histories of alcoholic and idiopathic chronic pancreatitis. Pancreas 1996;12:318-20.

97 Ihse I, Arnesjo B, Kugelberg C, et al. Intestinal activities of trypsin, lipase, and phospholipase after a test meal. An evaluation of 474 examinations. Scand J Gastroenterol 1977;12:663-8.

98 Friess $\mathrm{H}$, Bohm J, Muller MW, et al. Maldigestion after total gastrectomy is associated with pancreatic insufficiency. Am J Gastroenterol 1996:91:341-7

99 Schwarz A, Buchler M, Usinger K, et al. Importance of the duodenal passage and pouch volume after total gastrectomy and reconstruction with the Ulm pouch: prospective randomized clinical study. World J Surg 1996;20:60-6. 
100 Heptner G, Domschke S, Domschke W. Exocrine pancreatic function after gastrectomy. Specificity of indirect tests. Gastroenterology 1989;97:147-53.

101 Gullo L, Costa PL, Ventrucci M, et al. Exocrine pancreatic function after total gastrectomy. Scand J Gastroenterol 1979;14:401-7.

102 Layer P, Keller J. Lipase supplementation therapy: standards, alternatives, and perspectives. Pancreas 2003;26:1-7.

103 Halm U, Loser C, Lohr M, et al. A double-blind, randomized, multicentre, crossover study to prove equivalence of pancreatin minimicrospheres versus microspheres in exocrine pancreatic insufficiency. Aliment Pharmacol Ther 1999; 13:951-7.

104 Layer $\mathbf{P}$, von der O, Holst JJ, et al. Altered postprandial motility in chronic pancreatitis: role of malabsorption. Gastroenterology 1997:112:1624-34.

105 DiMagno EP, Go VL, Summerskill WH. Relations between pancreatic enzyme ouputs and malabsorption in severe pancreatic insufficiency. N Engl J Med 1973;288:813-15.

106 Conwell DL, Zuccaro G, Morrow JB, et al. Cholecystokinin-stimulated peak lipase concentration in duodenal drainage fluid: a new pancreatic function test. Am J Gastroenterol 2002;97:1392-7.

107 Mizuno R, Hayakawa T, Noda A. Elastase secretion in pancreatic disease. Am J Gastroenterol 1985;80:113-17.

108 Brugge WR, Burke CA, Brand DL, et al. Increased interdigestive pancreatic trypsin secretion in alcoholic pancreatic disease. Dig Dis Sci 1985;30:431-9.

109 Funakoshi A, Tateishi K, Shinozaki H, et al. Plasma pancreastatin responses after intrajejunal infusion of liquid meal in patients with chronic pancreatitis. Dig Dis Sci 1990;35:721-5.

110 Hoeden R, Mesa AV, Delcourt A. Functional exploration of chronic pancreatitis by duodenal intubation. Comparative study of the Lundh meal and duodenal hormones based on a survey of literature. Secretin-caerulein test carried out by the authors. Prospective conclusions. Acta Gastroenterol Belg 1976;39:509-21.

111 Makela A, Kuusi T, Seppala K, et al. Duodenal secretion of phospholipase A2, amylase, and bicarbonate in chronic pancreatitis. J Gastroenterol 1998;33:260-6.

112 Rogos R, Appelt G, Moller T, et al. [Secretin-pancreozymin test with volume correction in the functional diagnosis of pancreatobiliary secretion]. Dtsch Z Verdau Stoffwechselkr 1987;47:242-51.

113 Nakamura T, Takeuchi T. Pancreatic steatorrhea, malabsorption, and nutrition biochemistry: a comparison of Japanese, European, and American patients with chronic pancreatitis. Pancreas 1997; 14:323-33.

114 Conwell DL, Zuccaro G Jr, Vargo JJ, et al. An endoscopic pancreatic function test with cholecystokinin-octapeptide for the diagnosis of chronic pancreatitis. Clin Gastroenterol Hepatol 2003;1:189-94.

115 Sarles H, Augustine P, Laugier R, et al. Pancreatic lesions and modifications of pancreatic juice in tropical chronic pancreatitis (tropical calcific diabetes). Dig Dis Sci 1994;39:1337-44.

116 Karlsborg M, Bang IC, Worning H. Pancreatic enzyme secretion and pancreatic pseudocysts in patients with chronic pancreatitis. Int $J$ Pancreatol 1997;21:199-203.

117 Pieramico O, Dominguez-Munoz JE, Nelson DK, et al. Interdigestive cycling in chronic pancreatitis: altered coordination among pancreatic secretion, motility, and hormones [see comments]. Gastroenterology 1995; 109:224-30.

118 Isaksson G, Lundquist I, Akesson B, et al. Effects of pectin and wheat bran on intraluminal pancreatic enzyme activities and on fat absorption as examined with the triolein breath test in patients with pancreatic insufficiency. Scand J Gastroenterol 1984; 19:467-72.

119 Ihse I, Lilja P, Evander A, et al. Time-related enzyme concentrations in duodenal aspirates after ingestion of a test meal. Scand J Gastroenterol 1977; 12:629-35.

120 Klass HJ, Sandle GI, Kay PM, et al. Quantitation of tryptic responses to endogenous and exogenous stimulation in chronic pancreatitis. Digestion 1986;35:95-101.

121 Regan PT, Malagelada JR, DiMagno EP, et al. Comparative effects of antacids, cimetidine and enteric coating on the therapeutic response to oral enzymes in severe pancreatic insufficiency. N Engl J Med 1977;297:854-8.

122 Layer $P$, Ohe M, Groeger $G$, et al. Luminal availability and digestive efficacy of substituted enzymes in pancreatic insufficiency [abstract]. Pancreas 1992;7:745.

123 Isaksson G, Lundquist I, thse I. Effect of dietary fiber on pancreatic enzyme activity in vitro. Gastroenterology 1982;82:918-24.

124 Ladas SD, Giorgiotis K, Raptis SA. Complex carbohydrate malabsorption in exocrine pancreatic insufficiency. Gut 1993;34:984-7.

125 Layer P, Zinsmeister AR, DiMagno EP. Effects of decreasing intraluminal amylase activity on starch digestion and postprandial gastrointestinal function in humans. Gastroenterology 1986;91:41-8.

126 Hiele $M$, Ghoos $Y$, Rutgeerts $P$, et al. Starch digestion in normal subjects and patients with pancreatic disease, using a $13 \mathrm{CO} 2$ breath test. Gastroenterology 1989;96:503-9.

127 Jeppesen PB, Mortensen PB. Colonic digestion and absorption of energy from carbohydrates and medium-chain fat in small bowel failure. JPEN J Parenter Enteral Nutr 1999;23(5 Suppl):S101-S105.

128 Nordgaard I, Mortensen PB. Digestive processes in the human colon. Nutrition 1995;11:37-45

129 Bond JH Jr, Levitt MD. Fate of soluble carbohydrate in the colon of rats and man. J Clin Invest 1976;57:1158-64.

130 Layer P, Carlson GL, DiMagno EP. Partially purified white bean amylase inhibitor reduces starch digestion in vitro and inactivates intraduodenal amylase in humans. Gastroenterology 1985;88:1895-902.
131 Keller J, Conrads H, Goebell H, et al. Differential responses of human pancreatic and biliary secretion to graded ileal lipid perfusion [abstract]. Digestion 1998;59:206.

132 Slaff J, Jacobson D, Tillman CR, et al. Protease-specific suppression of pancreatic exocrine secretion. Gastroenterology 1984;87:44-52.

133 Isaksson G, lhse I. Pain reduction by an oral pancreatic enzyme preparation in chronic pancreatitis. Dig Dis Sci 1983;28:97-102.

134 Conwell DL, Zuccaro G, Morrow JB, et al. Analysis of duodenal drainage fluid after cholecystokinin (CCK) stimulation in healthy volunteers. Pancreas 2002;25:350-4

135 Gullo L, Costa PL, Fontana G, et al. Investigation of exocrine pancreatic function by continuous infusion of caerulein and secretin in normal subjects and in chronic pancreatitis. Digestion 1976;14:97-107.

136 Kitagawa M, Naruse S, Ishiguro H, et al. Evaluating exocrine function tests for diagnosing chronic pancreatitis. Pancreas 1997;15:402-8.

137 Hardt PD, Marzeion AM, Schnell-Kretschmer H, et al. Fecal elastase 1 measurement compared with endoscopic retrograde cholangiopancreatography for the diagnosis of chronic pancreatitis. Pancreas 2002;25:e6-e9.

138 Lankisch PG, Seidensticker F, Otto J, et al. Secretin-pancreozymin test (SPT) and endoscopic retrograde cholangiopancreatography (ERCP): both are necessary for diagnosing or excluding chronic pancreatitis. Pancreas 1996;12:149-52.

139 Keller J, Layer P. Severe pancreatic insufficiency in inflammatory bowel disease. Interesting IBD cases 1997; 28:1-5.

140 Osawa S, Kataoka K, Sakagami J, et al. Relation between morphologic changes in the main pancreatic duct and exocrine pancreatic function after a secretin test. Pancreas 2002;25:12-19.

141 Harada H, Hayashi T, Ono A, et al. Analysis of human pure pancreatic juice in chronic pancreatitis and cancer of the pancreas. Gastroenterol Jpn 1978;13:461-7.

142 DiMagno EP, Malagelada JR, Go VL. Relationship between alcoholism and pancreatic insufficiency. Ann N Y Acad Sci 1975;252:200-7.

143 Layer P, Hotz J, Goebell H. Stimulatory effect of hypercalcemia on pancreatic secretion is prevented by pretreatment with cholecystokinin and cholinergic agonists. Pancreas 1986;1:478-82.

144 Andersen JR, Bendtsen F, Ovesen L, et al. Pancreatic insufficiency. Duodenal and jejunal $\mathrm{pH}$, bile acid activity, and micellar lipid solubilization. Int J Pancreatol 1990;6:263-70.

145 Moreau H, Laugier R, Gargouri Y, et al. Human preduodenal lipase is entirely of gastric fundic origin. Gastroenterology 1988;95:1221-6.

146 Sternby B, Holtmann G, Kelly DG, et al. Effect of gastric or duodenal nutrient infusion on gastric and pancreatic lipase secretion [abstract]. Gastroenterology 1992;102:292.

147 Renou C, Carriere F, Ville E, et al. Effects of lansoprazole on human gastric lipase secretion and intragastric lipolysis in healthy human volunteers. Digestion 1902;63:207-13.

148 Moreau H, Bernadac A, Gargouri Y, et al. Immunocytolocalization of human gastric lipase in chief cells of the fundic mucosa. Histochemistry 1989;91:419-23.

149 Sarles J, Moreau H, Verger R. Human gastric lipase: ontogeny and variations in children. Acta Paediatr 1992:81:51 1-13.

150 Gregory PC. Gastrointestinal pH, motility/transit and permeability in cystic fibrosis. J Pediatr Gastroenterol Nutr 1996;23:513-23.

151 Moreau J, Bovisson M, Balas D, et al. Gastric lipase in alcoholic pancreatitis. Comparison of secretive profiles following pentagastrin stimulation in normal adults and patients with pancreatic insufficiency. Gastroenterology 1990;99:175-80.

152 Woidemann M, Sternby B, Larsen S, et al. Cephalic phase of lipolysis is impaired in pancreatic insufficiency: role of gastric lipase. Scand J Gastroenterol 2000:35:204-11.

153 Wojdemann M, Olsen O, Norregaard P, et al. Gastric lipase secretion after sham feeding and cholinergic blockade. Dig Dis Sci 1997;42:1070-5.

154 Rinderknecht H. Pancreatic secretory enzymes. In: Go VL, ed. The pancreas: biology, pathobiology and disease. New York: Raven Press, 1993:219-51.

155 Bovo P, Cataudella G, Di F, V, et al. Intraluminal gastric $\mathrm{pH}$ in chronic pancreatitis. Gut 1995;36:294-8.

156 Regan PT, Malagelada JR, DiMagno EP, et al. Rationale for the use of cimetidine in pancreatic insufficiency. Mayo Clin Proc 1978;53:79-83.

157 Adler G, Hupp T, Kern HF. Course and spontaneous regression of acute pancreatitis in the rat. Virchows Arch A Pathol Anat Histol 1979;382:31-47.

158 Evander A, Hederstrom E, Hultberg B, et al. Exocrine pancreatic secretion in acute experimental pancreatitis. Digestion 1982;24:159-67.

159 Niederau C, Niederau M, Luthen R, et al. Pancreatic exocrine secretion in acute experimental pancreatitis. Gastroenterology 1990;99:1 120-7.

160 Murayama KM, Drew JB, Nahrwold DL, et al. Acute edematous pancreatitis impairs pancreatic secretion in rats. Surgery 1990;107:302-10.

161 Czako L, Yamamoto M, Otsuki M. Exocrine pancreatic function in rats after acute pancreatitis. Pancreas 1997; 15:83-90.

162 Czako L, Yamamoto M, Otsuki M. Pancreatic fluid hypersecretion in rats after acute pancreatitis. Dig Dis Sci 1997;42:265-72.

163 Dominguez-Munoz JE, Pieramico O, Buchler $M$, et al. Exocrine pancreatic function in the early phase of human acute pancreatitis. Scand J Gastroenterol 1995; 30:186-91.

164 Regan PT, Malagelada JR, Go VL, et al. A prospective study of the antisecretory and therapeutic effects of cimetidine and glucagon in human acute pancreatitis. Mayo Clin Proc 1981; 56:499-503.

165 Mitchell CJ, Playforth MJ, Kelleher J, et al. Functional recovery of the exocrine pancreas after acute pancreatitis. Scand J Gastroenterol 1983;18:5-8. 
166 Garnacho MJ, Aznar MA, Corrochano DM et al. [Evolution of exocrine function of the pancreas after acute pancreatitis. Prognosis factors]. Rev Esp Enferm Apar Dig 1989;76:19-24.

167 Ogden JM, O'Keefe SJ, Louw JA, et al. Duodenal juice total protein and pancreatic enzyme synthesis, turnover, and secretion in patients after acute pancreatitis. Gut 1993;34:1261-6.

168 Bozkurt T, Maroske D, Adler G. Exocrine pancreatic function after recovery from necrotizing pancreatitis. Hepatogastroenterology 1995:42:55-8.

169 Boreham B, Ammori BJ. A prospective evaluation of pancreatic exocrine function in patients with acute pancreatitis: correlation with extent of necrosis and pancreatic endocrine insufficiency. Pancreatology 2003;3:303-8.

170 Seidensticker F, Otto J, Lankisch PG. Recovery of the pancreas after acute pancreatitis is not necessarily complete. Int J Pancreatol 1995;17:225-9.

171 DiMagno EP, Malagelada JR, Go VL. The relationships between pancreatic ductal obstruction and pancreatic secretion in man. Mayo Clin Proc 1979;54:157-62.

172 Perez MM, Newcomer AD, Moertel CG, et al. Assessment of weight loss, food intake, fat metabolism, malabsorption, and treatment of pancreatic insufficiency in pancreatic cancer. Cancer 1983;52:346-52.

173 Kato H, Nakao A, Kishimoto W, et al. 13C-labeled trioctanoin breath test for exocrine pancreatic function test in patients after pancreatoduodenectomy. Am J Gastroenterol 1993;88:64-9.

174 Riordan JR, Rommens JM, Kerem B, et al. Identification of the cystic fibrosis gene: cloning and characterization of complementary DNA. Science 1989:245: 1066-73.

175 Durie PR. The pathophysiology of the pancreatic defect in cystic fibrosis. Acta Paediatr Scand Suppl 1989;363:41-4

176 Scheele GA, Fukuoka SI, Kern HF, et al. Pancreatic dysfunction in cystic fibrosis occurs as a result of impairments in luminal $\mathrm{pH}$, apical trafficking of zymogen granule membranes, and solubilization of secretory enzymes. Pancreas 1996;12:1-9.

177 Kopelman H, Durie P, Gaskin K, et al. Pancreatic fluid secretion and protein hyperconcentration in cystic fibrosis. N Engl J Med 1985;312:329-34.

178 Cleghorn G, Benjamin L, Corey M, et al. Serum immunoreactive pancreatic lipase and cationic trypsinogen for the assessment of exocrine pancreatic function in older patients with cystic fibrosis. Pediatrics 1986;77:301-6.

179 Schwachman HD, Dooley RR, Guilmette F, et al. Cystic fibrosis of the pancreas with varying degrees of pancreatic insufficiency. Am J Dis Child 1956;92:347-68.

180 Weizman Z, Forstner GG, Gaskin KJ, et al. Bentiromide test for assessing pancreatic dysfunction using analysis of para-aminobenzoic acid in plasma and urine. Studies in cystic fibrosis and Shwachman's syndrome. Gastroenterology 1985;89:596-604.

181 Walkowiak J, Cichy WK, Herzig KH. Comparison of fecal elastase-1 determination with the secretin-cholecystokinin test in patients with cystic fibrosis. Scand J Gastroenterol 1999;34:202-7.

182 Littlewood JM, Wolfe SP. Control of malabsorption in cystic fibrosis. Paediatr Drugs 2000;2:205-22.

183 Durno C, Corey M, Zielinski J, et al. Genotype and phenotype correlations in patients with cystic fibrosis. Gastroenterology 2002;123:1857-64.

184 Walkowiak J, Nousia-Arvanitakis S, Agguridaki C, et al. Longitudinal follow-up of exocrine pancreatic function in pancreatic sufficient cystic fibrosis patients using the fecal elastase-1 test. J Pediatr Gastroenterol Nutr 2003;36:474-8

185 Johansen HK, Nir M, Hoiby N, et al. Severity of cystic fibrosis in patients homozygous and heterozygous for delta F508 mutation. Lancet 1991;337:631-4.

186 Kristidis P, Bozon D, Corey M, et al. Genetic determination of exocrine pancreatic function in cystic fibrosis. Am J Hum Genet 1992;50:1178-84.

187 Walkowiak J, Herzig KH, Witt M, et al. Analysis of exocrine pancreatic function in cystic fibrosis: one mild CFTR mutation does not exclude pancreatic insufficiency. Eur J Clin Invest 2001;31:796-801.

188 Nouri-Sorkhabi MH, Chapman BE, Kuchel PW, et al. Parallel secretion of pancreatic phospholipase $A(2)$, phospholipase $A(1)$, lipase, and colipase in children with exocrine pancreatic dysfunction. Pediatr Res 2000;48:735-40.

189 Balasubramanian K, Zentler-Munro PL, Batten JC, et al. Increased intragastric acid-resistant lipase activity and lipolysis in pancreatic steatorrhoea due to cystic fibrosis. Pancreas 1992;7:305-10.

190 Augarten A, Katznelson D, Dubenbaum L, et al. Serum lipase levels pre and post Lundh meal: evaluation of exocrine pancreatic status in cystic fibrosis. Int J Clin Lab Res 1998;28:226-9.

191 Harris R, Norman AP, Payne WW. The effect of pancreatin therapy on fat absorption and nitrogen retention in children with fibrocystic disease of the pancreas. Arch Dis Child 1955;30:424-7.

192 Bouquet J, Sinaasappel M, Neijens HJ. Malabsorption in cystic fibrosis: mechanisms and treatment. J Pediatr Gastroenterol Nutr 1988;7(Suppl 1): $530-\$ 35$.

193 Heijerman HG, Lamers CB, Bakker W, et al. Improvement of fecal fat excretion after addition of omeprazole to pancrease in cystic fibrosis is related to residual exocrine function of the pancreas. Dig Dis Sci 1993;38: 1-6.

194 Bruno MJ, Rauws EA, Hoek FJ, et al. Comparative effects of adjuvant cimetidine and omeprazole during pancreatic enzyme replacement therapy. Dig Dis Sci 1994;39:988-92

195 Heijerman HG, Lamers CB, Bakker W. Omeprazole enhances the efficacy of pancreatin (pancrease) in cystic fibrosis. Ann Intern Med 1991;114:200-1.

196 Proesmans M, De Boeck K. Omeprazole, a proton pump inhibitor, improves residual steatorrhoea in cystic fibrosis patients treated with high dose pancreatic enzymes. Eur J Pediatr 2003;162:760-3.
197 Carriere F, Grandval P, Renou C, et al. Quantitative study of digestive enzyme secretion and gastrointestinal lipolysis in chronic pancreatitis. Clin Gastroenterol Hepatol 2004;2.

198 Layer P, Keller J. Gastric lipase and pancreatic exocrine insufficiency. Clin Gastroenterol Hepatol 2005:3:25-7.

199 Abrams CK, Hamosh M, Hubbard VS, et al. Lingual lipase in cystic fibrosis. Quantitation of enzyme activity in the upper small intestine of patients with exocrine pancreatic insufficiency. J Clin Invest 1984;73:374-82.

200 Abrams CK, Hamosh M, Dutta SK, et al. Role of nonpancreatic lipolytic activity in exocrine pancreatic insufficiency. Gastroenterology 1987;92:125-9

201 Taylor CJ, Hillel PG, Ghosal S, et al. Gastric emptying and intestinal transit of pancreatic enzyme supplements in cystic fibrosis. Arch Dis Child 1999:80:149-52.

202 Symonds EL, Omari TI, Webster JM, et al. Relation between pancreatic lipase activity and gastric emptying rate in children with cystic fibrosis. J Pediatr 2003;143:772-5.

203 Bali A, Stableforth DE, Asquith P. Prolonged small-intestinal transit time in cystic fibrosis. BMJ (Clin Res Ed) 1983;287:1011-13.

204 Dalzell AM, Freestone NS, Billington D, et al. Small intestinal permeability and orocaecal transit time in cystic fibrosis. Arch Dis Child 1990;65:585-8.

205 Escobar H, Perdomo M, Vasconez F, et al. Intestinal permeability to $51 \mathrm{Cr}$ EDTA and orocecal transit time in cystic fibrosis. J Pediatr Gastroenterol Nutr 1992;14:204-7.

206 Murphy MS, Brunetto AL, Pearson AD, et al. Gut hormones and gastrointestinal motility in children with cystic fibrosis. Dig Dis Sci 1992;37:187-92.

207 Warshaw AL, Rattner DW, Fernandez-del CC, et al. Middle segment pancreatectomy: a novel technique for conserving pancreatic tissue. Arch Surg 1998;133:327-31

208 Jalleh RP, Williamson RC. Pancreatic exocrine and endocrine function after operations for chronic pancreatitis. Ann Surg 1992;216:656-62.

209 Lankisch PG, Fuchs K, Schmidt H, et al. [Results of operative treatment of chronic pancreatitis, especially exocrine and endocrine functions (author's transl)]. Dtsch Med Wochenschr 1975;100:1048-60.

210 Lohr-Happe A, Peiper M, Lankisch PG. Natural course of operated pseudocysts in chronic pancreatitis. Gut 1994:35:1479-82.

211 Yamaguchi K, Yokohata K, Ohkido M, et al. Which is less invasive-distal pancreatectomy or segmental resection? Int Surg 2000;85:297-302.

212 Yamaguchi K, Yokohata K, Nakano K, et al. Which is a less invasive pancreatic head resection: PD, PPPD, or DPPHR? Dig Dis Sci 2001:46:282-8.

213 Yasuda H, Takada T, Toyota N, et al. Limited pancreatectomy: significance of postoperative maintenance of pancreatic exocrine function. $J$ Hepatobiliary Pancreat Surg 2000;7:466-72.

214 Eddes EH, Masclee AA, Lamers CB, et al. Duodenum preserving resection of the head of the pancreas in painful chronic pancreatitis. Eur $J$ Surg 1996;162:545-9.

215 Ikenaga $\mathbf{H}$, Katoh $\mathrm{H}$, Motohara T, et al. Duodenum-preserving resection of the head of the pancreas--modified procedures and long-term results. Hepatogastroenterology 1995;42:706-10.

216 Izbicki JR, Bloechle C, Knoefel WT, et al. Duodenum-preserving resection of the head of the pancreas in chronic pancreatitis. A prospective, randomized trial. Ann Surg 1995;221:350-8.

217 Beger HG, Schlosser W, Friess HM, et al. Duodenum-preserving head resection in chronic pancreatitis changes the natural course of the disease: a single-center 26-year experience. Ann Surg 1999;230:512-19.

218 Ohtsuka T, Yamaguchi K, Chiiiiwa K, et al. Postoperative pancreatic exocrine function influences body weight maintenance after pyloruspreserving pancreatoduodenectomy. Am J Surg 2001;182:524-9.

219 Dunger DB, Burns C, Ghale GK, et al. Pancreatic exocrine and endocrine function after subtotal pancreatectomy for nesidioblastosis. J Pediatr Surg 1988;23:112-15.

220 Kodama M, Tanaka T. Residual function of exocrine pancreas after operation for chronic pancreatitis by $\mathrm{N}$-benzoyl-L-tyrosyl-p-aminobenzoic acid test (NBT-PABA test). Digestion 1984;30:41-6.

221 Sato N, Yamaguchi K, Yokohata K, et al. Short-term and long-term pancreatic exocrine and endocrine functions after pancreatectomy. Dig Dis Sci 1998:43:2616-21.

222 Frey CF, Child CG, Fry W. Pancreatectomy for chronic pancreatitis. Ann Surg 1976;184:403-13.

223 Layer P, Keller J. How to make use of pancreatic function tests. In: Buechler M, ed. Chronic pancreatitis: Novel concepts in biology and therapy. Oxford: Blackwell Science, 2002:233-42

224 Kogire M, Inove K, Doi R, et al. Pancreatic exocrine deficiency after partial pancreatectomy in conscious dogs. Eur J Surg 1993;159:283-6.

225 Sommer H. Functional recovery of the exocrine pancreas in rats after partial resection. Eur Surg Res 1987;19:318-22.

226 Hotz J, Goberna R, Clodi PH. Reserve capacity of the exocrine pancreas. Enzyme secretion and fecal fat assimilation in the 95 percent pancreatectomized rat. 1973;9:212-23.

227 Malagelada JR, Go VL, Summerskill WH. Altered pancreatic and biliary function after vagotomy and pyloroplasty. Gastroenterology 1974:66:22-7.

228 Wormsley KG. The effect of vagotomy on the human pancreatic response to direct and indirect stimulation. Scand J Gastroenterol 1972;7:85-91.

229 Layer P, Melle U. Indication for pancreatic enzyme substitution following small intestinal resection (short bowel syndrome). Pancreatology 2001;1(suppl 1):49-54.

230 Nousia-Arvanitakis S, Karagiozoglou-Lamboudes T, Aggouridaki C, et al. Influence of jejunal morphology changes on exocrine pancreatic function in celiac disease. J Pediatr Gastroenterol Nutr 1999;29:81-5. 
231 Maton PN, Selden AC, Fitzpatrick ML, et al. Defective gallbladder emptying and cholecystokinin release in celiac disease. Reversal by gluten-free diet. Gastroenterology 1985;88:391-6

232 Koop I, Bozkurt T, Adler G, et al. Plasma cholecystokinin and pancreatic enzyme secretion in patients with coeliac sprue. Z Gastroenterol 1987;25:124-9.

233 DiMagno EP, Go WL, Summerskill WH. Impaired cholecystokininpancreozymin secretion, intraluminal dilution, and maldigestion of fat in sprue. Gastroenterology 1972;63:25-32.

234 Schappi MG, Smith VV, Cubitt D, et al. Faecal elastase 1 concentration is a marker of duodenal enteropathy. Arch Dis Child 2002;86:50-3.

235 Carroccio A, lacono G, Montalto $G$, et al. Exocrine pancreatic function in children with coeliac disease before and after a gluten free diet. Gut 1991:32:796-9.

236 Carroccio $A$, lacono $G$, Montalto $G$, et al. Pancreatic enzyme therapy in childhood celiac disease. A double-blind prospective randomized study. Dig Dis Sci 1995:40:2555-60.

237 Carroccio A, lacono G, Montalto G, et al. Pancreatic insufficiency in celiac disease is not dependent on nutritional status. Dig Dis Sci 1994;39:2235-42.

238 Regan PT, DiMagno EP. Exocrine pancreatic insufficiency in celiac sprue: a cause of treatment failure. Gastroenterology 1980;78:484-7.

239 Perri F, Pastore M, Festa V, et al. Intraduodenal lipase activity in celiac disease assessed by means of $13 \mathrm{C}$ mixed-triglyceride breath test. J Pediatr Gastroenterol Nutr 1998;27:407-10.

240 Otte M, Thurmayr GR, Dageforde J, et al. [Pancreatic secretion in domestic sprue]. Disch Med Wochenschr 1985;110:259-64.

241 Walkowiak J, Herzig KH. Fecal elastase-1 is decreased in villous atrophy regardless of the underlying disease. Eur J Clin Invest 2001;31:425-30.

242 Morales M, Galvan E, Mery CM, et al. Exocrine pancreatic insufficiency in tropical sprue. Digestion 2001;63:30-4.

243 Carroccio $A$, lacono $G$, Lerro $P$, et al. Role of pancreatic impairment in growth recovery during gluten-free diet in childhood celiac disease. Gastroenterology 1997; 112:1839-44.

244 Fine KD, Meyer RL, Lee EL. The prevalence and causes of chronic diarrhea in patients with celiac sprue treated with a gluten-free diet. Gastroenterology 1997;112:1830-8.

245 Weizman Z, Ben Zion YZ, Binsztok M, et al. Correlation of clinical characteristics and small bowel histopathology in celiac disease. J Pediatr Gastroenterol Nutr 1997:24:555-8.

246 Collins BJ, Bell PM, Boyd S, et al. Endocrine and exocrine pancreatic function in treated coeliac disease. Pancreas 1986;1:143-7.

247 Lohr M, Kloppel G. [Pathology of the pancreas in chronic type 1 diabetes mellitus: B-cell content, exocrine atrophy and angiopathy]. Verh Dtsch Ges Pathol 1987;71:114-19.

248 Alzaid A, Aideyan O, Nawaz S. The size of the pancreas in diabetes mellitus. Diabet Med 1993;10:759-63.

249 Gilbeau JP, Poncelet V, Libon E, et al. The density, contour, and thickness of the pancreas in diabetics: CT findings in 57 patients. AJR Am J Roentgenol 1992;159:527-31.

250 Silva ME, Vezozzo DP, Ursich MJ, et al. Ultrasonographic abnormalities of the pancreas in IDDM and NIDDM patients. Diabetes Care 1993;16:1296-7.

251 Imagawa A, Hanafusa T, Miyagawa J, et al. A proposal of three distinct subtypes of type 1 diabetes mellitus based on clinical and pathological evidence. Ann Med 2000;32:539-43.

252 Imagawa A, Hanafusa T, Tamura S, et al. Pancreatic biopsy as a procedure for detecting in situ autoimmune phenomena in type 1 diabetes: close correlation between serological markers and histological evidence of cellular autoimmunity. Diabetes 2001;50:1269-73.

253 Gepts W. Pathology of the pancreas in juvenile diabetes [abstract]. Diabetes 1965;14:619-33.

254 Lazarus SS, Volk BW. The effect of protracted glucagon administration on blood glucose and pancreatic morphology. Endocrinology 1958;63:359-71.

255 Warren S, LeCompte PM. The pathology of diabetes mellitus. Philadelphia: Lea and Febiger, 1952

256 Imagawa A, Hanafusa T, Miyagawa J, et al. A novel subtype of type 1 diabetes mellitus characterized by a rapid onset and an absence of diabetesrelated antibodies. Osaka IDDM Study Group. N Engl J Med 2000;342:301-7.

257 Kloppel G, Clemens A. [Etiology and pathogenesis of insulin-dependent diabetes mellitus]. Verh Dtsch Ges Pathol 1996;80:93-103.

258 Kloppel G, Clemens A. [Insulin-dependent diabetes mellitus. Current aspects of morphology, etiology and pathogenesis]. Pathologe 1996;17:269-75.

259 Goda K, Sasaki E, Nagata K, et al. Pancreatic volume in type 1 and type 2 diabetes mellitus. Acta Diabetol 2001;38:145-9.

260 Chey WY, Shay H, Shuman CR. External pancreatic secretion in diabetes mellitus. Ann Intern Med 1963;59:812-21.

261 Frier BM, Saunders JH, Wormsley KG, et al. Exocrine pancreatic function in juvenile-onset diabetes mellitus. Gut 1976;17:685-91.

262 Gröger G, Keller J, Bertram C, et al. Pancreatic enzyme responses are altered in patients with insulin dependent diabetes mellitus [abstract]. Digestion 1999;60:378.

263 Hardt PD, Krauss A, Bretz L, et al. Pancreatic exocrine function in patients with type 1 and type 2 diabetes mellitus. Acta Diabetol 2000;37:105-10.

264 Icks A, Haastert B, Giani G, et al. Low fecal elastase-1 in type I diabetes mellitus. Z Gastroenterol 2001;39:823-30.

265 Lankisch PG, Manthey G, Otto J, et al. Exocrine pancreatic function in insulin-dependent diabetes mellitus. Digestion 1982;25:211-16.
266 Pollard H, Miller L, Brewer W. External secretion of the pancreas and daibetes (study of secretin test). Am J Dig Dis 1943;10:20.

267 Vacca JB, Henke WJ, Knight WA. The exocrine pancreas in diabetes mellitus. Ann Intern Med 1964;61:242-7.

268 Hardt PD, Hauenschild A, Nalop J, et al. High prevalence of exocrine pancreatic insufficiency in diabetes mellitus. A multicenter study screening fecal elastase 1 concentrations in 1,021 diabetic patients. Pancreatology 2003;3:395-402.

269 Keller J, Brueckel S, Gresens A, et al. Gastric emptying disturbances correlate with pancreatic exocrine dysfunction in patients with long-standig diabetes mellitus [abstract]. Gastroenterology 2004;126(Suppl 2):W1232.

270 Rathmann W, Haastert B, Icks A, et al. Low faecal elastase 1 concentrations in type 2 diabetes mellitus. Scand J Gastroenterol 2001;36:1056-61.

271 el Newihi H, Dooley CP, Saad C, et al. Impaired exocrine pancreatic function in diabetics with diarrhea and peripheral neuropathy. Dig Dis Sci 1988;33:705-10.

272 Lankisch PG, Schmidt I. Fecal elastase 1 is not the indirect pancreatic function test we have been waiting for [letter; comment]. Dig Dis Sci 2000:45:166-7.

273 Keller J, Layer P. Acinar-islet interactions: Pancreatic exocrine insufficiency in diabetes mellitus. In: Johnson CD, Imrie CW, eds. Pancreatic disease. Basic science and clinical management. London: Springer Verlag, 2004:267-78.

274 Logsdon CD. Stimulation of pancreatic acinar cell growth by CCK, epidermal growth factor, and insulin in vitro. Am J Physiol 1986;251/4 Pt 1):G487-G494.

275 Singh J. Mechanism of action of insulin on acetylcholine-evoked amylase secretion in the mouse pancreas. J Physiol 1985;358:469-82.

276 Singh J, Adeghate E, Salido GM, et al. Interaction of islet hormones with cholecystokinin octapeptide-evoked secretory responses in the isolated pancreas of normal and diabetic rats. Exp Physiol 1999;84:299-318

277 Matsushita K, Okabayashi Y, Koide M, et al. Potentiating effect of insulin on exocrine secretory function in isolated rat pancreatic acini. Gastroenterology 1994;106:200-6.

278 Kanno T, Saito A. The potentiating influences of insulin on pancreozymininduced hyperpolarization and amylase release in the pancreatic acinar cell. J Physiol 1976;261:505-21.

279 Kramer MF, Tan HT. The peri-insular acini of the pancreas of the rat. Z Zellforsch Mikrosk Anat 1968;86:163-70.

280 Muller WA, Faloona GR, Aguilar-Parada E, et al. Abnormal alpha-cell function in diabetes. Response to carbohydrate and protein ingestion. N Engl J Med 1970;283:109-15.

281 Unger RH, Aguilar-Parada E, Muller WA, et al. Studies of pancreatic alpha cell function in normal and diabetic subjects. J Clin Invest 1970;49:837-48.

282 Ertan A, Arimura A, Akdamar K, et al. Pancreatic immunoreactive somatostatin and diabetes mellitus. Dig Dis Sci 1984:29:625-30.

283 Dyck WP, Texter ECJ, Lasater JM, et al. Influence of glucagon on pancreatic exocrine secretion in man. Gastroenterology 1970;58:532-9.

284 Konturek SJ, Tasler J, Obtulowicz W. Characteristics of inhibition of pancreatic secretion by glucagon. Digestion 1974;10:138-49.

285 Emoto T, Miyata M, Izukura M, et al. Simultaneous observation of endocrine and exocrine functions of the pancreas responding to somatostatin in man. Regul Pept 1997;68:1-8.

286 Panicot L, Mas E, Thivolet $C$, et al. Circulating antibodies against an exocrine pancreatic enzyme in type 1 diabetes. Diabetes 1999:48:2316-23.

287 Mally MI, Cirulli V, Hayek A, et al. ICA69 is expressed equally in the human endocrine and exocrine pancreas. Diabetologia 1996;39:474-80.

288 Semakula C, Vandewalle CL, Van Schravendiij CF, et al. Abnormal circulating pancreatic enzyme activities in more than twenty-five percent of recent-onset insulin-dependent diabetic patients: association of hyperlipasemia with high-titer islet cell antibodies. Belgian Diabetes Registry. Pancreas 1996;12:321-33.

289 Lipp RW, Schnedl WJ, Hammer HF, et al. Effects of postprandial walking on delayed gastric emptying and intragastric meal distribution in longstanding diabetics. Am J Gastroenterol 2000;95:419-24.

290 Glasbrenner B, Bruckel J, Gritzmann R, et al. Cephalic phase of pancreatic polypeptide release: a valid test of autonomic neuropathy in diabetics? Diabetes Res Clin Pract 1995;30:1 17-23.

291 Glasbrenner B, Dominguez-Munoz E, Riepl RL, et al. Cholecystokinin and pancreatic polypeptide release in diabetic patients with and without autonomic neuropathy. Dig Dis Sci 1995;40:406-11.

292 Loba JM, Saryusz-Wolska M, Czupryniak L, et al. Pancreatic polypeptide secretion in diabetic patients with delayed gastric emptying and autonomic neuropathy. J Diabetes Complications 1997;11:328-33.

293 Nilsson H, Bergstrom B, Lilja B, et al. Prospective study of autonomic nerve function in type 1 and type 2 diabetic patients: 24 hour heart rate variation and plasma motilin levels disturbed in parasympathetic neuropathy. Diabet Med 1995:12:1015-21.

294 Achem-Karam SR, Funakoshi A, Vinik Al, et al. Plasma motilin concentration and interdigestive migrating motor complex in diabetic gastroparesis: effect of metoclopramide. Gastroenterology 1985;88:492-9.

295 Rushakoff RA, Goldfine ID, Beccaria U, et al. Reduced postprandial cholecystokinin (CCK) secretion in patients with noninsulin-dependent diabetes mellitus: evidence for a role for CCK in regulating postprandial hyperglycemia. J Clin Endocrinol Metab 1993;76:489-93.

296 Hirota M, Hashimoto M, Hiratsuka M, et al. Alterations of plasma immunoreactive glucagon-like peptide-1 behavior in non-insulin-dependent diabetics. Diabetes Res Clin Pract 1990;9:179-85.

297 Bytzer P, Talley NJ, Leemon M, et al. Prevalence of gastrointestinal symptoms associated with diabetes mellitus: a population-based survey of 15,000 adults. Arch Intern Med 2001;161:1989-96. 
298 Talley SJ, Bytzer P, Hammer J, et al. Psychological distress is linked to gastrointestinal symptoms in diabetes mellitus. Am J Gastroenterol 2001;96:1033-8.

299 O'Keefe SJ, Cariem AK, Levy M. The exacerbation of pancreatic endocrine dysfunction by potent pancreatic exocrine supplements in patients with chronic pancreatitis. J Clin Gastroenterol 2001;32:319-23.

300 Seibold F, Mork H, Tanza S, et al. Pancreatic autoantibodies in Crohn's disease: a family study. Gut 1997;40:481-4.

301 Stocker W, Otte M, Ulrich S, et al. Autoimmunity to pancreatic juice in Crohn's disease. Results of an autoantibody screening in patients with chronic inflammatory bowel disease. Scand J Gastroenterol Suppl 1987; 139:41-52.

302 Heikius B, Niemela S, Lehtola J, et al. Pancreatic duct abnormalities and pancreatic function in patients with chronic inflammatory bowel disease. Scand J Gastroenterol 1996:31:517-23.

303 Herrlinger KR, Stange EF. The pancreas and inflammatory bowel diseases. Int J Pancreatol 2000;27:171-9.

304 Chapin LE, Baggenstoss AH. Regional enteritis associated visceral changes. Gastroenterology 1956;30:404-15.

305 Dreiling DA. Studies in pancreatic function. The use of the secretin test in the diagnosis of pancreatitis and the demonstration of pancreatic insufficiencies in gastrointestinal disorders. Gastroenterology 1953;24:540-55.

306 Angelini G, Cavallini G, Bovo P, et al. Pancreatic function in chronic inflammatory bowel disease. Int J Pancreatol 1988;3:185-93.

307 Keller J, Hoene K, Wilder M, et al. Disturbed integration of pancreatic and intestinal motor functions in inflammatory bowel disease [abstract]. Pancreas 2001;23:445.

308 Hegnhoi J, Hansen CP, Rannem T, et al. Pancreatic function in Crohn's disease. Gut 1990:31:1076-9.

309 Keller J, Melle U, Hoene K, et al. Decreased digestive stimulation of pancreatic enzyme secretion in Crohn's disease [abstract]. Pancreas 2000;21:453.

310 Keller J, Hoene K, Wilder M, et al. Disturbed hormonal regulation may contribute to pancreatic exocrine dysfunction in inflammatory bowel disease [abstract]. Gastroenterology 2002;122:1138.
311 Franke A, Keller J, Holst JJ, et al. Glucagon-like peptide-1 decreases human endogenously stimulated exocrine pancreatic secretion [abstract]. Pancreas 1996;13:436.

312 Grandt D, Bein S, Beglinger C, et al. Peptide YY inhibits interdigestive pancreatic enzyme secretion in humans [abstract]. Pancreas 1995;11:430.

313 Grandt D, Gschossmann JM, Schimiczek M, et al. Peptide YY inhibits lowdose but not high-dose CCK-stimulated enzyme secretion in humans [abstract]. Gastroenterology 1995; 108:972.

314 Kingham JG, Levison DA, Fairclough PD. Diarrhoea and reversible enteropathy in Zollinger-Ellison syndrome. Lancet 1981;2:610-12.

315 Keller J, Layer P. Pancreatic Enzyme Supplementation Therapy. Curr Treat Options Gastroenterol 2003;6:369-74.

316 Meyer JH, Lake R. Mismatch of duodenal deliveries of dietary fat and pancreatin from enterically coated microspheres. Pancreas 1997; 15:226-35.

317 Raimondo M, DiMagno EP. Lipolytic activity of bacterial lipase survives better than that of porcine lipase in human gastric and duodenal content. Gastroenterology 1994; 107:231-5

318 Suzuki A, Mizumoto A, Sarr MG, et al. Bacterial lipase and high-fat diets in canine exocrine pancreatic insufficiency: a new therapy of steatorrhea? Gastroenterology 1997; 112:2048-55.

319 Suzuki A, Mizumoto A, Rerknimitr R, et al. Effect of bacterial or porcine lipase with low- or high-fat diets on nutrient absorption in pancreaticinsufficient dogs. Gastroenterology 1999;116:431-7.

320 Kuhel DG, Zheng S, Tso P, et al. Adenovirus-mediated human pancreatic lipase gene transfer to rat bile: gene therapy of fat malabsorption. Am J Physiol Gastrointest Liver Physiol 2000;279:G1031-G1036.

321 Maeda H, Danel C, Crystal RG. Adenovirus-mediated transfer of human lipase complementary DNA to the gallbladder. Gastroenterology 1994; 106:1638-44

322 Keller J, Groger G, Cherian L, et al. Circadian coupling between pancreatic secretion and intestinal motility in humans. Am J Physiol 2001;280:G273-G278. 